\title{
Characterization of proteins of the Asp23 protein family in Bacillus subtilis
}

\author{
Dissertation \\ for the award of the degree \\ "Doctor rerum naturalium" \\ of the Georg-August-Universität Göttingen \\ within the doctoral program "Microbiology and Biochemistry" \\ of the Georg-August University School of Science (GAUSS)
}

submitted by

Dominik Tödter

from Uelzen

Göttingen 2016 


\section{Thesis Committee}

Prof. Dr. Jörg Stülke (Supervisor and $1^{\text {st }}$ Reviewer)

(Institute for Microbiology and Genetics, Department of General Microbiology, University of Göttingen)

Dr. Fabian Commichau ( $2^{\text {nd }}$ Reviewer)

(Institute for Microbiology and Genetics, Department of General Microbiology, University of Göttingen)

Prof. Dr. Ralf Ficner

(Institute for Microbiology and Genetics, Department of Molecular Structural Biology, University of Göttingen)

\section{Members of the Examination Board}

Referee: Prof. Dr. Stefanie Pöggeler

(Institute for Microbiology and Genetics, Department of Genetics of Eukaryotic Microorganisms, University of Göttingen)

$2^{\text {nd }}$ Referee: Prof. Dr. Henning Urlaub

(Max Planck Institute for Biophysical Chemistry, Bioanalytical Mass Spectrometry Group)

$3^{\text {rd }}$ referee: Prof. Dr. Ivo Feußner

(Albrecht von Haller Institute, Department of Plant Biochemistry, University of Göttingen)

Date of oral examination: 24.01.2017 
I hereby declare that this thesis entitled "Characterization of proteins of the Asp23 protein family in Bacillus subtilis" has been written independently and with no other sources and aids than quoted.

Dominik Tödter 


\section{Danksagung}

Mein erster Dank geht an dieser Stelle an Prof. Dr. Jörg Stülke. Dass du mittlerweile schon zum dritten Mal eine Abschlussarbeit von mir betreut hast, spricht eigentlich für sich. Ich danke dir ganz herzlich für deine Betreuung und Unterstützung, nicht nur während meiner Doktorarbeit, sondern auch schon seit meiner Bachelorarbeit. Danke, dass du mir diesen Abschluss ermöglicht hast!

Dr. Fabian Commichau danke ich nicht nur für die Übernahme des Korreferats, sondern vor allem auch für seine Hilfsbereitschaft und Anregungen während meiner Doktorarbeit. Des Weiteren danke ich Prof. Dr. Ralf Ficner für die Teilnahme an meinem Thesis Committee, sowie Prof. Dr. Stefanie Pöggeler, Prof. Dr. Henning Urlaub und Prof. Dr. Ivo Feußner für die Teilnahme an meiner Prüfungskommission.

Erwähnen möchte ich auch die Hilfe von Achim Dickmanns, der mir bei Fragen zur Proteinaufreinigung oft mit seinem fachlichen Rat zur Seite stand. Außerdem danke ich meinen Bachelor- und Masterstudenten Laura Griese, Lars Zimmerningkat und Anika Klewing für ihre Beiträge zu meiner Arbeit. Besonders Anika war eine große Hilfe und auch nach ihrer Abgabe immer für ein Gespräch offen. Danke dafür! Meinen „Labor-Homies“ Daniel Reuß und Dr. Christopher Zschiedrich danke ich für die wunderbare Atmosphäre im Labor und im Büro! Ihr hattet immer ein offenes Ohr für mich und seid für jeden Spaß zu haben gewesen.

Ein besonderer Dank geht an die beiden guten Seelen des Labors, Dr. Katrin Gunka und Christina Herzberg. Ihr seid mir nicht nur bei wissenschaftlichen Fragen immer eine große Hilfe gewesen, sondern es war auch immer angenehm mit euch über alltägliche Dinge sprechen zu können. Danke für eure Offenheit und Hilfsbereitschaft, die ihr schon seit Jahren allen Studenten und Kollegen entgegenbringt. Haltet das Labor weiterhin so am Laufen! In diesem Zuge danke ich auch Silvia Carrillo-Castellón dafür, dass sie mir durch ihre Arbeit den Laboralltag sehr erleichtert hat.

Weiterhin danke ich auch Jonathan Rosenberg und Jan Gundlach für interessante (Fach)gespräche, manchmal auch bei einem(!) Bier, und für die schöne Zeit außerhalb des Labors. Allen übrigen und ehemaligen Kollegen der AGS und der HIF sei ebenfalls für die Unterstützung und Hilfsbereitschaft, sowie das tolle Arbeitsklima gedankt. 
Zu guter Letzt danke ich meinen Freunden, insbesondere den „Uelzener Jungs“, Martin, Jana, Sabine und Ira, meiner Familie und vor allem meinen Eltern dafür, dass sie mich in den letzten Jahren stets motiviert und gefördert haben. Danke für eure Unterstützung und euren Rückhalt! 



\section{Table of contents}

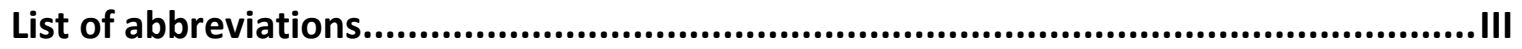

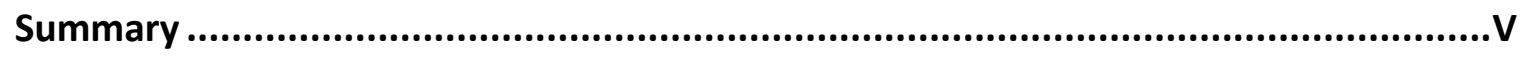

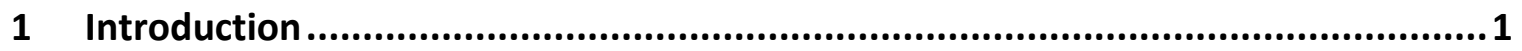

1.1 YqhY, an Asp23 protein with a (non-)essential function ....................................1

1.2 Fatty acid metabolism in prokaryotes ..............................................................

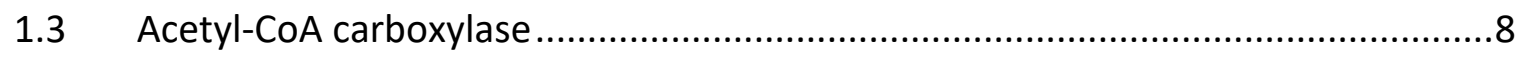

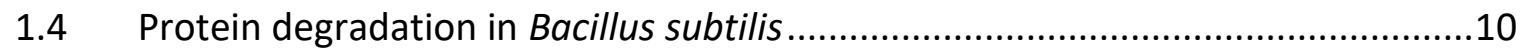

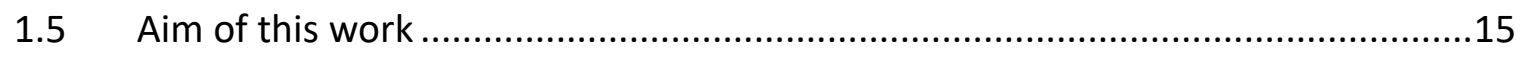

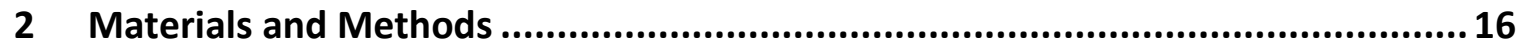

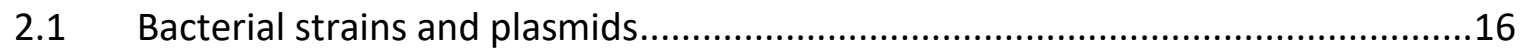

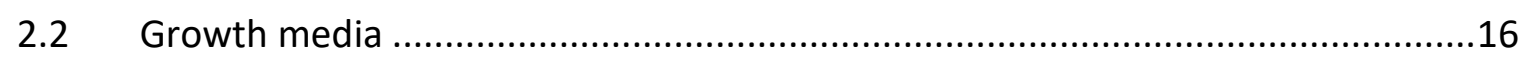

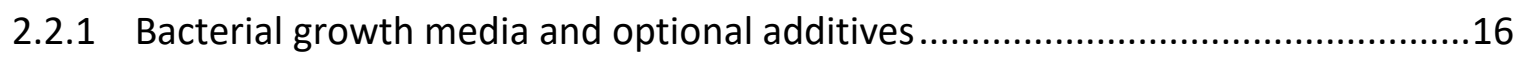

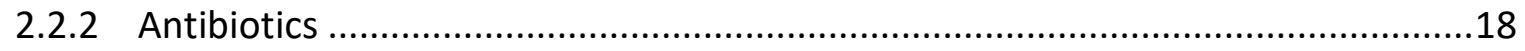

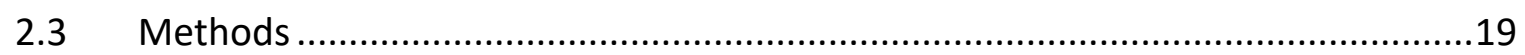

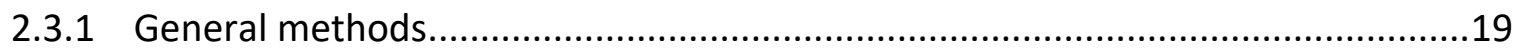

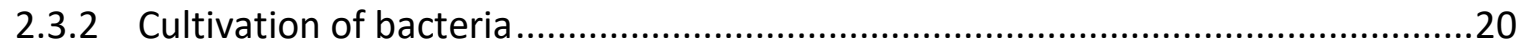

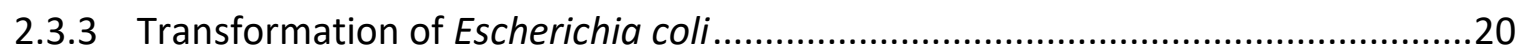

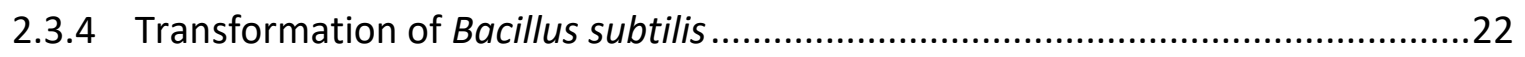

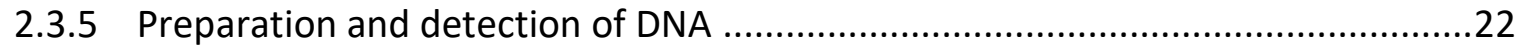

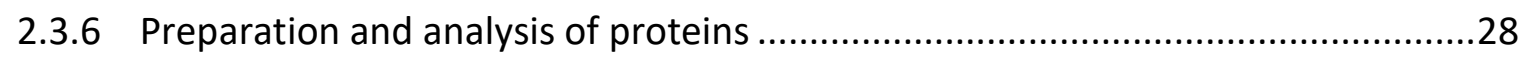

2.3.7 Bacterial Adenylate Cyclase-based two-hybrid system (BACTH)...........................36

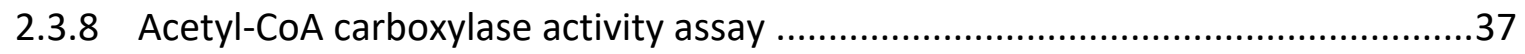

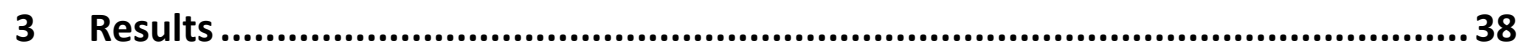

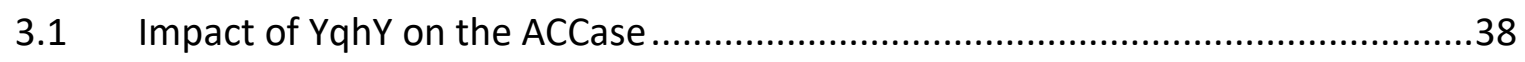

3.1.1 $\Delta y q h Y$ suppressor mutations are located in the acetyl-CoA subunits ...................38

3.1.2 The absence of YqhY results in an increased formation of lipophilic clusters ......39

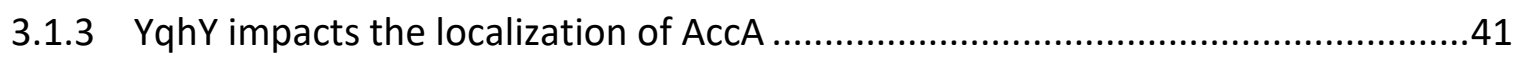

3.1.4 Investigation of an interaction of YqhY with the acetyl-CoA complex ..................42

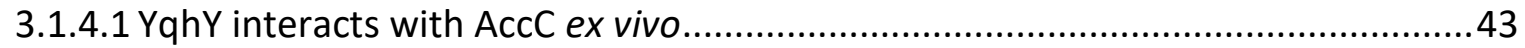

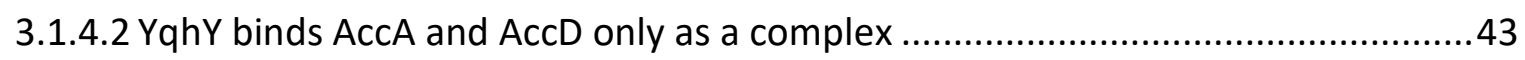


3.1.5 Influence of YqhY on the acetyl-CoA carboxylase activity ..................................45

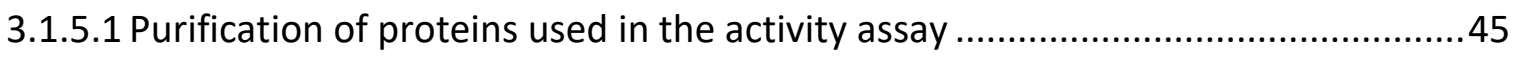

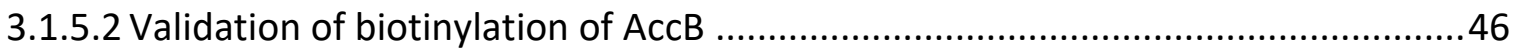

3.1.5.3 YqhY does not directly influence the acetyl-CoA carboxylase activity .................47

3.1.5.4 Suppressor mutations in yqhY deletions strains decrease the activity of the acetyl-CoA carboxylase ....................................................................................49

3.2 The possible role of YqhY in Clp-mediated protein degradation..........................50

3.2.1 $\Delta y q h Y$-suppressor mutants hint to involvement in Clp-mediated proteolysis......50

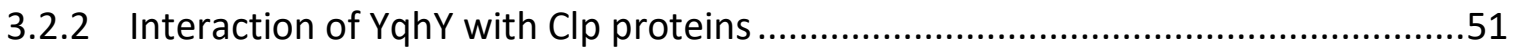

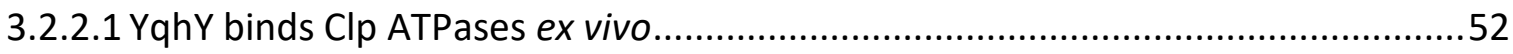

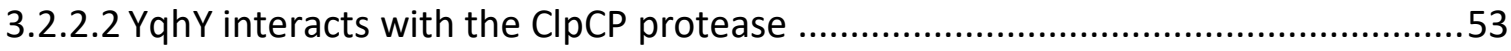

3.2.3 Analyzing the interaction of YqhY with Clp adaptor proteins.............................54

3.2.4 The ACCase subunits are no substrate of ClpCP protease ...................................55

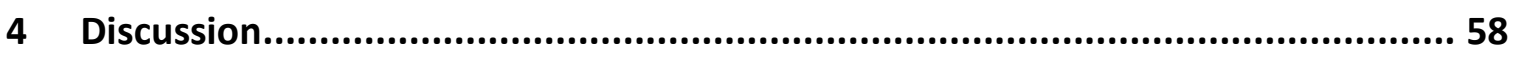

4.1 The role of YqhY in regulation of acetyl-CoA carboxylase activity .......................58

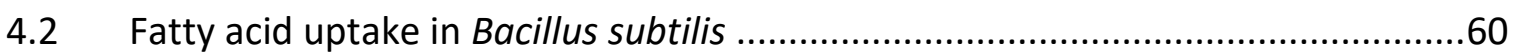

4.3 YqhY, a potential adaptor protein mediating Clp degradation? .........................61

4.4 Connecting protein degradation and fatty acid synthesis ................................62

4.5 Increased malonyl-CoA amounts may lead to unspecific protein acylation .........64

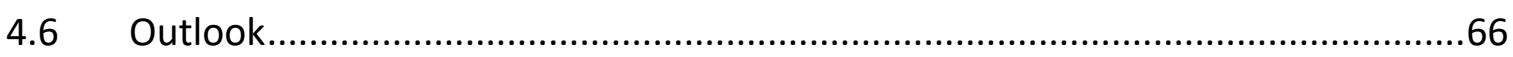

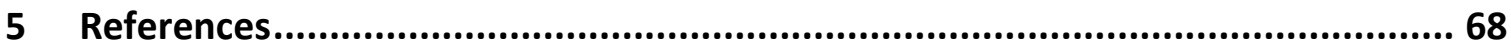

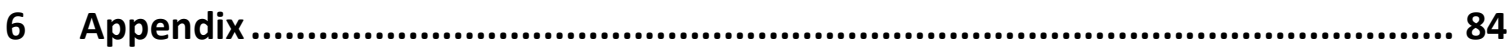

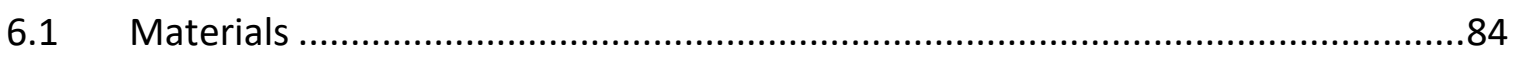

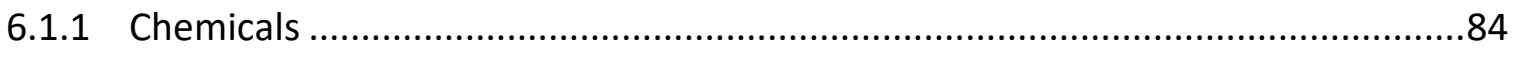

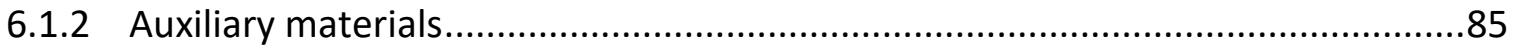

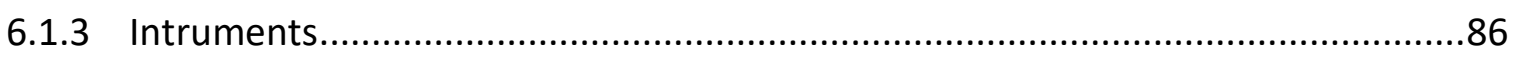

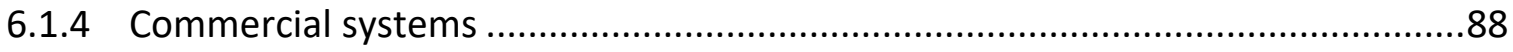

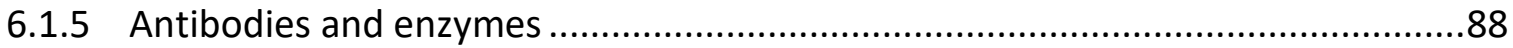

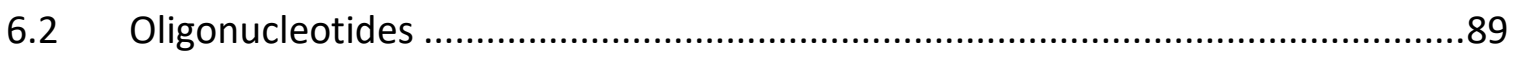

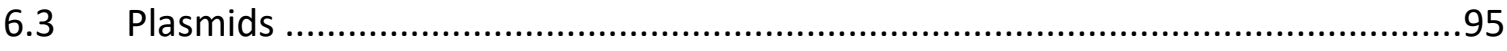

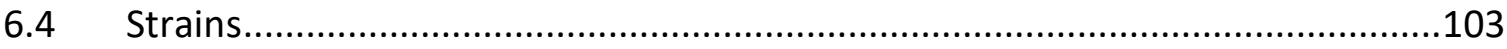




\section{List of abbreviations}

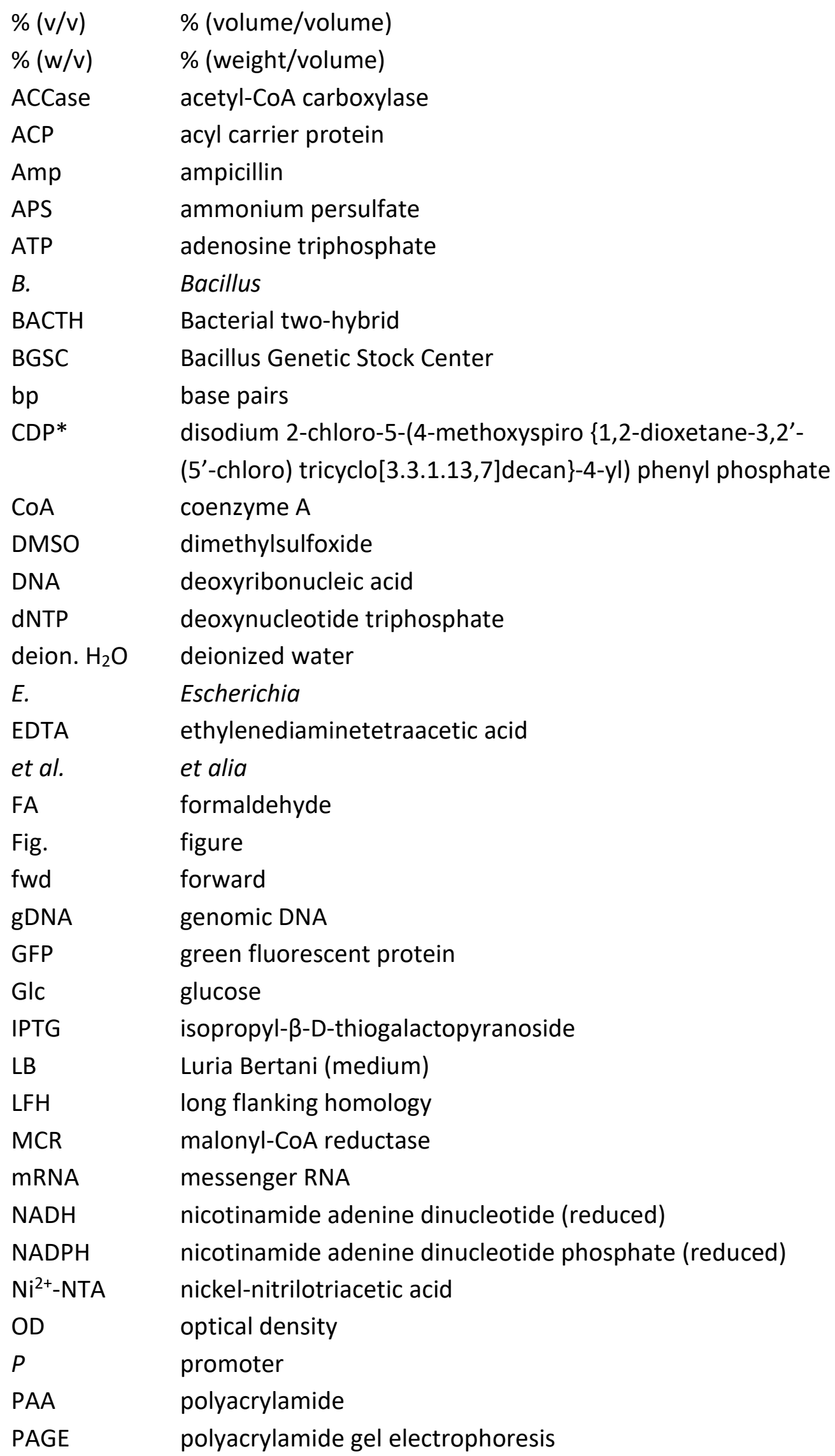




$\begin{array}{ll}\text { PCR } & \text { polymerase chain reaction } \\ \text { pH } & \text { power of hydrogen } \\ \text { PVDF } & \text { polyvinylidene difluoride } \\ \text { RNA } & \text { ribonucleic acid } \\ \text { RT } & \text { room temperature } \\ \text { rev } & \text { reverse } \\ \text { S. } & \text { Staphylococcus } \\ \text { SD } & \text { Shine-Dalgarno } \\ \text { SDS } & \text { sodium dodecyl sulfate } \\ \text { SP } & \text { sporulation medium } \\ \text { SPINE } & \text { Strep-protein interaction experiment } \\ \text { Tab. } & \text { table } \\ \text { TEMED } & \text { N,N,N',N'-tetramethylethylendiamine } \\ \text { Tris } & \text { tris-(hydroxymethyl)-aminomethane } \\ \text { U } & \text { units } \\ \text { X-Gal } & \text { 5-bromo-4-chloro-3-indolyl-ß-D-galactopyranoside } \\ \text { YFP } & \text { yellow fluorescent protein }\end{array}$




\section{Summary}

The acetyl-CoA carboxylase (ACCase) catalyzes the production of malonyl-CoA, the precursor in fatty acid biosynthesis. In almost all organisms, this is a fundamental process since fatty acids are the main components of membrane lipids and serve as precursor for energy supplying pathways. Especially in organisms like the soil bacterium Bacillus subtilis, that have to deal with different and quickly changing environmental conditions, the control of fatty acid homeostasis is important. Although many examples of ACCase regulation are found in other organisms, nothing is known about the regulation of the acetyl-CoA carboxylase in B. subtilis. The aim of this work was the characterization of the Asp23 protein YqhY. It could be shown that YqhY is able to interact with the AccAD subcomplex or the protease ClpCP. Moreover, cells lacking YqhY acquired suppressor mutations that were often located in the subunits of the acetyl-CoA carboxylase. Further investigations demonstrated that some mutations lead to decreased acetyl-CoA carboxylase activity. Therefore, it was assumed that YqhY regulates the activity of the ACCase by either acting as inhibitor or by promoting the degradation of the subunits. Despite these observations, an inhibitory effect of YqhY on the activity of the ACCase complex could not be proven and unchanged protein amounts of the subunits in the absence of ClpP indicated that they are not subject to proteolysis. However, localization experiments displayed the localization dependency of AccA on YqhY, providing the possibility of YqhY impacting the acetyl-CoA carboxylase activity by delocalization of parts of the complex. It is also conceivable that the absence of YqhY causes the accumulation of malonyl-CoA. This highly active compound could nonspecifically acylate many proteins of different pathways, leading to their inactivity and toxic effects for the cell. Although the precise role of YqhY remains elusive, the results of this work indicate a regulatory function in fatty acid synthesis. They provide possible ways how YqhY could be involved in this pathway and serve as a basis for future investigations. 



\section{Introduction}

\subsection{YqhY, an Asp23 protein with a (non-)essential function}

The Gram-positive bacterium Bacillus subtilis is one of the best studied organisms. The completely sequenced genome and the comprehensive knowledge about cellular processes makes it a perfect model organism for ongoing studies. This and the ability to easily manipulate the genetic structure, are also reasons for the intensive application in industries. Nevertheless, not all essential functions and pathways are totally understood and are in need of further studies. A fundamental aspect in this approach is the determination of the minimal gene set and basic requirements for $B$. subtilis to survive, like it is done in the recent work of Reuß et al. (2016). The authors suggested a reduced genome of 523 protein encoding genes and 119 genes coding for RNAs that allows growth at $37^{\circ} \mathrm{C}$ in complex medium. Among these genes, 245 are currently regarded as essential in B. subtilis.

The first essential gene set for B. subtilis was established in 2003 (Kobayashi et al.). In this study, only single genes were verified. But, the essentiality of a protein depends on certain environmental conditions and some functions can be executed by several proteins. The diadenylate cyclases CdaA, DisA and CdaS or the enoyl-ACP reductases Fabl and FabL are examples for that (Mehne et al., 2013; Parsons and Rock, 2013). In other words, the function carried out by these proteins only became essential when all encoding genes are deleted in combination. Gene pairs executing essential functions were named isologous (Thomaides et al., 2007). In this first evaluation of such isologous pairs, the unknown genes yqhY and yloU were added to the list of essential genes, whereas they were previously regarded as nonessential after single knockouts (Kobayashi et al., 2003). The encoded proteins YqhY and YloU are paralogues, sharing an identity of 32\%. They are both highly conserved and highly and constitutively expressed in Gram-positive bacteria (Fig. 1a) (Nicolas et al., 2012). Despite these facts already indicating a vital function of these proteins, single knockouts of $y q h Y$ and $y l o U$ were possible. Moreover, a successful double deletion of both genes refuted the theory of being an isologous essential gene pair. However, the importance of at least YqhY still remained. This became apparent by the occurrence of suppressor mutations as a consequence of an yqhY deletion (Tödter, 2013). 
Thus, the gene pair of $y q h Y$ and $y / o U$ is not essential, but it is crucial for growth under certain circumstances.

A

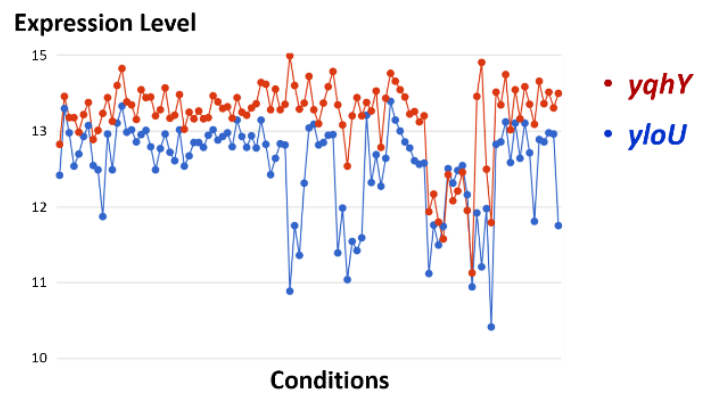

B

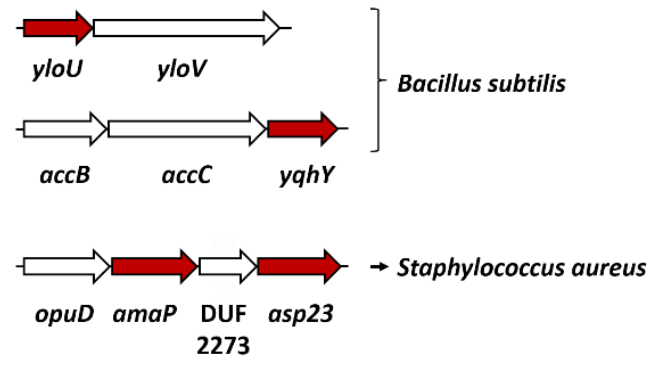

C

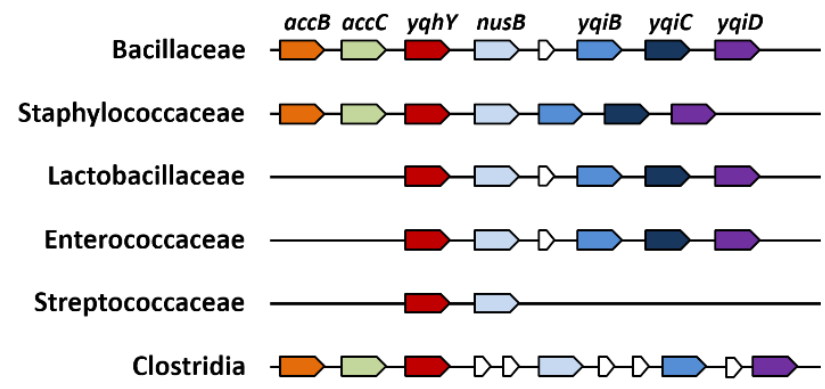

Fig. 1. (A) Expression levels of yqhY and yloU under different growth conditions (Nicolas et al., 2012; SubtiWiki database). The transcription pattern shows constitutive and high expression of yqhY and yloU. Only under glucose starvation and after phosphate limitation the expression is reduced. (B) Genetic context of $y l o U, y q h Y$ and asp23. Genes encoding Asp23 family members are shown in red. The representatives of this family in B. subtilis are YloU and YqhY. Their encoding genes a located in two distinct operons with yloV (putative dihydroxyacetone/ glyceraldehyde kinase) and $\operatorname{accB}$ (biotin carboxyl carrier protein) and accC (biotin carboxylase subunit), respectively. asp23 is cotranscribed with genes coding for the osmoprotectant transporter OpuD2, a small transmembrane protein belonging to the DUF2273 family and another transmembrane protein called AmaP (Müller et al., 2014). (C) Conservation accBC-yqhY operon throughout Firmicutes (according to STRING database). yqhY is highly conserved in Firmicutes and often clustered with accBC. Downstream of $y q h Y$ are genes located coding for subunits of exodeoxyribonuclease VII (yqiB, yqiC) and a geranyltransferase (yqiD). Gene names refer to B. subtilis 168 wild type genome (NC_000964).

$y q h Y$ is located in an operon with $a c c B$ and $a c c C$, both coding for subunits of the acetylCoA carboxylase. This gene cluster is highly conserved throughout Bacillales and YqhY shares high identities with its homologues in several representatives, for example Staphylococcus aureus (49\%), Listeria monocytogenes (54\%), Desmospora sp. 8437 (34\%) and Paenibacillus vortex (45\%). Outside Bacillales yqhY is not embedded in an operon with $a c c B$ and accC, but orthologues in Enterococcus faecalis (50\%), Lactococcus lactis (40\%) and Streptococcus pneumoniae (65\%) represent other orders of Bacilli. Even in other classes of Firmicutes, like Clostridia (Clostridium difficile (52\%)), homologues are present, 
showing the broad conservation of yqhY in organisms with many different lifestyles. In almost all organisms containing $y q h Y, n u s B$ is located downstream coding for a protein involved in transcription termination. Often, a conserved gene cluster follows with genes coding for subunits of exodeoxyribonuclease VII and a geranyltransferase (Fig. 1c). Strikingly, in nearly all Firmicutes the paralogue yloU forms an operon with yloV, a gene coding for a putative dihydroxyacetone/ glyceraldehyde kinase. This operon is even present in bacteria lacking yqhY.

In B. subtilis, an interaction of YqhY and YloU could be shown and both proteins were found to be in the cytosolic fraction. YloU is spread equally in the cell, whereas YqhY is localized at the cell poles. This polar localization is dependent on DivIVA, as YqhY shows a dispersed localization in the absence of this membrane anchor (Tödter, 2013). YqhY and YloU belong to the Asp23 protein family. The name giving protein is the alkaline shock protein 23 (Asp23) from S. aureus and all members of this family contain a domain of unknown function (DUF322). In most staphylococci Asp23 is one of four DUF322 proteins together with YqhY, YloU and AmaP. It is highly expressed and one of the most abundant proteins in the cytosolic fraction of S. aureus (Maass et al., 2011). In contrast to yqhY and $y / o U$, asp23 is co-transcribed with three other genes controlled by sigma factor $\sigma^{B}$ (Gertz et al., 1999). They encode the osmoprotectant transporter OpuD2, a small transmembrane protein belonging to the DUF2273 family and another transmembrane protein called AmaP (Fig. 1b). AmaP is another representative of the Asp23 family and functions as a membrane anchor for Asp23. The deletion of amaP, resulting in a delocalized Asp23 or the absence of Asp23 itself, lead to an increased expression of cell wall stress genes. The transcription of most of these genes is also upregulated in the presence of vancomycin (Müller et al., 2014). This antibiotic disturbs cell wall synthesis in Gram-positive bacteria and is used as one of the last actions against life-threatening infections, often caused by multi-resistant $S$. aureus strains.

Since S. aureus and B. subtilis are closely related, understanding the function of YqhY and YloU would help to decipher the function of Asp23 and in doing so, support the identification of new drug targets. In addition, the high conservation of proteins containing the DUF322 domain strongly points out the importance in cellular processes. Therefore, it is important to elucidate the physiological role of YqhY and YloU, in order to understand the fundamental mechanisms of the cell. 


\subsection{Fatty acid metabolism in prokaryotes}

Fatty acid metabolism is an essential pathway in most organisms, since the provision of fatty acids as membrane components and precursor for energy supplying pathways is crucial. Moreover, bacterial cells are often exposed to different environmental conditions. In order to adapt to abrupt changes in temperature, osmolarity, $\mathrm{pH}$ or salinity, an alteration of the membrane composition is necessary to adjust to those changes (Zhang and Rock, 2008). There are two types of fatty acid synthesis (FAS). Type I is found in eukaryotes and consists of only one protein carrying out all reactions of the pathway. In contrast, the FAS II in bacteria, plants and parasites is composed of several proteins of which each enzyme catalyzes a single reaction of the pathway (White et al., 2005).

The initiation phase of the FAS II in B. subtilis (Fig. 2) is started by the conversion of acetylCoA to malonyl-CoA performed by the acetyl-CoA carboxylase (ACCase). This enzyme complex is built up by four subunits, $A c c A, A c c B, A c c C$ and $A c c D$ (further description below) (Cronan and Waldrop, 2002). Afterwards, the malonate group is transferred to the acyl carrier protein (ACP) by the malonyl transacylase FabD (Zhang and Rock, 2008). The produced malonyl-ACP is then formed to $\beta$-ketoacyl-ACP by FabH (Parsons and Rock, 2013). In Gram-negative bacteria FabH condenses acetyl-CoA with malonyl-ACP to produce straight-chain fatty acids. On the other hand, many Gram-positive bacteria like B. subtilis and S. aureus preferentially condense short-chain acyl-CoA with malonyl-ACP to create branched-chain fatty acids. B. subtilis possesses two FabH isozymes (FabHA and FabHB) that enable also the consumption of acetyl-CoA for the production of straightchain fatty acids (Choi et al., 2000). The differences in substrate specificity of FabH are determined by the hydrophobic binding pocket. Structural analyses revealed that in Escherichia coli FabH this pocket is only big enough to harbor acetyl-CoA or propionylCoA, whereas in S. aureus FabH is able to bind acyl-CoAs with up to five carbon atoms (Qiu et al., 2005).

After the initiating step of FabH, $\beta$-ketoacyl-ACP is reduced by FabG in a NADPH dependent manner in the first reaction of the elongation cycle. The resulting product $\beta$ hydroxyacyl-ACP is then dehydrated to trans-2-enoyl-ACP by FabA and FabZ in E. coli. Although both enzymes catalyze the same reaction, only FabA is able to perform the cistrans isomerase reaction needed to synthesize unsaturated fatty acids. Gram-positive 
bacteria only possess FabZ and therefore, they mainly produce saturated fatty acids. An exception is Streptococcus pneumoniae which is also capable of forming unsaturated fatty acids. This is facilitated by FabM, an enzyme carrying out the same reaction as FabA despite having no similarity to it (Parsons and Rock, 2013). The completing step of elongation is the reduction of trans-2-enoyl-ACP to acyl-ACP. This is fulfilled by the widely expressed enzyme Fabl in the presence of NADH or NADPH (Heath and Rock, 1995). In $B$. subtilis the same reaction is executed by a second enoyl-ACP reductase (FabL) with a strong preference for NADPH (Heath et al., 2000).

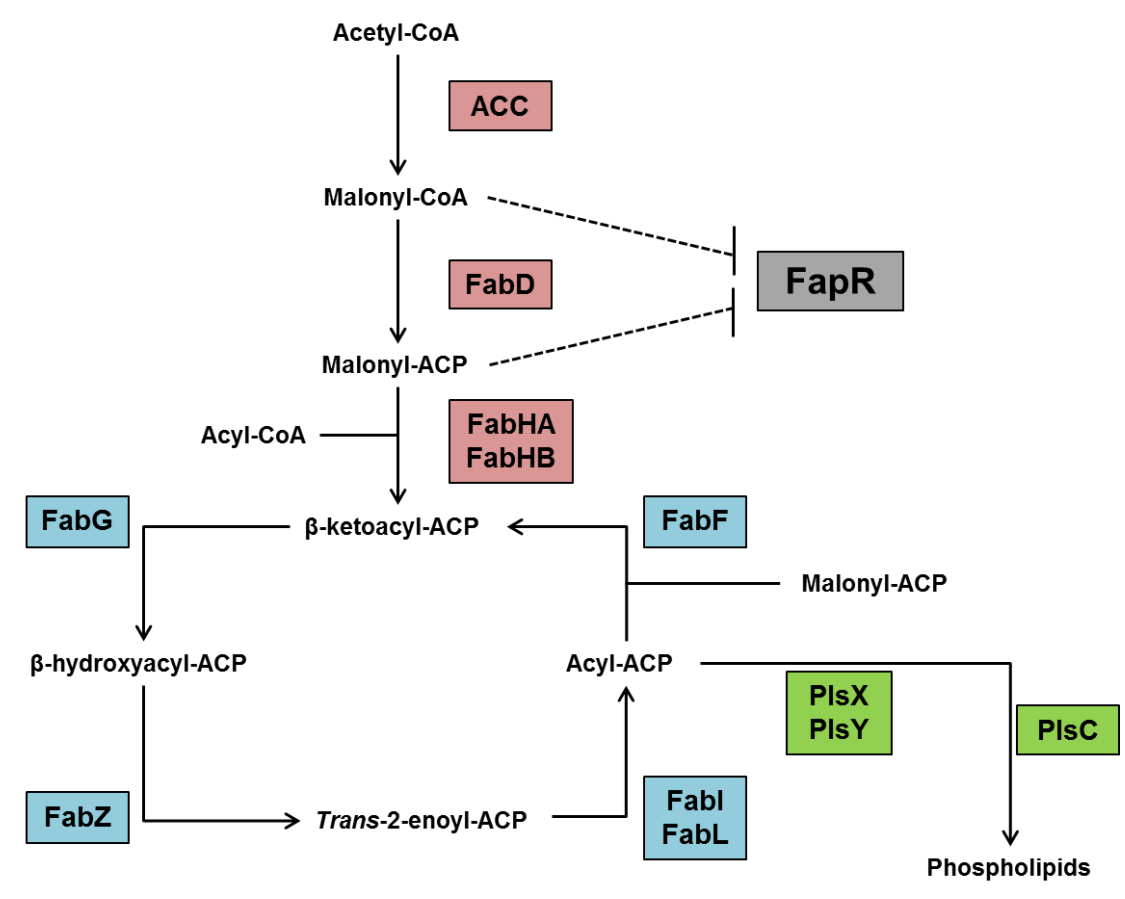

Fig. 2. Schematic overview of the fatty acid synthesis in B. subtilis (Klewing, 2015). Initiation cycle (red) is started by the production of malonyl-CoA by the acetyl-CoA carboxylase (ACC). The malonate group is transferred to the acyl carrier protein (ACP) by the malonyl transacylase FabD and subsequently the $\beta$ ketoacyl-ACP synthase FabH condenses acyl-CoA with malonyl-ACP. The elongation cycle (blue) is a repeating process, in which FabG reduces $\beta$-ketoacyl-ACP in a first reaction. In the second step, the resulting $\beta$-hydroxyacyl-ACP is dehydrated to enoyl-ACP by FabZ. At the end, the enoyl-ACP reductases Fabl or FabL complete the elongation. The resulting acyl-ACP is either condensed by FabF for a further round of elongation or it is used for phospholipid synthesis (green). PIsX and PIsY acylate glycerol-3-phosphate to 1acyl-glycerol-3-phosphate, to which another fatty acid is added to the 2-position by PIsC.

There are two possibilities for the further utilization of the newly produced acyl-ACP. Either it is condensed by FabB or FabF for another elongation round or it has reached a sufficient chain length and is used for phospholipid formation. In the latter process, the peripheral membrane protein PIsX converts acyl-ACP to acyl-phosphate. This step is 
essential since the following enzyme PlsY is not able to use acyl-ACP or acyl-CoA as substrates. The glycerol-phosphate acyltransferase PIsY connects a fatty acid to the 1position of glycerol-3-phosphate. In $\mathrm{\gamma}$-proteobacteria this reaction can also be taken over by PIsB. At the end, the internal membrane protein PlsC acylates the 2-position of 1-acylglycerol-3-phosphate (Lu et al., 2006).

An important feature of fatty acids is their composition. Depending on different environmental conditions, like temperature changes, the structure of the membrane is altered by the incorporation of unsaturated fatty acids. At low temperatures an increased membrane fluidity is necessary and as a result the ratio of unsaturated fatty acids in phospholipids is higher. With rising temperatures the cell is in need of an increased membrane rigidity, which bacteria accomplish by decreasing the amount of unsaturated fatty acids. As described above, in Gram-positive bacteria FabH is able to bind long-chain acyl-CoA, derived from exogenous fatty acids. This enables the introduction of iso or anteiso methyl branches, depending on the precursor (Zhang and Rock, 2008). For example, the availability of isoleucine is decisive for the provision of the branched chain anteiso precursor for FabH (Singh et al., 2008). Another mechanism is used in E. coli. Here, FabA isomerizes trans-2-decenoyl-ACP to cis-3-decenoyl-ACP at the 10-carbon stage in the elongation module (Heath and Rock, 1996a). However, a following elongation of the FabA product can only be initiated by FabB, because FabF is not able to condense cis-3decenoyl-ACP (Zhang and Rock, 2008). Since most bacteria do not contain the fabA-fabB genes, this route is only common in $\gamma$-proteobacteria. Other organisms came up with distinct solutions. In B. subtilis the desaturase Des inserts cis double bounds in fatty acids. The expression of the des gene is induced at low temperatures (Weber et al., 2001) and controlled by the two-component regulator DesRK. The membrane fluidity determines the state of the membrane-associated kinase DesK, which activates the transcription of des through phosphorylation of DesR (Aguilar et al., 2001).

Another way to control membrane homeostasis is transcriptional regulation. The transcription factor FadR is present in Gram-positive and Gram-negative bacteria. The homolog in E. coli is a member of the GntR family and a repressor of the fad regulon containing all genes required for transport, activation and degradation of fatty acids. (Dirusso et al., 1992). FadR binding to its operator depends on the presence of acyl-CoAs. The outer membrane protein FadL transports exogenous fatty acids into the cell 
(Higashitani et al., 1993) and the acyl-CoA synthase FadD converts them into long-chain acyl-CoAs (Pech-Canul et al., 2011). These in turn bind to FadR which leads to a release of FadR from its DNA binding site and de-repression of the fad regulon genes (Dirusso et al., 1992). In addition, FadR also acts as an transcription activator of fabA and fabB (Henry and Cronan, 1991). Its counterpart is FabR which represses fabA and fabB expression. Therefore, these two proteins control the properties of the membrane, since FabA and FabB are responsible for unsaturated fatty acid synthesis (Zhang et al., 2002). Although, the $B$. subtilis FadR also represses the genes of the $\beta$-oxidation, is does not accommodate any activator function. Furthermore, as a member of the TetR family, FadR in B. subtilis contains a distinct structure and the inhibiting long-chain acyl-CoAs are provided by the cytosolic synthetases LcfA and LcfB (Fujita et al., 2007; Parsons and Rock, 2013).

In order to regulate fatty acid biosynthesis the transcription factor FapR controls a regulon containing $a c p A, f a b D, f a b F, f a b G, f a b H A, f a b H B, f a b l, f a p R, p l s C$ and $p l s X$. This master regulator is highly conserved in Bacillus, Listeria and Staphylococcus, but not discovered in other species (Schujman et al., 2003). FapR is exclusively inhibited by malonyl-CoA. Upon binding of the ligand, the structural arrangement is changed and FapR is released from the DNA. Due to the ability of sensing the levels of malonyl-CoA, FapR is a perfect sensor for the status of fatty acid synthesis and capable to adjust the expression of the elongation cycle genes (Schujman et al., 2008). A disadvantage of this mechanism is the control only by the precursor of the synthesis. In E. coli another way of feedback inhibition is evolved by the end product acyl-ACP. One of three targets is the acetyl-CoA carboxylase, which is inhibited by long-chain acyl-ACP (Davis and Cronan, 2001). The other two are FabH and Fabl (Heath and Rock, 1996). All three enzymes are responsible for decisive reactions in fatty acid biosynthesis, since they provide the precursor malonyl-CoA or initiate or complete the elongation cycle. All in all, bacteria developed several mechanisms to precisely regulate the production and the composition of fatty acids in order to adapt to different environmental conditions. 


\subsection{Acetyl-CoA carboxylase}

The first committed step in fatty acid synthesis is the formation of the precursor malonylCoA, carried out by the acetyl-CoA carboxylase (Fig. 3) (Cronan and Waldrop, 2002). Its catalytic process is divided into two half-reactions. The first one is done by the biotin carboxylase $(\mathrm{AccC})$ and the biotin carboxyl carrier protein (AccB). Both form a subcomplex consisting of two AccC homodimers bound to four AccB (Fig. 4a) (Broussard et al., 2013a). In an ATP dependent reaction, AccC transfers a carboxyl group from bicarbonate to biotin, which is covalently attached to a single lysine residue of AccB. In the second half-reaction, acetyl-CoA is carboxylated by the carboxyltransferase (AcCAD) using the carboxyl group from caboxybiotin-AccB (Polyak et al., 2012). This second subcomplex is assembled by AccA and AccD to a $\alpha_{2} \beta_{2}$ heterotetramer (Fig. 4b), which forms the multimeric acetyl-CoA carboxylase together with $A c c B$ and $A c c C$ (Broussard et al., 2013b). It was shown that AccC and the carboxyltransferase both maintain their catalytic functions when they are separated, but only if unbound biotin is used as substrate (Guchhait et al., 1974). In the case of biotin linked to $A c c B$, reflecting the in vivo status, the subcomplexes have little to no activity, whereas only the whole ACCase complex exerts full activity (Broussard et al., 2013b).

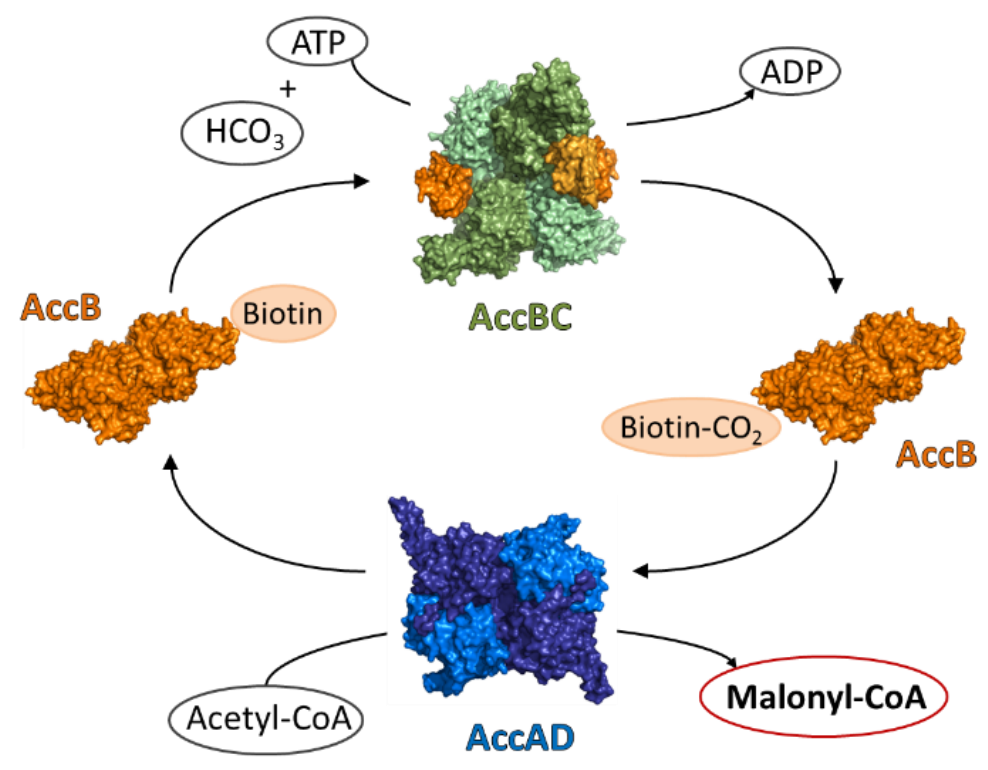

Fig. 3. Formation of malonyl-CoA by the acety-CoA carboxylase. Biotin is covalently bound to the biotin carboxyl carrier protein (AccB) and carboxylated by the biotin carboxylase (AccC) in the presence of ATP and bicarbonate. Following, the carboxyl group is transferred to acetyl-CoA by the carboxyltransferase (AccAD) resulting the precursor for fatty acid biosynthesis, malonyl-CoA. PDB files used here are, 3G8C for AccB, $4 \mathrm{HR7}$ for AccBC and 2F9I for AccAD. 


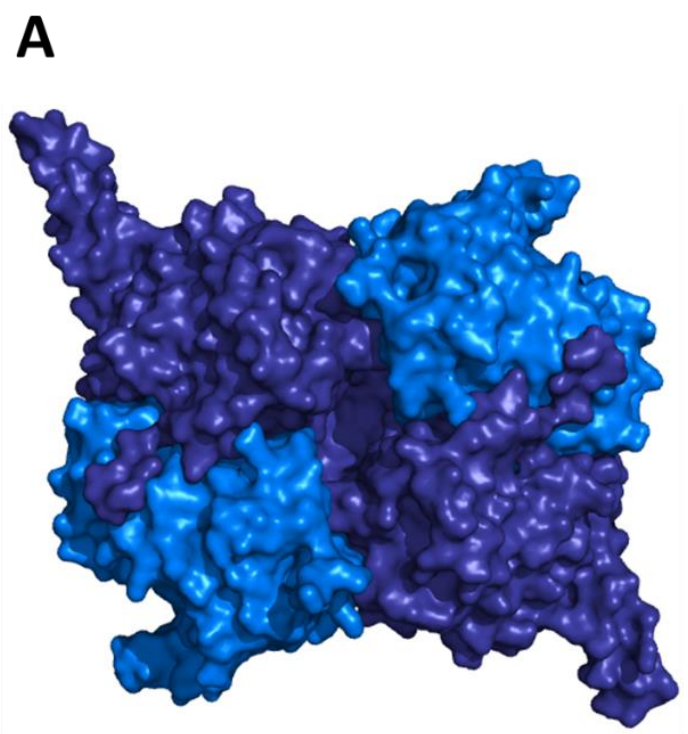

AccAD from S. aureus

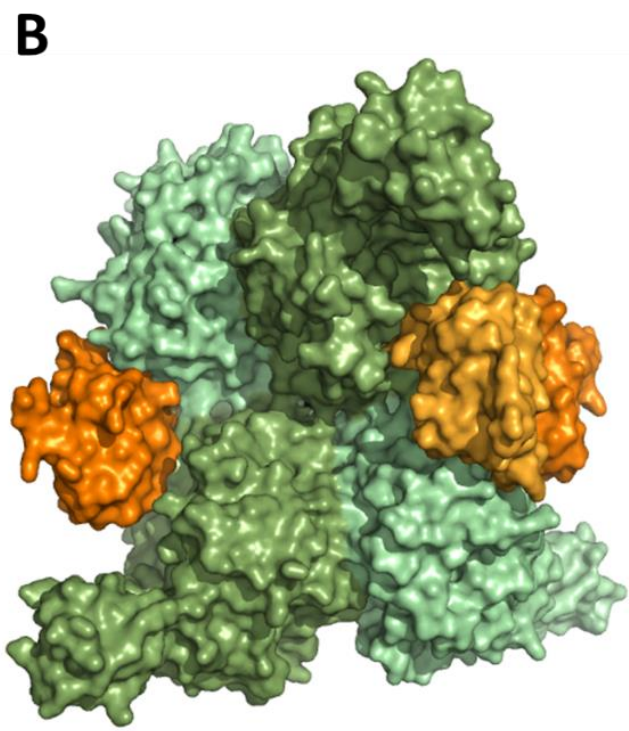

AccBC from E. coli

Fig. 4. Acetyl-CoA carboxylase subcomplexes. (A) The carboxyltransferase consists of two AccA (deep blue) and two AccD (light blue) subunits forming an $\alpha_{2} \beta_{2}$ heterotetramer (Broussard et al., 2013b). (B) Complex of the biotin carboxyl carrier protein AccB (orange, gold) and the biotin carboxylase AccC (light green, green). Two AccC homodimers form a tetramer, which is bound to four AccB molecules (Broussard et al., 2013a). PDB files used here are 2F9I for AccAD and 4HR7 for AccBC.

The genes encoding the biotin carboxyl carrier protein and the biotin carboxylase are $a c c B$ and $\operatorname{accC}$. These two genes are often found in clusters is Gram-positive as well as in Gramnegative bacteria. This allows coordinated expression which is important, since overexpression of the two subunits results either in disruption of biotin synthesis (AbdelHamid and Cronan, 2007) or inhibition of fatty acid synthesis (Karow et al., 1992). The expression of this operon is dependent on the growth rate (Li and Cronan, 1993), which is also the case in B. subtilis (Marini et al., 2001). Here, $\operatorname{accB}$ and $\operatorname{acc} C$ cluster as well, but they are additionally located in an operon with yqhY. This supports the idea, that YqhY is involved in the synthesis of fatty acids or its regulation in $B$. subtilis.

The carboxyltransferase encoding genes are $\operatorname{acc} A$ and $\operatorname{acc} D$, which are located in the same operon and upregulated by Spo0A in B. subtilis (Molle et al., 2003). During sporulation Spo0A binds to its binding box upstream of the -35 region and reactivates the malonylCoA synthesis (Pedrido et al., 2013).

In addition to the above mentioned inhibition by long-chain acyl-ACP (Davis and Cronan, 2001), there is another way to control ACCase activity in E. coli. The PII-like protein GInB 
forms a complex with $\mathrm{AccB}$ and $\mathrm{Acc} C$ and thereby decreases the ACCase activity about $40 \%$. This inhibition was reversed upon 2-oxoglutarate binding to $G \ln B$ and by $G \ln B$ uridylylation. The dependency on 2-oxoglutarate allows $G \ln B$ to measure the nutrient availability and to control the rate of malonyl-CoA production according to the need of fatty acids (Gerhardt et al., 2015). Such a regulatory mechanism by a PII-like protein is not known in B. subtilis. Like most Gram-positive bacteria, B. subtilis only possess one PII GInK homolog. Although GInK is closely related to GInB and their functions partially overlap (Forchhammer, 2008), the ACCase activity is not influenced by GlnK (Gerhardt et al., 2015).

The high conservation and the essential role in initiation of fatty acid synthesis, make the acetyl-CoA carboxylase an interesting target of inhibition studies and drug therapy. Nevertheless, many aspects about its regulation, especially in $B$. subtilis, remain elusive and need further investigation. A yet unknown role in ACCase regulation in B. subtilis could be fulfilled by the unknown protein YqhY, since the knockout leads to mutations affecting the ACCase subunits and the encoding gene is located in an operon with the $\operatorname{acc} B C$ cluster.

\subsection{Protein degradation in Bacillus subtilis}

The degradation of proteins plays a major role in protein homeostasis in all cells. The control of protein quality and removal of misfolded and aggregated proteins is especially important in cells exposed to threatening environments like heat, oxidative stress or salt stress. Moreover, proteolysis is also involved in signaling pathways by controlling the abundance of transcription factors and other regulators. In eukaryotes, ubiquitin is used to label proteins for degradation via the proteasome. Bacteria came up with other ways to get rid of ineffective proteins or control certain pathways by proteolysis (Battesti and Gottesman, 2013). The AAA+ (ATPase associated with diverse cellular functions) proteases are degradation complexes that utilize adaptor proteins or recognition sequences, called degrons, to dispose selected proteins. These complexes contain an ATPase subunit which is built up by Hsp100/Clp proteins. E. coli possesses the ATPases ClpA, ClpX and HslU, whereas B. subtilis has two additional ATPases in ClpC and ClpE, while lacking ClpA (Kirstein et al., 2009b). The ATPases form a hexameric ring, in which 
substrates are unfolded and forwarded through a central axial pore to a chamber in the proteolytic unit (Sauer and Baker, 2011). In case of ClpP, this chamber, containing the active sites, is assembled by two heptameric rings (Wang et al., 1997) and only small peptides can pass the rings to reach the active center in the absence of an ATPase (Lee et al., 2010). In addition to ClpP, the proteolytic unit can also be build up by HsIV (also known as (lpQ). An overview of the AAA+ proteases and their adaptor proteins in B. subtilis is shown in Fig. 5.

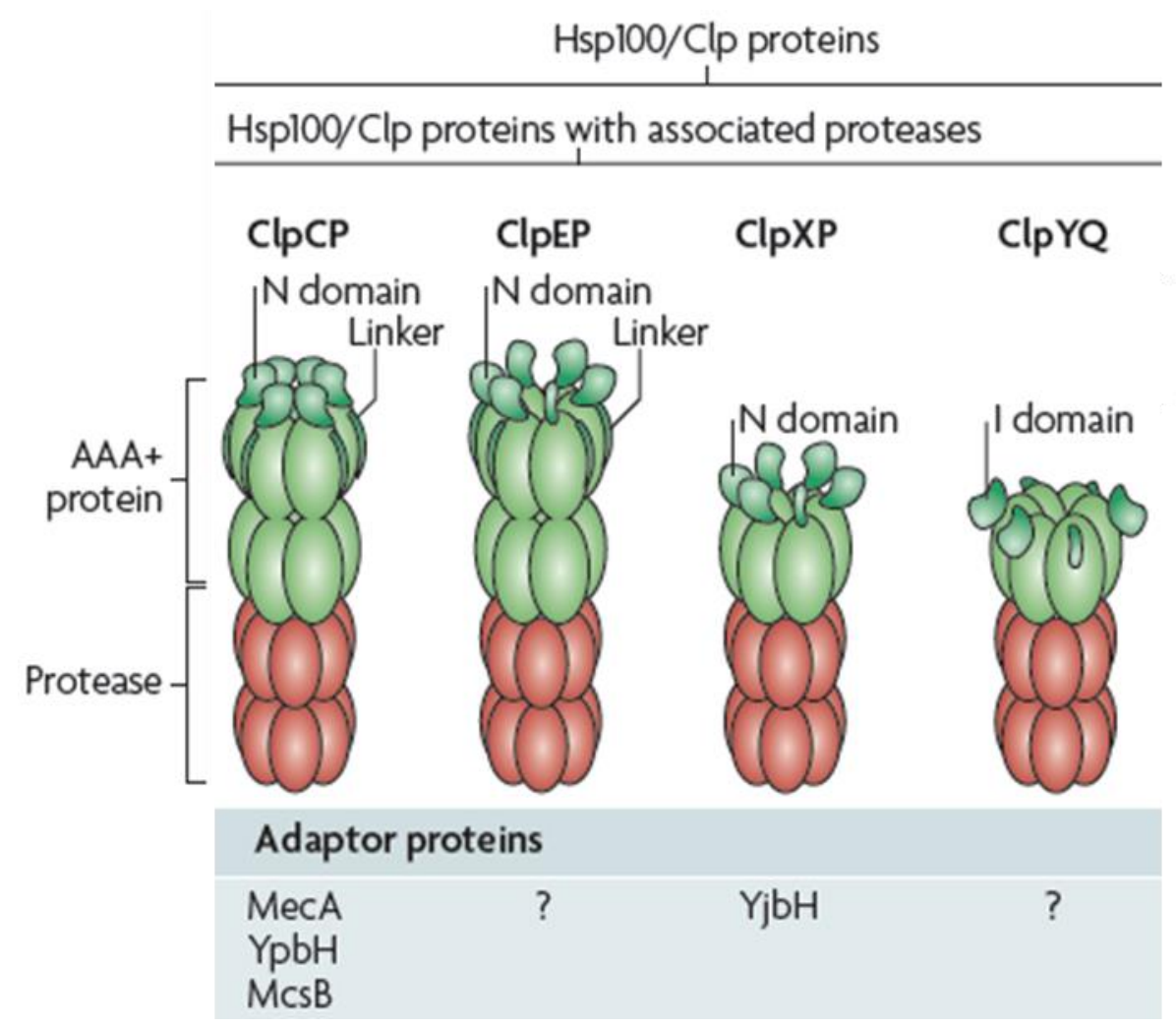

Fig. 5. Composition and adaptor proteins of Hsp100/Clp proteins and AAA+ proteases in B. subtilis (adapted from Kirstein et al., 2009b). The proteolytic subunits ClpP and ClpQ are shown in red and the ATPases ClpC, ClpE, ClpX and ClpY are in green. The corresponding adaptor proteins are listed below.

The transcription of $\mathrm{ClpC}, \mathrm{ClpE}, \mathrm{ClpX}$ and $\mathrm{ClpP}$ is repressed by CtsR and strongly upregulated during heat stress (see below). Nevertheless, ClpC is also present in nonstressed cells (Molière and Turgay, 2013) and a recent study suggested a model in which $\mathrm{ClpC}$ is active independent of any co-factors. It was presumed that post-translationally arginine phosphorylation destabilizes the native structure of proteins and marks them as substrates for ClpCP degradation. Phosphorylated arginine residues are recognized by the $\mathrm{N}$-terminal domain of $\mathrm{ClpC}$ which subsequently recruits the target proteins to the proteolytic unit (Trentini et al., 2015). This is in contrast to the previous assumption, that 
$\mathrm{ClpC}$ activity depends on binding to its adaptor proteins MecA, YpbH and McsB (Kirstein et al., 2006; Kirstein et al., 2007).

Like its paralogue $\mathrm{YpbH}$, MecA tags misfolded and aggregated proteins for ClpCP degradation (Schlothauer et al., 2003). On the other hand, MecA also regulates competence development through binding of ComK. This master regulator activates the transcription of competence genes and protein levels are kept low by ClpCP degradation at exponential growth. During stationary growth, the anti-adaptor ComS is expressed as consequence of a quorum sensing pathway. Subsequently, ComS binds to MecA and replaces ComK. The released ComK induces transcription of its own gene and the genes necessary for competence (Turgay et al., 1998). According to another theory, the degradation of ComK benefits motility gene expression. The activation of the competence genes comFA by ComK leads to a read-through transcription of flgM. The encoded protein is an anti-sigma factor inhibiting the transcription of the flagellar proteins Hag and FliD. Thus, maintaining low ComK concentrations allows mobility gene expression (Molière and Turgay, 2013).

The third known adaptor protein for $\mathrm{ClpC}$ is $\mathrm{McsB}$, responsible for targeting the repressor CtsR (Kirstein et al., 2007). As mentioned before, CtsR prevents expression of the class III heat shock genes, including $c t s R, c l p C, c l p E, c l p P$ and $m c s A$ and $m c s B$ (Derré et al., 1999). The degradation of CtsR by ClpCP occurs after its phosphorylation by McsB, which also bears a kinase activity. The auxiliary protein McsA stimulates the autophosphorylation of arginine residues of $\mathrm{McsB}$, which in turn phosphorylates CtsR (Kirstein et al., 2007; Fuhrmann et al., 2009). This mechanism is antagonized via dephosphorylation of McsB by the arginine phosphatase YwIE (Kirstein et al., 2007). Additionally, ClpC binds to unphosphorylated McsB and this interaction also prevents kinase activity (Elsholz et al., 2011a). Taken together, under normal growth conditions unphosphorylated McsB is connected with $\mathrm{ClpC}$ and $\mathrm{CtsR}$ represses the transcription of the heat shock genes. A shift to high temperatures provokes a conformational change of CtsR and the regulator is released from the DNA (Elsholz et al., 2010). At the same time, McsB is displaced from ClpC by MecA targeting unfolded proteins (Kirstein et al., 2007). The free McsB is subsequently phosphorylated and marks CtsR for degradation. This means that proteolysis is not needed for activation of heat shock gene transcription, but for removal of inactive CtsR (Molière and Turgay, 2013). 
$M s c B$ is also involved in oxidative stress response. Exposed to disulfide stress, two conserved cysteine residues of McsA were oxidized, resulting in the separation of the McsAB complex (Elsholz et al., 2011b). Despite the absence of McsA, McsB is still able to bind CtsR and remove it from the operator (Kirstein et al., 2005). In Gram-positive bacteria lacking McsA and McsB, the ATPase ClpE was suggested to take over this function. During disulfide stress, the zinc finger domain of $\mathrm{ClpE}$ is oxidized, enabling an interaction between ClpE and CtsR. Again, this finally leads to CtsR inactivation and de-repression of the CtsR regulon (Elsholz et al., 2011b). Apart from that, the role of ClpE is poorly understood. It is hardly detectable under normal growth conditions, but the amount of ClpE is significantly increased for a short time after heat stress, until it is degraded by ClpCP (Gerth et al., 2004). So far, no adaptor protein is known for ClpE (Kirstein et al., 2009b), but ClpEP is proposed to be part of protein quality control in response to high temperatures. In the early phase of heat stress, ClpEP removes inactive CtsR until ClpCP starts to degrade ClpE and finalizes the decay of the remaining CtsR. This points out a backup function for ClpE in heat shock response in B. subtilis (Miethke et al., 2006). Moreover, in Streptococcus mutans, the ClpEP protease degrades SsrA-tagged proteins (Tao and Biswas, 2015). The ssrA gene codes for a so called tmRNA that adds a signal peptide to unfinished proteins. The transcription of the ssrA gene is induced by heat stress and high ethanol concentrations (Muto et al., 2000). In case of an incomplete translation, the tmRNA occupies the A-site of a stalled ribosome and transfers alanine to the nascent polypeptide. At the same time, the original mRNA is released and translation is switched to the tmRNA ORF. Afterwards, the residual part of the SsrA-tag (AGKTNSFNQNVALAA) is added and translation terminates at a stop codon in the end. This reaction rather provides a way to release stalled ribosomes than tag specific proteins for degradation (Moore and Sauer, 2007).

In B. subtilis, ClpCP and ClpEP lack this ability whereas ClpXP is the only proteolytic unit that degrades SsrA-tagged proteins (Wiegert and Schumann, 2001). A more important role plays ClpXP in the adaptation to oxidative stress. With the help of the adaptor protein $\mathrm{YjbH}, \mathrm{ClpXP}$ controls the protein levels of Spx (Garg et al., 2009). This transcriptional regulator induces genes involved in thiol homeostasis, cysteine biosynthesis, detoxification and NADPH production (Zuber, 2009). On the other hand, Spx sequesters the C-terminal domain of the $\alpha$-subunit of the RNA polymerase and prevents the binding 
of transcriptional activators like ResD and ComA (Nakano et al., 2003). During normal growth, Spx is constantly degraded by ClpXP (Molière and Turgay, 2013), but it is stabilized under oxidative stress. This is due to oxidation of a zinc-binding domain leading to inactivation of ClpX (Zhang and Zuber, 2007). Another stabilizing factor is YirB, an antiadaptor protein of $\mathrm{YjbH}$, preventing the interaction of $\mathrm{YjbH}$ and $\mathrm{Spx}$ and therefore the destruction by ClpXP (Kommineni et al., 2011).

A special Hsp100/Clp ATPase is ClpB in E. coli, that does not interact with ClpP (Kirstein et al., 2009b). Instead, ClpB refolds aggregated proteins together with small heat shock proteins and DnaK (Mogk et al., 2003). Homologs of this unfoldase are not present in $B$. subtilis, however, in vitro experiments demonstrated disaggregation activity for the ClpCMecA complex in the absence of ClpP (Schlothauer et al., 2003). These findings implicate that $\mathrm{ClpC}$ has a similar function to $\mathrm{ClpB}$ in dissolving of aggregated proteins (Molière and Turgay, 2013). LonA and LonB are further exceptions for proteases as both harbor their ATP hydrolysis and proteolysis functions within the same polypeptide chain (Duman and Löwe, 2010). They are thought to be part of sporulation regulation, since lonB is particularly transcribed under sporulation conditions and LonA very likely degrades the sigma factor $\sigma^{G}$. Furthermore, $\sigma^{H}$-mediated gene expression is possibly controlled by LonA and LonB at low pH (Molière and Turgay, 2013).

The need of controlled and directed protein degradation is obvious. Bacteria not only face challenges during changing environments, they also have to adjust protein expression and regulate the concentrations of specific proteins at different stages of development. The Gram-negative $\alpha$-proteobacterium Caulobacter crescentus uses an adaptor hierarchy to manage the degradation of key factors during the transition from a swarmer cell stage to a stalked cell stage. For this purpose, the proteolytic complex ClpXP is loaded with several different adaptor proteins depending on the substrates. The first adaptor CpdR promotes the destruction of one class of substrates. Moreover, the priming of ClpXP by CpdR is a prerequisite for binding of the adaptor RcdA that facilitates the degradation of a second class of substrates. The third class of substrates is tethered by PopA which in turn can only bind to RcdA. At the same time, PopA prevents the degradation of RcdA-dependent protease substrates. Thus, at a higher level of the hierarchy adaptors can serve as antiadaptors for substrates reliant only on the lower levels of the hierarchy (Joshi et al., 2015). 
Last but not least, pivotal proteins participating in proteolysis are interesting targets for antibiotic treatment. For example, acyldepsipeptide (ADEP) binds to ClpP and prohibits the complex formation with Clp ATPases, which convey substrate specificity and are needed for the decomposition of large polypeptides. Simultaneously, ADEP binding leads to a conformational change enabling ClpP to nonspecifically degrade unfolded proteins and nascent polypeptides emitted by ribosomes (Kirstein et al., 2009a). The broad range of regulatory functions carried out by proteases as well as the involvement in almost all substantial cellular processes, points out the importance of Clp-mediated protein degradation. Nevertheless, in many of these processes the exact mode of action of the proteases remains unclear and the discovery of new targets and the possible concomitant need of novel adaptor proteins are challenging questions.

\subsection{Aim of this work}

The aim of this work was the characterization of one representative of the Asp23 protein family in Bacillus subtilis, YqhY. Despite all members of this family are both highly conserved and highly expressed in Gram-positive bacteria, almost nothing is known about the functions of Asp23 proteins. Previous studies already pointed out a vital function of YqhY, since the deletion of the encoding gene revealed an impaired phenotype and resulted in the rapid acquisition of suppressor mutations that affect the subunits of the acetyl-CoA carboxylase (Tödter, 2013). This protein complex catalyzes the first committed step in fatty acid biosynthesis, the conversion of acetyl-CoA to malonyl-CoA. The observed genetic link between YqhY and the acetyl-CoA carboxylase suggests an involvement of YqhY in fatty acid synthesis. Studies on the impact of the suppressor mutations were performed and a possible influence of YqhY on the acetyl-CoA carboxylase was investigated, in order to gain further insights for the role of YqhY and Asp23 proteins in general. 


\section{Materials and Methods}

Materials: Chemicals, utilities, equipment, commercial systems, proteins, antibodies, enzymes and oligonucleotides are listed in the appendix.

\subsection{Bacterial strains and plasmids}

See appendix of this work

\subsection{Growth media}

Buffers, solutions and media were prepared with deionized water and autoclaved ( $20 \mathrm{~min}$ at $121^{\circ} \mathrm{C}$ and $\left.2 \mathrm{bar}\right)$. Thermolabile substances were dissolved and sterilized by filtration. Solutions are related to water, other solvents are indicated. Basic media were supplemented with agar $(1.5 \% \mathrm{w} / \mathrm{v})$ for solidification.

\subsubsection{Bacterial growth media and optional additives}

IPTG

Stock solution: $0.5 \mathrm{M}$,

final concentration: $0.5 \mathrm{mM}$ in medium

X-Gal

Stock solution: $40 \mathrm{mg} / \mathrm{ml} \mathrm{X-Gal} \mathrm{in} \mathrm{DMF,}$

final concentration: $40 \mu \mathrm{g} / \mathrm{ml}$ in medium

$5 \times$ C-Salts

$$
\begin{array}{lll}
20 & \mathrm{~g} & \mathrm{KH}_{2} \mathrm{PO}_{4} \\
80 & \mathrm{~g} & \mathrm{~K}_{2} \mathrm{HPO}_{4} \times 3 \mathrm{H}_{2} \mathrm{O}
\end{array}
$$

$16.5 \mathrm{~g} \quad\left(\mathrm{NH}_{4}\right) 2 \mathrm{SO}_{4}$

to 1 I deion. $\mathrm{H}_{2} \mathrm{O}$

III' salts

$\begin{array}{rll}0.232 & \mathrm{~g} & \mathrm{MnSO}_{4} \times 4 \mathrm{H}_{2} \mathrm{O} \\ 12.3 \mathrm{~g} & \mathrm{MgSO}_{4} \times 7 \mathrm{H}_{2} \mathrm{O}\end{array}$

to 1 I deion. $\mathrm{H}_{2} \mathrm{O}$ 
1x C minimal medium

$$
\begin{array}{rll}
20 & \mathrm{ml} & 5 \times \mathrm{C} \text { salts } \\
1 & \mathrm{ml} & \text { Tryptophan }(5 \mathrm{mg} / \mathrm{ml}) \\
1 & \mathrm{ml} & \text { Ferric ammonium citrate }(2.2 \mathrm{mg} / \mathrm{ml}) \\
1 & \mathrm{ml} & \text { III'salts } \\
\text { to } 100 \mathrm{ml} \text { deion. } \mathrm{H}_{2} \mathrm{O}
\end{array}
$$

$1 \times$ CSE medium

$$
\begin{array}{lll}
20 & \mathrm{ml} & 5 \times \text { C-salts } \\
1 & \mathrm{ml} & \text { Tryptophan }(5 \mathrm{mg} / \mathrm{ml}) \\
1 & \mathrm{ml} & \text { Ferric ammonium citrate }(2.2 \mathrm{mg} / \mathrm{ml}) \\
1 & \mathrm{ml} & \text { III 'salts } \\
2 & \mathrm{ml} & \text { Potassium glutamate }(40 \%) \\
2 & \mathrm{ml} & \text { Sodium succinate }(30 \%) \\
\text { to } 100 \mathrm{ml} \text { deion. } \mathrm{H}_{2} \mathrm{O}
\end{array}
$$

10x MN medium

$$
\begin{array}{rll}
136 & \mathrm{~g} & \mathrm{~K}_{2} \mathrm{HPO}_{4} \times 3 \mathrm{H}_{2} \mathrm{O} \\
60 & \mathrm{~g} & \mathrm{KH}_{2} \mathrm{PO}_{4} \\
10 & \mathrm{~g} & \text { Sodium citrate } \times 2 \mathrm{H}_{2} \mathrm{O}
\end{array}
$$

to 1 I deion. $\mathrm{H}_{2} \mathrm{O}$

MNGE medium

$$
\begin{aligned}
& 877 \mu \mathrm{l} \quad 10 \times \mathrm{MN} \text { medium } \\
& 1 \mathrm{ml} \quad \text { Glucose (20\%) } \\
& 50 \mu \mathrm{l} \quad \text { Potassium glutamate (40\%) } \\
& 50 \mu \mathrm{l} \quad \text { Ferric ammonium citrate }(2.2 \mathrm{mg} / \mathrm{ml}) \\
& 100 \mu \mathrm{l} \quad \text { Tryptophan }(5 \mathrm{mg} / \mathrm{ml}) \\
& 30 \mu \mathrm{l} \quad \mathrm{MgSO}_{4} \times 7 \mathrm{H}_{2} \mathrm{O}(1 \mathrm{M}) \\
& +/-\quad 100 \mu l \quad \text { CAA (10\%) } \\
& \text { to } 10 \mathrm{ml} \text { deion. } \mathrm{H}_{2} \mathrm{O}
\end{aligned}
$$



LB-medium
$10 \mathrm{~g} \quad$ Trypton
$5 \mathrm{~g} \quad$ Yeast extract
$10 \mathrm{~g} \quad \mathrm{NaCl}$
to 1 I deion. $\mathrm{H}_{2} \mathrm{O}$

SP-Medium $\begin{array}{rll}8 & \mathrm{~g} & \text { Nutrient Broth } \\ 0.25 & \mathrm{~g} & \mathrm{MgSO}_{4} \times 7 \mathrm{H}_{2} \mathrm{O} \\ 1 & \mathrm{~g} & \mathrm{KCl} \\ \text { to } 1 \text { I deion. } \mathrm{H}_{2} \mathrm{O} & \\ \text { autoclave, after cooling down addition of: } \\ 1 & \mathrm{ml} & \mathrm{CaCl}_{2}(0.5 \mathrm{M}) \\ 1 & \mathrm{ml} & \mathrm{MnCl}_{2}(10 \mathrm{mM}) \\ 2 & \mathrm{ml} & \text { Ferric ammonium citrate }(2.2 \mathrm{mg} / \mathrm{ml})\end{array}$

\subsubsection{Antibiotics}

Antibiotics were prepared as 1000 -fold concentrated stock solutions. Ampicillin, spectinomycin, lincomycin and kanamycin were dissolved in deionized water, chloramphenicol, erythromycin and tetracycline in $70 \%$ ethanol. All solutions were sterile filtrated and stored at $-20^{\circ} \mathrm{C}$. Autoclaved medium was chilled down to approximately $50^{\circ} \mathrm{C}$, and antibiotics were added to their final concentration. For light sensitive additives such as tetracycline, incubation occurred in the dark.

\section{Selection concentration for B. subtilis}

$\begin{array}{lc}\text { Chloramphenicol } & 5 \mu \mathrm{g} / \mathrm{ml} \\ \text { Erythromycin } & 2 \mu \mathrm{g} / \mathrm{ml}^{1} \\ \text { Kanamycin } & 5 \mu \mathrm{g} / \mathrm{ml} \\ \text { Lincomycin } & 25 \mu \mathrm{g} / \mathrm{ml}^{1} \\ \text { Spectinomycin } & 150 \mu \mathrm{g} / \mathrm{ml} \\ \text { Tetracycline } & 12.5 \mu \mathrm{g} / \mathrm{ml}\end{array}$

${ }^{1}$ For selection on ermC a mixture of erythromycin and lincomycin was used in their respective concentrations, see above. 
Selection concentration for $E$. coli

Ampicillin

Spectinomycin

Kanamycin
$100 \mu \mathrm{g} / \mathrm{ml}$

$100 \mu \mathrm{g} / \mathrm{ml}$

$50 \mu \mathrm{g} / \mathrm{ml}$

\subsection{Methods}

\subsubsection{General methods}

Some general methods used in this work that are described in the literature are listed in Tab. 1.

Tab. 1. General methods

\begin{tabular}{ll}
\hline Method & Reference \\
\hline Absorption measurement & Sambrook et al., 1989 \\
Ethidiumbromide staining & Sambrook et al., 1989 \\
Precipitation of nucleic acids & Sambrook et al., 1989 \\
Gel electrophoresis of DNA & Sambrook et al., 1989 \\
Plasmid preparation from E. coli & Sambrook et al., 1989 \\
Ligation of DNA fragments & Sambrook et al., 1989 \\
Determination of protein amounts & Bradford, 1976 \\
Gel electrophoresis of proteins (denaturating) & Laemmli, 1970 \\
Sequencing according to the chain termination method & Sanger et al., 1977
\end{tabular}




\subsubsection{Cultivation of bacteria}

Unless otherwise stated, E. coli was grown in LB medium at $37^{\circ} \mathrm{C}$ and $200 \mathrm{rpm}$ in tubes and flasks. B. subtilis was grown in LB medium, CSE-Glc and MNGE medium at $37^{\circ} \mathrm{C}$ or $28^{\circ} \mathrm{C}$ in tubes and Erlenmeyer flasks. Fresh colonies from plates were used for inoculation. Furthermore, overnight liquid cultures were used. Growth was measured at a wavelength of $600 \mathrm{~nm}$. For the calculation of the generation time the optical density of cultures in the logarithmic growth phase was used (Commichau et al., 2015).

\section{Storage of bacteria}

E. coli was kept on LB medium agar plates up to four weeks at $4^{\circ} \mathrm{C}$. For long-term storage DMSO cultures were established. SP agar plates and tubes were used for the long-term storage of $B$. subtilis. For the storage of bacteria in DMSO cultures were prepared with $900 \mu \mathrm{l}$ of a fresh overnight culture mixed with $100 \mu \mathrm{l}$ of DMSO (100\%). Stocks were frozen and stored at $-80^{\circ} \mathrm{C}$ (Commichau et al., 2015).

\subsubsection{Transformation of Escherichia coli}

\section{Preparation of competent cells in SOB medium}

A single colony of $E$. coli $\mathrm{DH} 5 \alpha$ or XL1 Blue was used to inoculate an overnight culture in 4 $\mathrm{ml}$ LB medium. This culture was used to inoculate $50 \mathrm{ml}$ of LB medium. The culture was incubated at $37^{\circ} \mathrm{C}$ and $200 \mathrm{rpm}$ in baffled flasks for $8 \mathrm{~h}$.

$6 \mathrm{ml}$ of this culture were used for inoculation of $250 \mathrm{ml} \mathrm{SOB}$-medium and incubated over night at $18^{\circ} \mathrm{C}$. After reaching an $\mathrm{OD}_{600}$ of $0.5-0.9$ the culture was cooled down by incubation for $10 \mathrm{~min}$ on ice. The cells were harvested by centrifugation (10 min; 4000 $\mathrm{rpm} ; 4^{\circ} \mathrm{C}$ ) and resuspended in $80 \mathrm{ml}$ of ice-cold TB-buffer. After centrifugation (10 min; $4000 \mathrm{rpm} ; 4^{\circ} \mathrm{C}$ ), the cells were resuspended in $20 \mathrm{ml}$ of ice-cold TB buffer. DMSO (7\% final concentration) was added and aliquots of $200 \mu \mathrm{l}$ were frozen in liquid nitrogen and stored at $-70^{\circ} \mathrm{C}$ (Commichau et al., 2015). 


\begin{tabular}{|c|c|c|c|}
\hline \multirow[t]{4}{*}{ SOB medium } & 20 & g & Trypton \\
\hline & 5 & g & Yeast extract \\
\hline & 0.58 & g & $\mathrm{NaCl}$ \\
\hline & 0.186 & g & $\mathrm{KCl}$ \\
\hline & \multicolumn{3}{|c|}{ to 1 I deion. $\mathrm{H}_{2} \mathrm{O}$, autoclave } \\
\hline & 10 & $\mathrm{mM}$ & $\mathrm{MgCl}_{2}$ \\
\hline & 10 & $\mathrm{mM}$ & $\mathrm{MgSO}_{4}$ \\
\hline \multirow[t]{6}{*}{ TB buffer (pH 6.7) } & 3.46 & g & PIPES \\
\hline & 18.64 & g & $\mathrm{KCl}$ \\
\hline & \multicolumn{3}{|c|}{ to 1 I deion. $\mathrm{H}_{2} \mathrm{O}$, autoclave } \\
\hline & 2.2 & g & $\mathrm{CaCl}_{2} \times \mathrm{H}_{2} \mathrm{O}$ \\
\hline & 18.64 & g & $\mathrm{KCl}$ \\
\hline & 55 & $\mathrm{ml}$ & $\mathrm{MnCl}_{2}(1 \mathrm{M})$ \\
\hline
\end{tabular}

\section{Preparation of competent cells with $\mathrm{CaCl}_{2}$}

A single colony of $E$. coli DH5 $\alpha$ or XL1 Blue was used to inoculate an overnight culture in 4 $\mathrm{ml} \mathrm{LB}$ medium. The next day, $50 \mathrm{ml}$ of LB medium were inoculated to an $\mathrm{OD}_{600}$ of 0.05 with the overnight culture and incubated at $37^{\circ} \mathrm{C}$ and $200 \mathrm{rpm}$. After reaching an $\mathrm{OD}_{600}$ of $0.3-$ 0.5 , the cells were harvested by centrifugation ( $10 \mathrm{~min} ; 5000 \mathrm{rpm} ; 4^{\circ} \mathrm{C}$ ) and resuspended in $5 \mathrm{ml}$ of ice-cold $\mathrm{CaCl}_{2}$. The cells were kept on ice for $30 \mathrm{~min}$ and afterwards centrifuged again (10 min; $4000 \mathrm{rpm} ; 4^{\circ} \mathrm{C}$ ). The pellet was resuspended in ice-cold $\mathrm{CaCl}_{2}$ and subsequently used for transformation (Commichau et al., 2015).

\section{Transformation of competent Escherichia coli cells}

$100 \mu \mathrm{l}$ of the competent cells were mixed with DNA and kept on ice for $30 \mathrm{~min}$. The heat shock was performed at $42^{\circ} \mathrm{C}$ for $60-90 \mathrm{~s}$. Afterwards, the samples were incubated for 5 min on ice. After addition of $400 \mu$ LB medium, the samples were incubated for additional $60 \mathrm{~min}$ at $37^{\circ} \mathrm{C}$ at $200 \mathrm{rpm} .100 \mu \mathrm{l}$ and the concentrated rest were plated on LB selection plates (Commichau et al., 2015). 


\subsubsection{Transformation of Bacillus subtilis}

\section{Preparation of competent cells}

$10 \mathrm{ml}$ of MNGE medium containing 1\% CAA were inoculated with an overnight culture of B. subtilis to an $\mathrm{OD}_{600}$ of 0.1 . This culture was grown at $37^{\circ} \mathrm{C}$ with agitation until an $\mathrm{OD}_{600}$ of 1-1.3 was reached. Then, the culture was diluted with $10 \mathrm{ml}$ MNGE medium without CAA and incubated again for one hour. After this incubation step, $400 \mu \mathrm{l}$ of competent cells were incubated with DNA for $30 \mathrm{~min}$ at $37^{\circ} \mathrm{C}$ with shaking. Afterwards, $100 \mu \mathrm{l}$ of expression mix were added and the samples were incubated at $37^{\circ} \mathrm{C}$ for one hour. $100 \mu \mathrm{l}$ and the concentrated rest of the cell suspensions were spread onto SP containing the appropriate antibiotics for selection (Commichau et al., 2015).

\begin{tabular}{|c|c|c|}
\hline \multirow[t]{4}{*}{ Expression mix } & $500 \mu \mathrm{l}$ & Yeast extract (5\%) \\
\hline & $250 \mu \mathrm{l}$ & CAA $(10 \%)$ \\
\hline & $250 \mu \mathrm{l}$ & deion. $\mathrm{H}_{2} \mathrm{O}$ \\
\hline & $50 \mu \mathrm{l}$ & Tryptophan (5mg/ml) \\
\hline
\end{tabular}

\subsubsection{Preparation and detection of DNA}

\section{Preparation of plasmid DNA from E. coli}

Plasmid DNA was prepared from E. coli carrying the desired plasmid. For high copy vectors an overnight culture of $4 \mathrm{ml}$ with cells carrying the desired plasmid was harvested. For low copy vectors $20 \mathrm{ml}$ of an overnight culture were harvested. The plasmid DNA was isolated using the NucleoSpin ${ }^{\circledR}$ Plasmid Kit (Macherey-Nagel) according to the manufacturer's instructions. Deionized water was used for elution of the DNA from the columns. All steps were performed at room temperature (Commichau et al., 2015).

\section{Isolation of genomic DNA of B. subtilis}

B. subtilis cultures were grown overnight in $4 \mathrm{ml} \mathrm{LB}$ medium and harvested the next day. The genomic DNA was isolated using the peqGOLD Bacterial DNA Kit (PEQLAB) following the manufacturer's instructions. Deionized water was used for elution of the DNA from the columns (Commichau et al., 2015). 


\section{Purification of DNA}

After PCR, restriction and dephosphorylation DNA fragments were purified with the QIAquick PCR Purification Kit (Qiagen) following the manufacturer's instructions. Deionionized water was used for elution of the DNA from the columns (Commichau et al., 2015).

\section{Agarose gel electrophoresis}

For analytical and preparative separation of DNA fragments, agarose gels containing Midori Green stain and 1\% (w/v) agarose in TAE buffer were prepared. The DNA samples were mixed with $5 \times$ DNA loading dye and loaded onto the gel. The gel was run at a voltage of $80-140 \mathrm{~V}$ until the separation of the DNA was sufficient. Afterwards, the DNA was detected and documented by Gel Doc ${ }^{T M} X R+(B i o-R a d)$. For the estimation of the size of the DNA fragments $\lambda$-DNA marker was used (Commichau et al., 2015).

\begin{tabular}{|c|c|c|c|}
\hline \multirow[t]{3}{*}{$50 x$ TAE buffer (pH 8) } & 242 & g & Tris base \\
\hline & 57.1 & $\mathrm{ml}$ & Acetic acid (100\%) \\
\hline & 100 & $\mathrm{ml}$ & $0.5 \mathrm{M}$ EDTA \\
\hline & \multicolumn{3}{|c|}{ Add to $1 \mathrm{I}$ deion. $\mathrm{H}_{2} \mathrm{O}$} \\
\hline \multirow[t]{5}{*}{ 5x DNA loading dye } & 5 & $\mathrm{ml}$ & Glycerol (100\%) \\
\hline & 4.5 & $\mathrm{ml}$ & deion. $\mathrm{H}_{2} \mathrm{O}$ \\
\hline & 200 & $\mu l$ & 50x TAE buffer \\
\hline & 0.01 & $\mathrm{~g}$ & Bromphenol blue \\
\hline & 0.01 & g & Xylene cyanol \\
\hline
\end{tabular}

\section{DNA extraction from agarose gel}

For the isolation of DNA fragments from preparative gels, the bands were visualized at a wavelength of $\lambda_{365}$. The bands were cut out and transferred into an Eppendorf tube. The purification of the DNA was performed with the peqGOLD Gel Extraction Kit (PEQLAB) according to the manufacturer's instructions (Commichau et al., 2015). 


\section{Sequencing of DNA}

Sequencing was done based on the chain termination method (Sanger) with fluorescence labeled dideoxynucleotides. The sequencing reactions were conducted by SeqLab (Göttingen, Germany) and the Laboratorium für Genomanalyse $\left(\mathrm{G}_{2} \mathrm{~L}\right)$ of the Georg-AugustUniversity Göttingen.

\section{Restriction of DNA}

The restriction of DNA with endonucleases was performed with buffers recommended by the manufacturer. Reaction buffers, concentration of enzymes and DNA as well as incubation temperature and incubation time were chosen according to the manufacturer's instructions. (Commichau et al., 2015).

\section{Dephosphorylation of DNA}

To avoid re-circularization of a previously digested DNA vector, the 5' phosphate groups of the linearized vector were removed prior to the ligation reaction. The dephosphorylation of the 5 '-prime end of DNA fragments was performed with the FastAP alkaline phosphatase (ThermoFisher) with buffers supplied by the manufacturer. Therfore, $1 \mu \mathrm{l}$ FastAP $(1 \mathrm{U} / \mu \mathrm{l})$ were added to the restriction mix and incubated at $37^{\circ} \mathrm{C}$ for 10 min (Commichau et al., 2015).

\section{Ligation of DNA}

DNA fragments were ligated using T4-DNA ligase (ThermoFisher) with buffers supplied by the manufacturer. The ligation reaction contained 10 - $200 \mathrm{ng}$ of vector DNA and an excess of the DNA fragment (insert to vector molar ratio of 3:1). The reaction was started after addition of $5 \cup$ T4-DNA ligase in a final volume of $20 \mu$. The ligation occurred for at least $1 \mathrm{~h}$ at RT or overnight at $16^{\circ} \mathrm{C}$ (Commichau et al., 2015).

\section{Polymerase chain reaction (PCR)}

DNA was amplified by PCR with specific oligonucleotide primers. For each DNA fragment of interest, primers were designed. For cloning of DNA fragments into plasmid vectors, recognition sequences for specific restriction endonucleases were added via primers at both ends of the amplified DNA fragments. Oligonucleotides were purchased from Sigma- 
Aldrich (Munich, Germany). All oligonucleotides used in this work are listed in the appendix.

The PCR reactions were performed in a total volume of $50 \mu \mathrm{l}$ and for amplification Phusion $^{\mathrm{TM}}$ polymerase was used. For check PCR the Taq polymerase (own purification) was used.

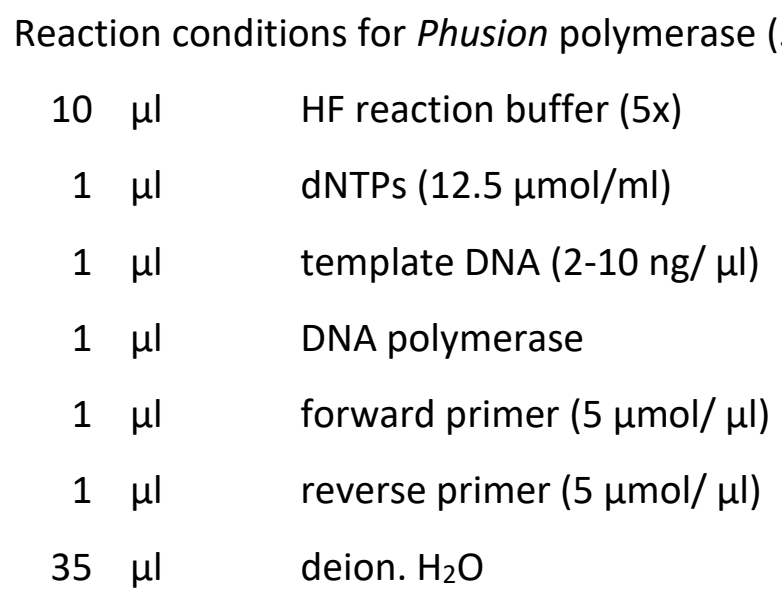

The sample was mixed and placed in a thermocycler. After an initial DNA denaturation step, a cycle consisting of three steps including denaturation, primer annealing and primer elongation was performed for 30 times. The reaction was terminated after a final elongation step by cooling down to $15^{\circ} \mathrm{C}$. Time and temperature for denaturation, time of annealing and elongation temperature remained constant for each reaction. The annealing temperature $(\mathrm{Tm})$ was dependent on the length of the oligonucleotide and its G+C content. (Commichau et al., 2015).

\section{Standard program for the Phusion ${ }^{\mathrm{TM}}$ polymerase}

\begin{tabular}{llll}
\hline denaturation & $95^{\circ} \mathrm{C}$ & $5 \mathrm{~min}$ & \\
denaturation & $95^{\circ} \mathrm{C}$ & $20 \mathrm{~s}$ & $30 \mathrm{x}$ \\
annealing & $\mathrm{Tm}-5\left[{ }^{\circ} \mathrm{C}\right]$ & $30 \mathrm{~s}$ & $30 \mathrm{x}$ \\
elongation & $72^{\circ} \mathrm{C}$ & $30 \mathrm{~s}$ per $1 \mathrm{~kb}$ & $30 \mathrm{x}$ \\
elongation & $72^{\circ} \mathrm{C}$ & $10 \mathrm{~min}$ & \\
break & $15^{\circ} \mathrm{C}$ & $\infty$ & \\
\hline
\end{tabular}


Reaction conditions for Taq polymerase $(25 \mu \mathrm{l})$ :

$\begin{array}{rrl}2.5 & \mu l & \text { Taq reaction buffer }(10 \mathrm{x}) \\ 1 & \mu \mathrm{l} & \text { dNTPs }(12.5 \mu \mathrm{mol} / \mathrm{ml}) \\ 1 & \mu \mathrm{l} & \text { template DNA }(2-10 \mathrm{ng} / \mu \mathrm{l}) \\ 1 & \mu \mathrm{l} & \text { DNA polymerase } \\ 1 & \mu \mathrm{l} & \text { forward primer }(5 \mu \mathrm{mol} / \mu \mathrm{l}) \\ 1 & \mu \mathrm{l} & \text { reverse primer }(5 \mu \mathrm{mol} / \mu \mathrm{l}) \\ 12.5 & \mu \mathrm{l} & \text { deion. } \mathrm{H}_{2} \mathrm{O}\end{array}$

Standard program for the Taq polymerase

\begin{tabular}{llll}
\hline denaturation & $95^{\circ} \mathrm{C}$ & $5 \mathrm{~min}$ & \\
denaturation & $95^{\circ} \mathrm{C}$ & $30 \mathrm{~s}$ & $30 \mathrm{x}$ \\
annealing & $\mathrm{Tm}-5\left[{ }^{\circ} \mathrm{C}\right]$ & $45 \mathrm{~s}$ & $30 \mathrm{x}$ \\
elongation & $72^{\circ} \mathrm{C}$ & $60 \mathrm{~s}$ per $1 \mathrm{~kb}$ & $30 \mathrm{x}$ \\
elongation & $72^{\circ} \mathrm{C}$ & $10 \mathrm{~min}$ & \\
break & $15^{\circ} \mathrm{C}$ & $\infty$ & \\
\hline
\end{tabular}

\section{Long flanking homology PCR (LFH-PCR)}

Deletion of a gene in B. subtilis was performed with the long flanking homology PCR (LFHPCR) technique. For this purpose, genes that mediate resistance against chloramphenicol, erythromycin, kanamycin and spectinomycin were amplified from the plasmids pDG646, pDG780, pDG1726 and pGEM-cat, respectively (Guérout-Fleury et al., 1995). DNA fragments of about $1 \mathrm{~kb}$ flanking the target gene at its $5^{\prime}$ and $3^{\prime}$ ends were amplified. The $3^{\prime}$ end of the upstream fragment as well as the 5 ' end of the downstream fragment extended into the target gene in a way that all expression signals of genes up- and downstream of the gene remained intact. The joining of the two fragments to the resistance cassette was performed in a second PCR. Joining was allowed by complementary sequences of $25 \mathrm{bp}$ that were attached to the single fragments by the respective primers. Thus, the $3^{\prime}$ end of the upstream fragment was linked with the 5 ' end of the resistance cassette and the 3 'end of the resistance with the 5 'end of the downstream fragment. For the LFH joining reaction, the up- and downstream fragments 
and the resistance cassette were used in equal molar ratios. The fused fragment was amplified by PCR using the forward primer of the upstream fragment and the reverse primer of the downstream fragment. B. subtilis was transformed with the purified PCR products and transformants were selected on plates. Clones were examined by check PCR for the integrity of the resistance cassette. The DNA sequence of the flanking regions was verified by sequencing (Commichau et al., 2015).

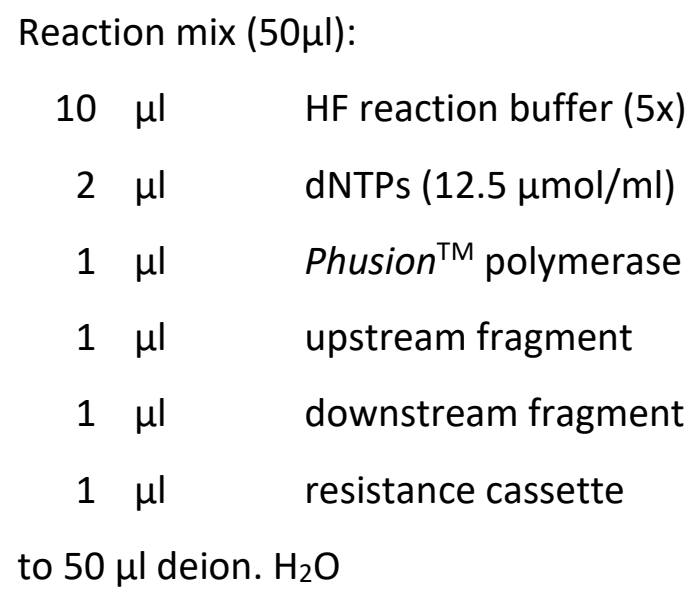

After a pre-incubation step, the primer were added to the mix

$5 \mu \mathrm{l} \quad$ forward primer $(5 \mu \mathrm{mol} / \mu \mathrm{l})$

$5 \mu \mathrm{l} \quad$ reverse primer $(5 \mu \mathrm{mol} / \mu \mathrm{l})$

LFH standard program

\begin{tabular}{lllll}
\hline & denaturation & $95^{\circ} \mathrm{C}$ & $5 \mathrm{~min}$ & \\
& denaturation & $95^{\circ} \mathrm{C}$ & $30 \mathrm{~s}$ & $10 \mathrm{x}$ \\
$1^{\text {st }}$ step & annealing & $\mathrm{Tm}-5\left[{ }^{\circ} \mathrm{C}\right]$ & $30 \mathrm{~s}$ & $10 \mathrm{x}$ \\
& elongation & $72^{\circ} \mathrm{C}$ & $30 \mathrm{~s}$ per $1 \mathrm{~kb}$ & $10 \mathrm{x}$ \\
& break & $15^{\circ} \mathrm{C}$ & $\infty$ & \\
\hline
\end{tabular}

Addition of primer 
LFH standard program

\begin{tabular}{lllll}
\hline & denaturation & $95^{\circ} \mathrm{C}$ & $30 \mathrm{~s}$ & $20 \mathrm{x}$ \\
\multirow{2}{*}{$2^{\text {nd }}$ step } & annealing & $\mathrm{Tm}-5\left[{ }^{\circ} \mathrm{C}\right]$ & $30 \mathrm{~s}$ & $20 \mathrm{x}$ \\
& elongation & $72^{\circ} \mathrm{C}$ & $30 \mathrm{~s}$ per $1 \mathrm{~kb}$ & $20 \mathrm{x}$ \\
& elongation & $72^{\circ} \mathrm{C}$ & $10 \mathrm{~min}$ & \\
& break & $15^{\circ} \mathrm{C}$ & $\infty$ & \\
\hline
\end{tabular}

\subsubsection{Preparation and analysis of proteins}

\section{Overexpression of proteins in E. coli}

An overnight culture of $E$. coli, carrying the relevant plasmid, was used to inoculate a new culture in $\mathrm{LB}$ medium to an $\mathrm{OD}_{600}$ of 0.1 . This culture was grown at $37^{\circ} \mathrm{C}(200 \mathrm{rpm})$ until they had reached an $\mathrm{OD}_{600}$ of 0.6-0.8. At this point, the expression of recombinant proteins was induced by the addition of isopropyl- $\beta$-D-thio-galactopyranoside (IPTG, final concentration: $1 \mathrm{mM}$ ). After $3 \mathrm{~h}$ the culture was harvested by centrifugation ( $15 \mathrm{~min} ; 8000$ $\left.\mathrm{rpm} ; 4^{\circ} \mathrm{C}\right)$. The pellet was resuspended in buffer $\mathrm{W}$ or in ZAP buffer and centrifuged again. After removing the supernatant the cells were stored at $-20^{\circ} \mathrm{C}$ (Commichau et al., 2015).

\section{Cell disruption with the French ${ }^{\oplus}$ press}

The cell pellet was resuspended in buffer $\mathrm{W}$ or in ZAP buffer and filled in the precooled bomb. The disruption took place with a pressure of 18000 PSI and was performed at least three times (Commichau et al., 2015).

\section{Purification of $\mathrm{His}_{6}$-tagged proteins}

For protein purification, the frozen pellets were resuspended in cold ZAP buffer containing $10 \mathrm{mM}$ imidazole and subsequently disrupted by the French ${ }^{\circledR}$ pressure cell as described above. Cell debris and other insoluble material were removed by ultracentrifugation $(1 \mathrm{~h}$; $35000 \mathrm{rpm} ; 4^{\circ} \mathrm{C}$ ). The supernatant was loaded onto a $2 \mathrm{ml}$ bed volume of $\mathrm{Ni}^{2+}-\mathrm{NTA}$ resin (Qiagen) in a Poly-Prep Chromatography Column (Biorad). The $\mathrm{Ni}^{2+}-\mathrm{NTA}$ resin was preequilibrated with $20 \mathrm{ml}$ ZAP buffer containing $10 \mathrm{mM}$ imidazole. After washing with 10$20 \mathrm{ml}$ of ZAP buffer containing $10 \mathrm{mM}$ imidazole the $\mathrm{His}_{6}$-tagged proteins were eluted. The elution was performed with ZAP buffer containing an increasing concentration of 
imidazole (for example $50 \mathrm{mM}, 100 \mathrm{mM}, 200 \mathrm{mM}$, and $500 \mathrm{mM}$ ). To analyze the purification success, samples of each fraction were loaded onto a polyacrylamide gel and after electrophoresis stained with Coomassie brilliant blue. The relevant fractions were combined and dialyzed overnight. The protein concentration was determined using the Bradford assay (Commichau et al., 2015).

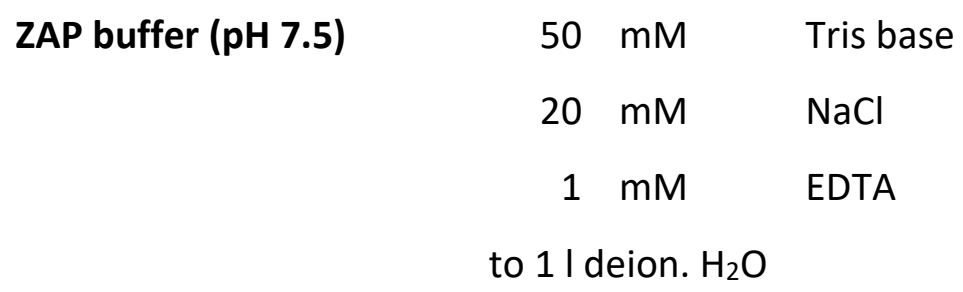

\section{Purification of Strep-tagged proteins}

For protein purification, the frozen pellets were resuspended in cold buffer $\mathrm{W}$ and subsequently disrupted by the French ${ }^{\circledR}$ pressure cell as described above. Cell debris and other insoluble material were removed by ultracentrifugation ( $1 \mathrm{~h} ; 35000 \mathrm{rpm} ; 4^{\circ} \mathrm{C}$ ). The supernatant was loaded onto $1 \mathrm{ml}$ Strep-Tactin Sepharose (IBA) in a Poly-Prep Chromatography Column (Biorad). Pre-equilibration of the matrix was performed with 10$20 \mathrm{ml}$ of buffer W. After washing 4-6 times with $1.5 \mathrm{ml}$ buffer $\mathrm{W}$, the bound proteins were eluted with buffer $E$ in 4 fractions $(1 \times 500 \mu \mathrm{l}, 3 \times 1 \mathrm{ml})$. The fractions were analyzed by SDSPAGE (Commichau et al., 2015).

\begin{tabular}{|c|c|c|c|}
\hline \multirow[t]{3}{*}{ Buffer W (pH 8) } & & $100 \mathrm{mM}$ & Tris base \\
\hline & & $150 \mathrm{mM}$ & $\mathrm{NaCl}$ \\
\hline & & \multicolumn{2}{|c|}{ Add to $1 \mathrm{I}$ deion. $\mathrm{H}_{2} \mathrm{O}$} \\
\hline \multirow[t]{4}{*}{ Buffer E (pH 8) } & & $100 \mathrm{mM}$ & Tris base \\
\hline & & $150 \mathrm{mM}$ & $\mathrm{NaCl}$ \\
\hline & & $2.5 \mathrm{mM}$ & D-desthiobiotin \\
\hline & or & $10 \mathrm{mM}$ & Biotin \\
\hline
\end{tabular}




\section{Dialysis of proteins}

The elution fractions were dialyzed against the desired buffer, which was in excess of about 1000 fold, in a dialysis tube overnight. (Commichau et al., 2015).

\section{Sodium dodecyl sulfate polyacrylamide gel electrophoresis (SDS-PAGE)}

Proteins were analyzed by SDS-PAGE as described by Laemmli (1970). Protein samples were mixed with $5 x$ SDS loading dye and denatured by boiling at $95^{\circ} \mathrm{C}$ for $30 \mathrm{~min}$. The polyacrylamide concentration of the gels was chosen according to the expected proteins sizes varying from 8 to $15 \%(\mathrm{v} / \mathrm{v})$. Samples were loaded onto the prepared gel. Electrophoresis was performed at $100-180 \mathrm{~V}$ until the bromphenol blue had reached the lower end of the gel. During electrophoresis, proteins were first focused in the stacking gel and subsequently separated by their molecular mass in the running gel. The selfconstructed protein marker Page King and the purchased protein marker PageRuler Plus (ThermoFisher) were used as size standards (Commichau et al., 2015).

5x SDS loading dye
$\begin{array}{rlll}1.4 & \mathrm{ml} & \text { Tris- } \mathrm{HCl} \mathrm{pH} \mathrm{6.8} \mathrm{(1.5} \mathrm{M)} \\ 5 & \mathrm{ml} & \text { Glycerol (100\%) } \\ 0.5 & \mathrm{~g} & \text { SDS } \\ 1.6 & \mathrm{ml} & \beta \text {-Mercaptoethanol } \\ 0.02 & \mathrm{~g} & \text { Bromphenol blue } \\ & \mathrm{ml} & \text { Bromphenol blue } \\ \text { to } 10 \mathrm{ml} \text { deion. } \mathrm{H}_{2} \mathrm{O}\end{array}$


5\% Stacking gel

$\begin{array}{rll}1.3 & \mathrm{ml} & \text { Acrylamide-Bisacrylamide (30\%) } \\ 1 & \mathrm{ml} & \text { Tris- } \mathrm{HCl} \mathrm{pH} 6.8(1.5 \mathrm{M}) \\ 5.5 & \mathrm{ml} & \text { deion. } \mathrm{H}_{2} \mathrm{O} \\ 80 & \mu \mathrm{l} & \text { SDS }(10 \%) \\ 80 & \mu \mathrm{l} & \text { APS (10\%) } \\ 8 & \mu \mathrm{l} & \text { TEMED }\end{array}$

8\% Running gel

$\begin{array}{rll}4 & \mathrm{ml} & \text { Acrylamide-Bisacrylamide (30\%) } \\ 3.8 & \mathrm{ml} & \text { Tris-HCl pH } 8.8(1 \mathrm{M}) \\ 6.9 & \mathrm{ml} & \text { deion. } \mathrm{H}_{2} \mathrm{O} \\ 150 & \mu \mathrm{l} & \text { SDS (10\%) } \\ 150 & \mu \mathrm{l} & \text { APS (10\%) } \\ 9 & \mu \mathrm{l} & \text { TEMED }\end{array}$

$12 \%$ Running gel

$\begin{array}{rrll}6 & \mathrm{ml} & \text { Acrylamide-Bisacrylamide (30\%) } \\ 3.8 & \mathrm{ml} & \text { Tris- } \mathrm{HCl} \mathrm{pH} 8.8(1 \mathrm{M}) \\ 4.9 & \mathrm{ml} & \text { deion. } \mathrm{H}_{2} \mathrm{O} \\ 150 & \mu \mathrm{l} & \text { SDS (10\%) } \\ 150 & \mu \mathrm{l} & \text { APS (10\%) } \\ 6 & \mu \mathrm{l} & \text { TEMED }\end{array}$

\begin{tabular}{|c|c|c|}
\hline \multirow[t]{6}{*}{ 15\% Running gel } & $7.5 \mathrm{ml}$ & Acrylamide-Bisacrylamide (30\%) \\
\hline & $3.8 \mathrm{ml}$ & Tris-HCl pH 8.8 (1 M) \\
\hline & $3.4 \mathrm{ml}$ & deion. $\mathrm{H}_{2} \mathrm{O}$ \\
\hline & $150 \mu l$ & SDS (10\%) \\
\hline & $150 \mu l$ & APS (10\%) \\
\hline & $6 \mu l$ & TEMED \\
\hline
\end{tabular}

\section{Coomassie staining of polyacrylamide gels}

Protein gels were stained with Coomassie Brilliant Blue. For this purpose, the gels were incubated in staining solution for $30 \mathrm{~min}$ while shaking. Afterwards, the gels were transferred in water and heated in the microwave to remove the staining. This process 
was repeated until an optimal contrast between protein bands and background was reached (Commichau et al., 2015).

Staining solution

$\begin{array}{rrll}0.5 & \% & \text { Coomassie Brillant Blue R250 } \\ 10 & \% & \text { Acetic acid } \\ 45 & \% & \text { Methanol } \\ 44.5 & \% & \text { deion. } \mathrm{H}_{2} \mathrm{O}\end{array}$

\section{Silver staining of polyacrylamide gels}

The silver staining of the protein bands was performed as described by (Nesterenko et al., 1994). For staining, the polyacrylamide gels were incubated with the following solutions with shaking (Commichau et al., 2015).

\begin{tabular}{lll} 
Step & Reagent & Duration \\
\hline Fixing & Fixing solution & 1 to $24 \mathrm{~h}$ \\
Washing & Ethanol $50 \%$ & $3 \times 20 \mathrm{~min}$ \\
Reduction & Thiosulfate solution & $1 \mathrm{~min}$ \\
Washing & deion. $\mathrm{H}_{2} \mathrm{O}$ & $3 \times 20 \mathrm{~s}$ \\
Staining & Impregnating & $15-25 \mathrm{~min}$ \\
Washing & deion. $\mathrm{H}_{2} \mathrm{O}$ & $2 \times 20 \mathrm{~s}$ \\
Developing & Developer & until sufficiently stained \\
Washing & deion. $\mathrm{H}_{2} \mathrm{O}$ & $2 \times 20 \mathrm{~s}$ \\
Stopping & Stop solution & 5 min
\end{tabular}




\begin{tabular}{|c|c|c|}
\hline \multirow[t]{4}{*}{ Fixing solution } & $50 \mathrm{ml}$ & Methanol (100\%) \\
\hline & $12 \mathrm{ml}$ & Acetic acid (100\%) \\
\hline & $100 \mu \mathrm{l}$ & Formaldehyde (37\%) \\
\hline & \multicolumn{2}{|c|}{ to $100 \mathrm{ml}$ deion. $\mathrm{H}_{2} \mathrm{O}$} \\
\hline \multirow[t]{2}{*}{ Thiosulfate solution } & $20 \mathrm{mg}$ & $\mathrm{Na}_{2} \mathrm{~S}_{2} \mathrm{O}_{3} \times 5 \mathrm{H}_{2} \mathrm{O}$ \\
\hline & \multicolumn{2}{|c|}{ to $100 \mathrm{ml}$ deion. $\mathrm{H}_{2} \mathrm{O}$} \\
\hline \multirow[t]{3}{*}{ Impregnator } & $0.2 \mathrm{~g}$ & $\mathrm{AgNO}_{3}$ \\
\hline & $37 \mu l$ & Formaldehyde (37\%) \\
\hline & \multicolumn{2}{|c|}{ to $100 \mathrm{ml}$ deion. $\mathrm{H}_{2} \mathrm{O}$} \\
\hline \multirow[t]{4}{*}{ Developer } & $6 \mathrm{~g}$ & $\mathrm{NaCO}_{3}$ \\
\hline & $2 \mathrm{ml}$ & Thiosulfate solution \\
\hline & $50 \mu l$ & Formaldehyde (37\%) \\
\hline & \multicolumn{2}{|c|}{ to $100 \mathrm{ml}$ deion. $\mathrm{H}_{2} \mathrm{O}$} \\
\hline \multirow[t]{2}{*}{ Stop solution } & $1.86 \mathrm{~g}$ & EDTA \\
\hline & \multicolumn{2}{|c|}{ to $100 \mathrm{ml}$ deion. $\mathrm{H}_{2} \mathrm{O}$} \\
\hline
\end{tabular}

\section{Strep-protein interaction experiment (SPINE) for the analysis of protein-protein interactions}

The Strep-protein interaction experiment (SPINE) was performed according to Herzberg et al., 2007. This experiment was used to identify potential interaction partners of $B$. subtilis proteins in vivo. Therefore, the gene of interest was cloned into the expression vectors pGP380, pGP382, pGP1389 or pGP1460. A preculture of $B$. subtilis carrying the appropriate plasmid was grown for $8 \mathrm{~h}$ at $37^{\circ} \mathrm{C}$ in LB medium. This culture was used to inoculate $50 \mathrm{ml} \mathrm{CSE}$ medium containing $0.5 \%$ glucose and was grown overnight at $37^{\circ} \mathrm{C}$. The next day, one liter of the same medium was then inoculated with the overnight culture to an $\mathrm{OD}_{600}$ of 0.1 . When this culture had reached an $\mathrm{OD}_{600}$ of $1.0,500 \mathrm{ml}$ were supplemented with paraformaldehyde ( $4 \%$ in PBS) to a final concentration of $0.6 \%$. This culture was and incubated for additional 15-20 min. Both types of culture were harvested 
by centrifugation (15 $\mathrm{min} ; 5,000 \mathrm{rpm} ; 4^{\circ} \mathrm{C}$ ). The cells were washed in buffer $\mathrm{W}$ and centrifuged again. The pellets were stored at $-20^{\circ} \mathrm{C}$. For the preparation of the crude extract, the cell pellet was resuspended in buffer $W$ and the cells were disrupted by the French ${ }^{\oplus}$ pressure cell as described above. Cell debris and other insoluble material were removed by ultracentrifugation $\left(1 \mathrm{~h} ; 35000 \mathrm{rpm} ; 4^{\circ} \mathrm{C}\right)$ and the supernatant was used for protein purification via Strep-Tactin Sepharose (IBA). The protein fractions were finally separated by SDS-PAGE (Commichau et al., 2015).

$\begin{array}{cccl}\text { 10x PBS (pH 6.5) } & 80 & g & \mathrm{NaCl} \\ 2 & g & \mathrm{KCl} \\ 26.8 & g & \mathrm{Na} 2 \mathrm{HPO} 4 \times 7 \mathrm{H} 2 \mathrm{O} \\ 2.4 & \mathrm{~g} & \mathrm{KH} 2 \mathrm{PO} 4 \\ \text { to } 1 \text { I deion. } \mathrm{H}_{2} \mathrm{O}\end{array}$

\section{Western blot analysis}

The desired amount of cell free crude extract was previously separated by SDS PAGE. The transfer of the proteins on a PVDF membrane was performed using a semi dry blotting machine. Activation of the PVDF membrane occurred by short incubation (30 s) in 100\% methanol. After blotting for 1-2 $\mathrm{h}$ with a current of $80 \mathrm{~mA}$, the membrane was incubated in blotto for 1-3 h or overnight. Ensuing, the primary antibody ( $\alpha$-FLAG, 1:10000 in blotto) was added and incubation for 2-3 $\mathrm{h}$ or overnight followed. The membrane was then washed three times for 30 min with blotto, the secondary antibody (anti-rabbit, 1:100000 in blotto) was added and after 30 min the membrane was washed again three times for 20 min with blotto. At last the membrane was rinsed in deionized water and subsequently incubated in buffer III for $5 \mathrm{~min}$. Detection of the proteins was enabled by the substrate CDP* (1:100 in buffer III). Chemiluminescence signals were detected by ChemoCam system (Intas). 


\begin{tabular}{|c|c|c|}
\hline \multirow[t]{4}{*}{ Transfer buffer } & $15.1 \mathrm{~g}$ & Tris \\
\hline & $72.1 \mathrm{~g}$ & Glycine \\
\hline & $750 \mathrm{ml}$ & Methanol (100\%) \\
\hline & \multicolumn{2}{|c|}{ to $5 \mathrm{I}$ deion. $\mathrm{H}_{2} \mathrm{O}$} \\
\hline \multirow[t]{4}{*}{ Blotto } & $100 \mathrm{ml}$ & TBS (10x) \\
\hline & $25 \mathrm{~g}$ & Skim milk powde \\
\hline & $1 \mathrm{ml}$ & Tween 20 \\
\hline & \multicolumn{2}{|c|}{ to 1 I deion. $\mathrm{H}_{2} \mathrm{O}$} \\
\hline \multirow[t]{3}{*}{ Buffer III (pH 9.5) } & $0.1 \mathrm{M}$ & Tris \\
\hline & $0.1 \mathrm{M}$ & $\mathrm{NaCl}$ \\
\hline & \multicolumn{2}{|c|}{ to 1 I deion. $\mathrm{H}_{2} \mathrm{O}$} \\
\hline \multirow[t]{3}{*}{ TBS (pH 7.6) } & $60 \mathrm{~g}$ & Tris \\
\hline & $90 \mathrm{~g}$ & $\mathrm{NaCl}$ \\
\hline & \multicolumn{2}{|c|}{ to 1 I deion. $\mathrm{H}_{2} \mathrm{O}$} \\
\hline
\end{tabular}

\section{Confirmation of AccB biotinylation}

The AccB protein was purified with Strep-Tactin Sepharose as described above. After that, in vitro biotinylation was carried out in a $10 \mathrm{ml}$ reaction mix:

$\begin{array}{rll}1 & \mathrm{mg} & \text { AccB } \\ 10 & \mathrm{mg} & \text { Crude extract of BirA expressing cells } \\ 1 & \mathrm{mM} & \text { Biotin } \\ 10 & \mathrm{mM} & \text { ATP } \\ 1 & \text { Tablet } & \text { cOmplete Mini EDTAfree protease inhibitor } \\ 50 & \mathrm{mM} & \text { Tris } \\ 100 & \mathrm{mM} & \mathrm{KCl}\end{array}$

The reaction was incubated for $1 \mathrm{~h}$ at $37^{\circ} \mathrm{C}$ and afterwards at $4^{\circ} \mathrm{C}$ overnight with slightly agitation. The next day, AccB was purified again using the ÄKTAprime system and a heparin column. The successful biotinylation was confirmed by Western blot analysis using Streptavidin-horseradish peroxidase (HPR) (see above). Therefore, the protein fractions were separated by SDS PAGE and transferred on a PVDF membrane. After 
blotting, the membrane was incubated in PBS containing 1\% BSA for 1-2 h. Then, the Streptavidin-HPR (1:5000 in PBS containing 1\% BSA and 0.1\% Tween20) was added, followed by incubation for 1-2 $\mathrm{h}$. The membrane was washed three times for 20 min with PBS and subsequently rinsed for $1 \mathrm{~min}$ in the developing solution (see below):

$\begin{array}{rll}2 & \mathrm{ml} & 1 \mathrm{M} \text { tris } \mathrm{pH} 8.5 \\ 100 & \mu \mathrm{l} & 2.5 \mathrm{mM} \text { luminol in DMSO } \\ 44 & \mu \mathrm{l} & 90 \mathrm{mM} \text { paracumaric acid in DMSO } \\ 6.15 & \mu \mathrm{l} & \mathrm{H}_{2} \mathrm{O}_{2} \\ \text { to } 20 \mathrm{ml} & \text { deion. } \mathrm{H}_{2} \mathrm{O}\end{array}$

Detection of the proteins was performed by the ChemoCam system (Intas).

\subsubsection{Bacterial Adenylate Cyclase-based two-hybrid system (BACTH)}

The bacterial two-hybrid system takes advantage of the reconstitution of the catalytic domain of the Bordetella pertussis adenylate cyclase (Karimova et al., 1998). To test a potential interaction between two proteins, the T18 and T25 domains of the adenylate cyclase were fused to the $\mathrm{N}$-terminal domain and to the $\mathrm{C}$-terminal domain of the protein of interest respectively. For this purpose, each gene was cloned into two high copy vectors (pUT18, pUT18C) and two low copy vectors (p25-N, pKT25) using the E. coli strain XL1blue. The co-transformation was carried out in the E. coli strain BTH101 and as positive control the plasmids pKT25-Zip and pUT18C-Zip were used. In these two plasmids the T18 and T25 domains are fused to a dimer forming leucine zipper. $30 \mu \mathrm{l}$ of competent cells were mixed with $5 \mu \mathrm{g}$ plasmid DNA $(2.5 \mu \mathrm{g}$ of the T18 domain and $2.5 \mu \mathrm{g}$ of the T25 domain) and incubated for $30 \mathrm{~min}$ on ice. After a heat shock for $90 \mathrm{sec}$ at $42^{\circ} \mathrm{C}, 120 \mu \mathrm{l}$ of LB medium were added to the cells and incubation for $2 \mathrm{~h}$ at $30^{\circ} \mathrm{C}$ followed. At last, $4 \mu \mathrm{l}$ of the cells were dropped on LB agar plates containing ampicillin, kanamycin, X-Gal and IPTG. Association of the two-hybrid proteins resulted in functional complementation between T25 and T18 fragments and lead to CAMP synthesis. CAMP then triggered the transcriptional activation of the lactose operon. The resulting conversion of X-Gal by the $\beta$-galactosidase yielded in the occurrence of blue colonies. Pictures were taken after $24 \mathrm{~h}$ and $48 \mathrm{~h}$ (Commichau et al., 2015). 


\subsubsection{Acetyl-CoA carboxylase activity assay}

The activity of the acetyl-CoA carboxylase was determined by coupling the conversion of acetyl-CoA to malonyl-CoA to the reaction of the malonyl-CoA reductase (MCR) from Chloroflexus aurantiacus (Kroeger et al., 2011). This enzyme uses malonyl-CoA as substrate in a NADPH dependent reaction to produce 3-hydroxypropionate (Hügler et al., 2002). The simultaneous oxidation of NADPH was monitored at $365 \mathrm{~nm}$ in a plate reader. The reaction was set up in a 96 well plate containing the ingredients listed below.

$\begin{array}{rll}0.1 & \mathrm{M} & \mathrm{KCl} \\ 20 & \mathrm{mM} & \mathrm{MgCl}_{2} \\ 10 & \mathrm{mM} & \text { ATP } \\ 0.5 & \mathrm{mM} & \text { DTT (Dithiothreitol) } \\ 10 & \mathrm{mM} & \mathrm{NaHCO}_{3} \\ 1 & \mathrm{mM} & \mathrm{NADPH} \\ 1.6 & \mathrm{mM} & \text { Acetyl-CoA } \\ 5 & \mu \mathrm{g} & \mathrm{MCR} \\ 100 & \mathrm{nM} & \text { AccAD } \\ 100 & \mathrm{nM} & \text { AccB } \\ 100 & \mathrm{nM} & \text { AccC } \\ 150 & \mu \mathrm{l} & 50 \mathrm{mM} \text { Tris/ 100mM KCl buffer (pH 8.5) }\end{array}$

The reaction was initiated by the addition of the MCR and incubated at $25^{\circ} \mathrm{C}$ for $12 \mathrm{~h}$. In case of the positive control without the addition of the ACCase and acetyl-CoA, the initial step was the addition of $0.3 \mathrm{mM}$ malonyl-CoA. 


\section{Results}

\subsection{Impact of YqhY on the ACCase}

\subsection{1 $\Delta y q h Y$ suppressor mutations are located in the acetyl-CoA subunits}

Previous experiments showed the non-essentiality of yqhY and yloU (Tödter, 2013). Nevertheless, the occurrence of suppressor mutants resulting from the knockout of yqhY still supports a vital role of YqhY for growth of $B$. subtilis, even if it is not essential. The mutations occurred after approximately five days of growth on SP agar plates. The genomic DNA of several clones was isolated and analyzed by sequencing. In many cases, the mutations were located in the subunits of the acetyl-CoA carboxylase (Fig. 6).

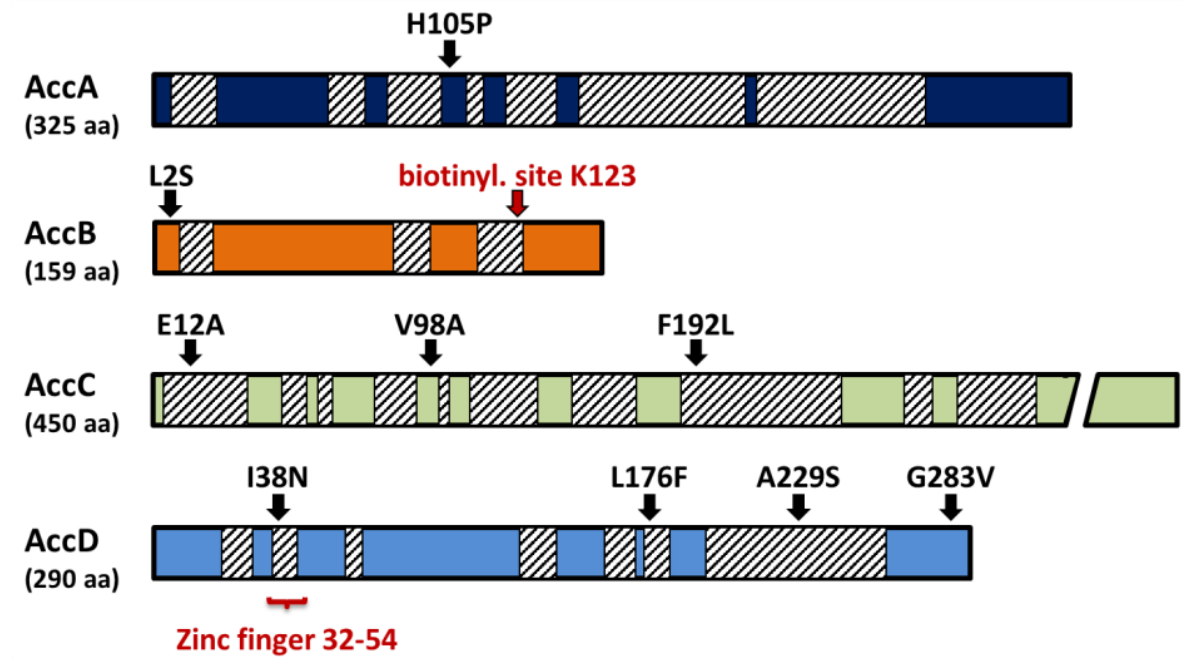

Fig. 6. Mutations in the acetyl-CoA carboxylase subunits. As a result of the deletion of yqhY, suppressor mutations were found in the subunits of the acetyl-CoA carboxylase (AccA, AccB, AccC and AccD). All mutations were single substitutions obtained from distinct clones. Many of them were located in highly conserved regions (hatched boxes).

Interestingly, every mutant contains a single substitution and all were found in all four subunits ( $A c c A, A c c B, A c c C$ and $A c c D)$. Moreover, often highly conserved regions were affected, or the mutations are closely located next to these regions. For example, the substitutions E12A in AccC is close to Y82 and V295. These residues are necessary for biotin attachment in the active site of AccC (Chou et al., 2009). The second mutation F192L is nearby the key side chains K116, K159, E201, H236 and K288 of the ATP binding pocket (Waldrop et al., 2012). The last substitution V98A is not located in a binding region, but it 
is also close to a conserved region and therefore maybe involved in complex stability or interaction with AccB. Regarding the substitutions in AccD, L176F and A229S are in close proximity to catalytic sites, which are surrounded by conserved residues. Since both affected residues are also highly conserved, they may be important for ACCase activity. Furthermore, $A c c D$ possesses a unique zinc-binding domain that is not only necessary for DNA binding but is probably also important for catalytic activity (Bilder et al., 2006). Thus, the mutation $138 \mathrm{~N}$ could result in activity changes. Another possibility is an altered DNA binding ability that would also impact the catalytic reaction, because DNA binding inhibits the enzymatic activity of the carboxyltransferase (Benson et al., 2008).

All in all, the obtained substitutions indicate a change in ACCase activity. This could be due to altered substrate affinities, structure changes or decreased abilities to bind other subunits.

\subsubsection{The absence of YqhY results in an increased formation of lipophilic clusters}

The knockout of yqhY showed a severe growth defect resulting in the occurrence of suppressor mutations. Since the majority of these mutations was located in the acetylCoA subunits, this indicated an altered fatty acid production. To test this hypothesis, the accumulation of lipophilic components was visualized using the stain FM4-64. The different strains were grown in LB medium and samples were taken at exponential and stationary growth phase. In a first approach, the strains Bs168, GP1765 ( $\Delta y q h Y)$, GP2322 ( $\Delta y q h Y$ AccD A229S) and GP2323 ( taken at the exponential growth phase revealed a significant effect, whereas cells taken at the stationary growth phase showed no phenotypic alteration compared to the wild type. The absence of YqhY lead to lipophilic accumulations at the cell poles and the cell membrane. This hints at an increased fatty acid synthesis in these areas of the cell. On the other hand, the clustering is revoked after suppressor mutations occurred in AccD. Although, the effect of mutations in the other subunits were not investigated, these observations indicate that the increased cluster formation is abolished in the suppressor mutants.

Moreover, the abundance of AccDA and YqhY was investigated. For this purpose, yqhY and the operon of $\operatorname{accDA}$ were cloned separately into $\mathrm{pBQ} 200$. This vector allows 
overexpression of target genes in B. subtilis. Again, samples were taken at exponential and stationary growth phase and stained with FM4-64. In both growth phases, neither the overexpression of $y q h Y$ nor accDA resulted in a significant phenotype. The cells showed a lipophilic pattern similar to the wild type.

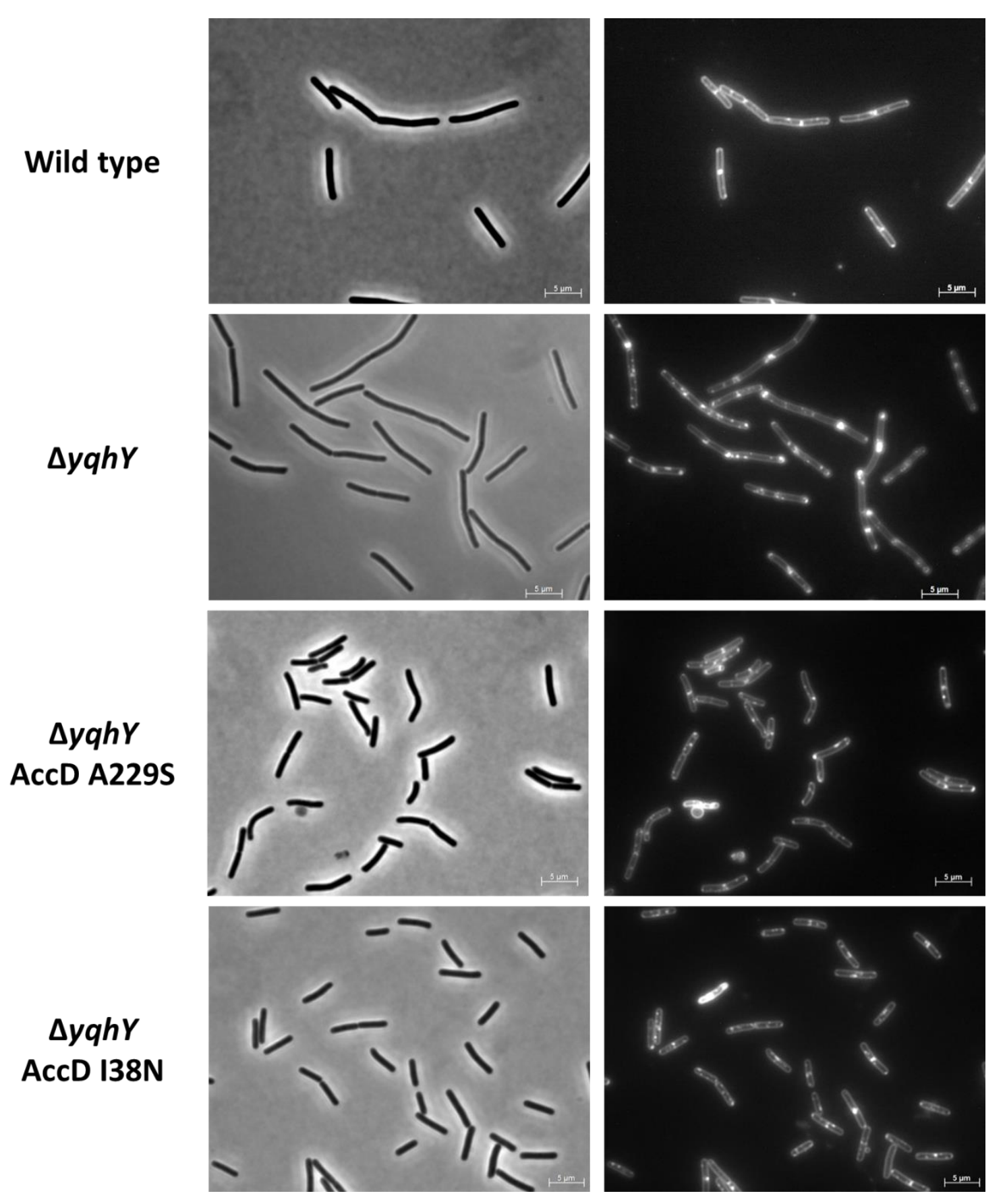

Fig. 7. Staining of lipophilic regions in the absence of YqhY. Samples were taken at exponential growth phase and treated with FM4-64. After the knockout of yqhY, lipophilic clusters were visible at the cell poles and near to the cell membrane. This cluster formation was abolished after the appearance of mutations in AccD. 


\subsubsection{YqhY impacts the localization of AccA}

The suppressor mutations in the acetyl-CoA carboxylase subunits and the cell staining with FM4-64 suggest a possible role of YqhY in fatty acid synthesis. A possible function could be YqhY acting as a localization factor. Therefore, it is important to know the localization of YqhY and the subunits of the ACCase. To do this, $\operatorname{acc} A, \operatorname{acc} B$ and $\operatorname{acc} C$ were each cloned into the vector pBP43 to implement a C-terminal GFP-fusion to the encoding proteins. The expression was kept under the control of the respective natural promoter. A GFP-fusion to AccD using the same plasmid was not possible without deleting the essential downstream gene accA. But due to the strong complex formation of AccA and $A c c D$, the localization of AccA also represents the localization of AccD. The cells were grown in LB medium and samples were taken at an $\mathrm{OD}_{600}$ of 1.5.
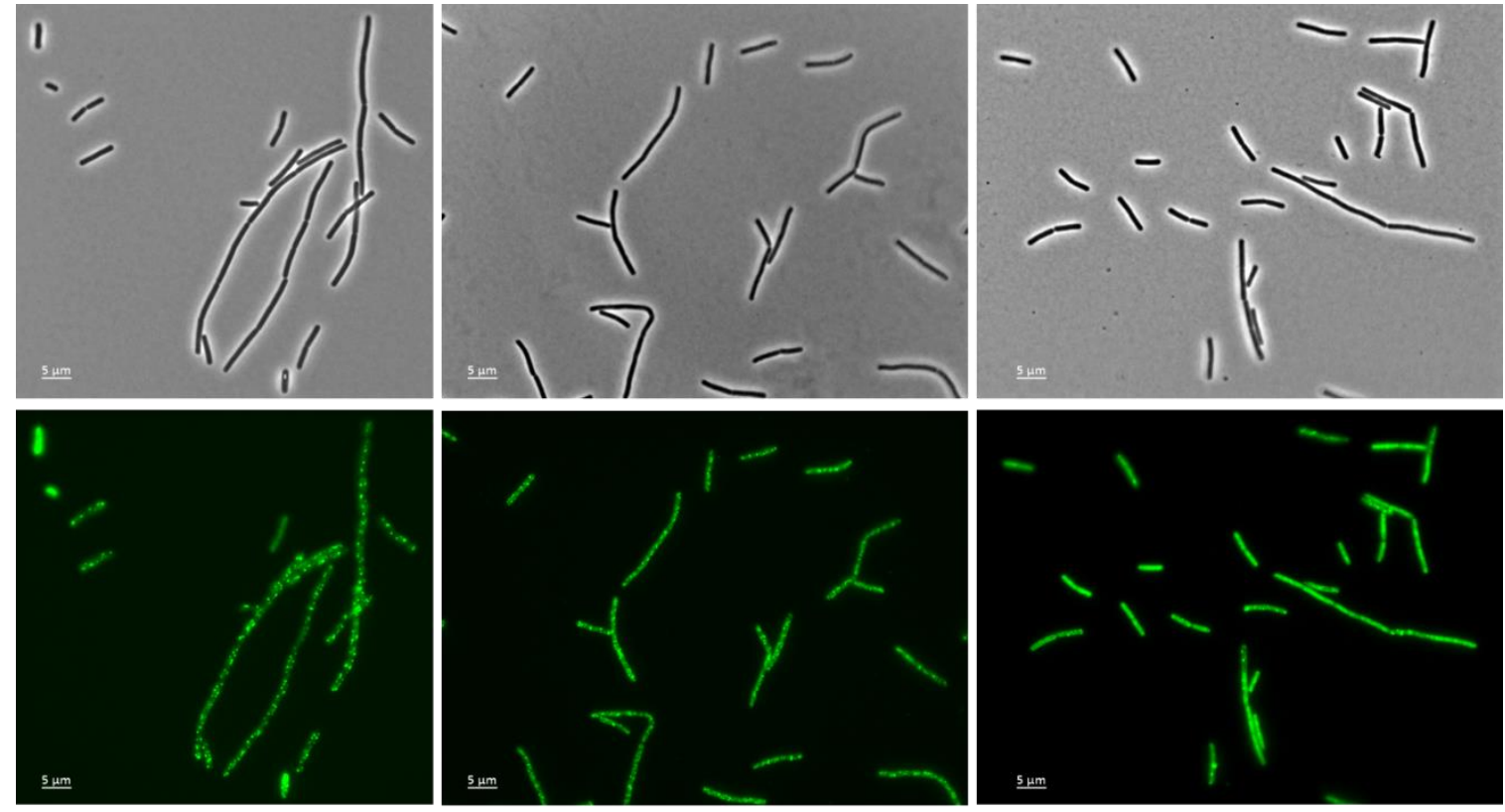

AccA-GFP

AccB-GFP

AccC-GFP

Fig. 8. Localization of AccA, AccB and AccC. The proteins were fused to a monomeric GFP at the C-terminus and visualized via fluorescence microscopy. All subunits were equally distributed in spots over the cell.

As shown in Fig. 8, all tested subunits where scattered equally in spots over the cell. This was in contrast to the cell pole localization of YqhY (Tödter, 2013). However, in the absence of YqhY the equal distribution of AccA changed towards a polar localization. The localization of the other subunits $A c c B$ and $A c c C$ was not affected in a $\Delta y q h Y$ background. 
In addition, the localization of AccA was analyzed in two suppressor mutant strains carrying mutations in AccD (GP1469) and AccA (GP1470). In both strains AccA again accumulates at the cell poles, which means that the occurrence of the suppressor mutations did not restore the phenotype to a wild type pattern (Fig. 9).
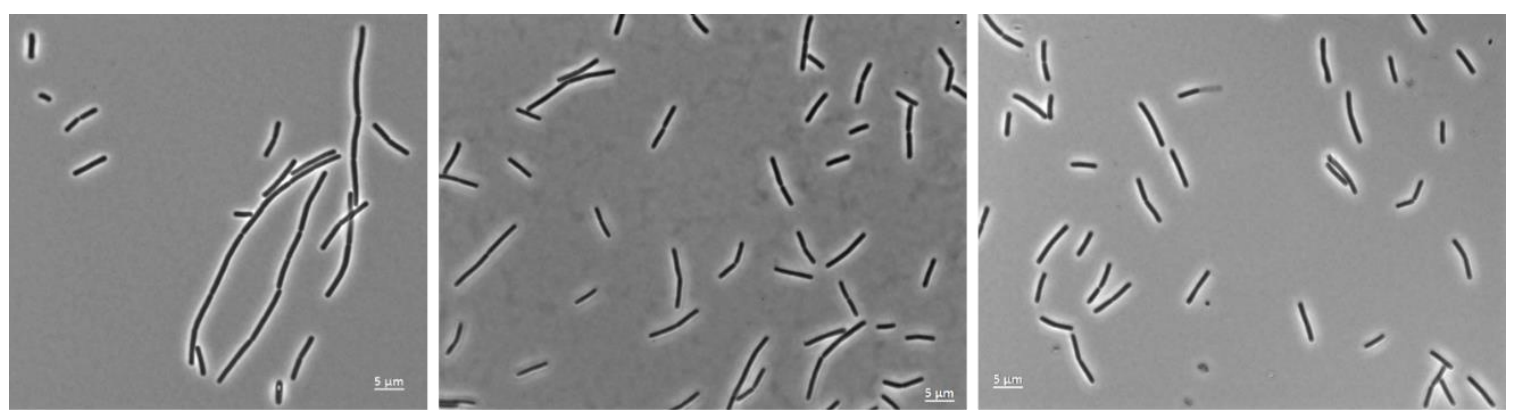

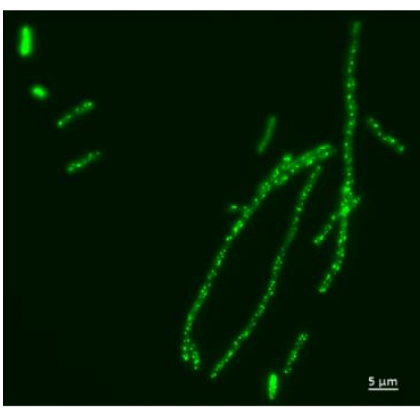

AccA-GFP

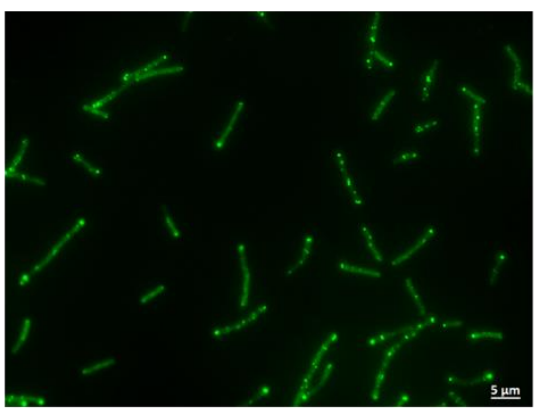

$\Delta y q h Y$ AccA-GFP

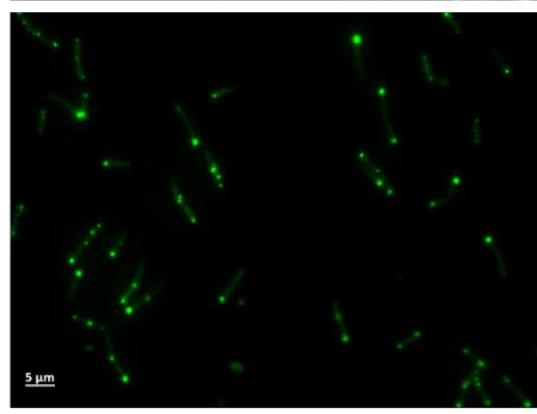

$\Delta y q h Y$ AccA H105P-GFP

Fig. 9. Localization of AccA in $\Delta y q h Y$ background. AccA was fused to a monomeric GFP at the C-terminus and visualized via fluorescence microscopy. In the wild type AccA was equally distributed in spots over the cell. In contrast to this, in the absence of YqhY the localization pattern changed towards a cell pole localization. This effect also remained after the occurrence of suppressor mutations as it is shown here for a mutation in AccA.

\subsubsection{Investigation of an interaction of YqhY with the acetyl-CoA complex}

Having a look at the genetic background of yqhY already reveals a connection to acetylCoA carboxylase. The gene forms an operon with $\operatorname{acc} B$ and $a c c C$, which encode for the carboxyltransferase. Moreover, the impact on the localization of AccA and the increased formation of lipophilic clusters support the idea that YqhY directly interacts with at least one subunit of the ACCase complex. 


\subsubsection{YqhY interacts with AccC ex vivo}

At first, the possible interaction of YqhY and the subunits was evaluated in a bacterial twohybrid assay. In doing so, yqhY as well as $a c c A, a c c B, \operatorname{acc} C$ and $\operatorname{acc} D$ were cloned into the bacterial two-hybrid vectors and in this way, the proteins were fused to the T18 and T25 domains. After two days, YqhY, AccA, AccB and AccC showed the already known selfinteractions. Besides, the complex formations of the carboxyltransferase (AccDA) and the AccBC complex were visible. Concerning YqhY, there was only an interaction with AccC (Fig. 10).

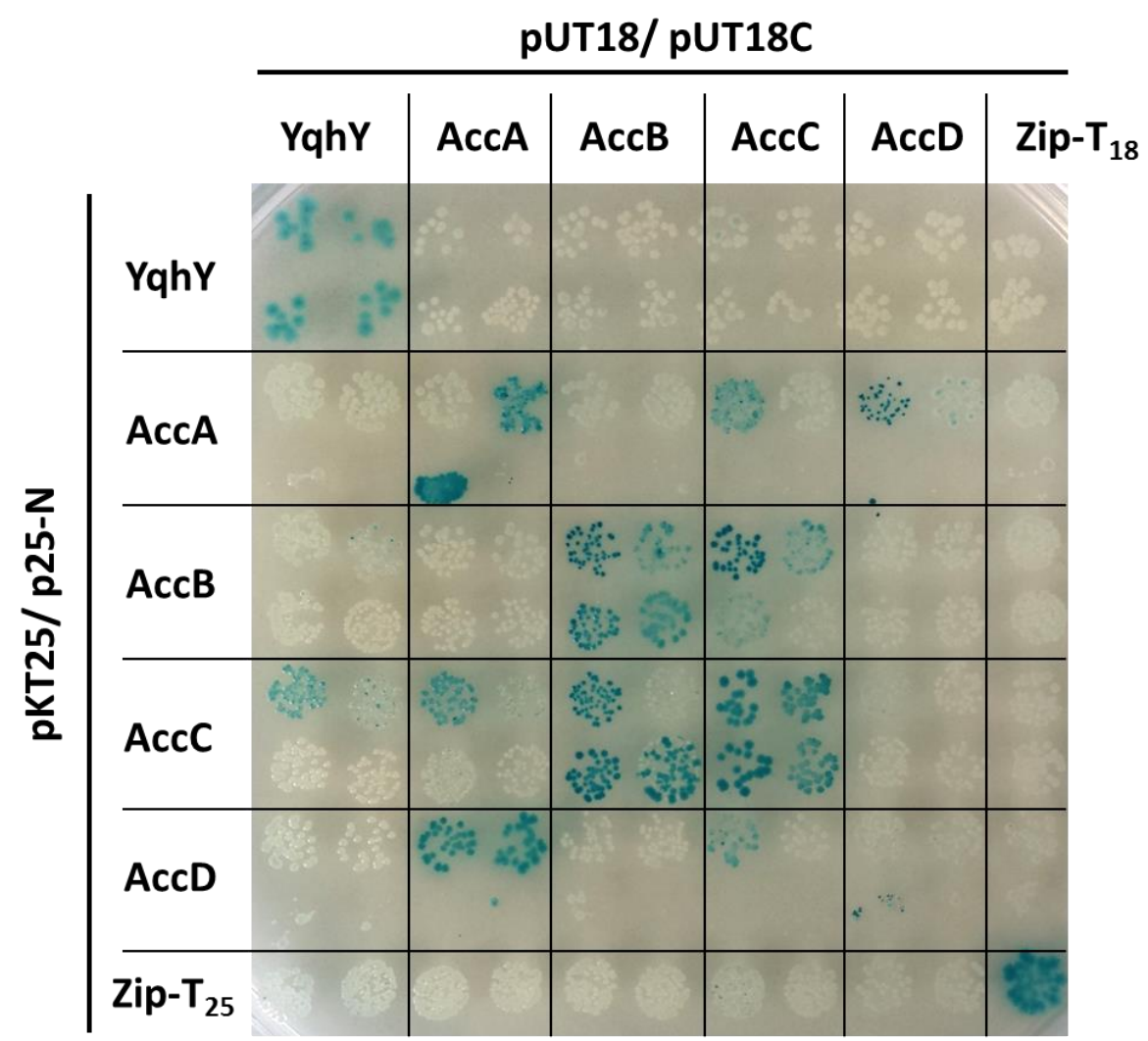

Fig. 10. Bacterial two-hybrid analysis of interactions between YqhY and the ACCase subunits. The respective genes were fused to the domains of the adenylate cyclase and incubated for two days. Interactions, indicated by blue colonies, were observable among the subunits themselves and between YqhY and AccC.

\subsubsection{YqhY binds AccA and AccD only as a complex}

In order to confirm the interaction between YqhY and AccC and examine again the noninteraction with the other subunits, a SPINE was performed. In this approach, YqhY functioned as a bait protein and was fused to a C-terminal Strep-tag. This was carried out by cloning the gene in the vector pGP1460, which integrates into the lacA locus and allows 
constitutive expression of $y q h Y$. The pray proteins, AccA, AccD and CshA, were fused to a C-terminal FLAG tag. accA and cshA were each cloned into pGP1331 to keep the expression under the control of the natural promoter. The same vector could not be used for a FLAG tag fusion to AccD, because accA would be deleted as a consequence. Therefore, $a c c D$ was overexpressed in the vector pGP1370. After the transformation of Bs168 with the plasmids, three different strains were derived. Each of those carried a Strep-tag fusion to YqhY and FLAG tag fusion to AccA, AccD or CshA. These strains were grown in CSE medium containing $0.5 \%$ glucose and treated with paraformaldehyde during growth to crosslink adjacent proteins. After the SPINE the proteins were detected via Western blot. The results are shown in Fig. 11.

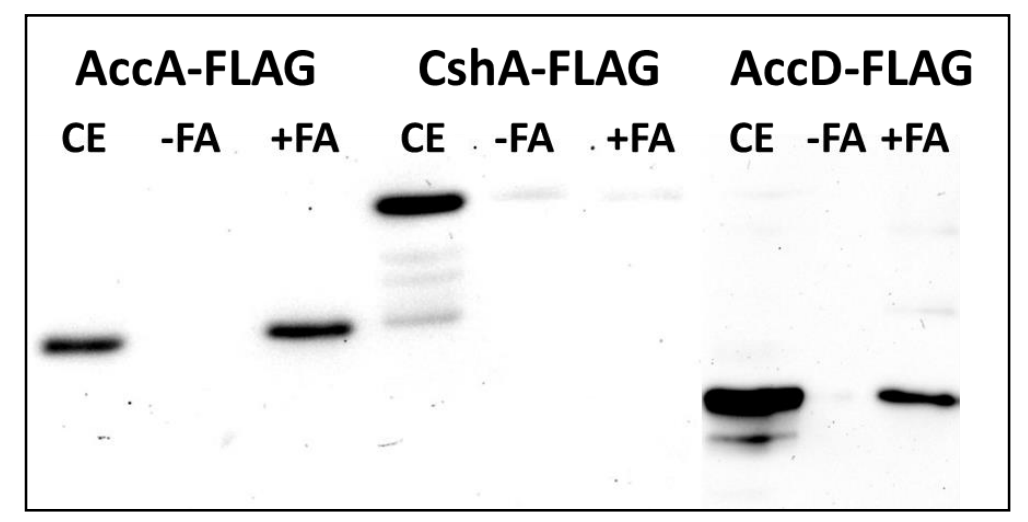

Fig. 11. Proof of interaction between YqhY and the carboxyltransferase via SPINE. Strains expressing YqhYStrep were grown in CSE medium containing $0.5 \%$ glucose, adjacent proteins were crosslinked by the addition of paraformaldehyde (FA). The pray proteins (AccA, CshA and AccD) were fused to a FLAG tag and detected by Western blot analysis. YqhY was purified using a StrepTactin column and was co-eluted with AccA and AccD. CshA functioned as a negative control.

AccA and AccD could be observed in the elution fractions, suggesting an interaction with YqhY. As both proteins form a strong complex, YqhY is expected to bind the AccDA complex instead of interacting with only one of these proteins. This assumption is reinforced by the non-interaction of YqhY and AccA and AccD in the bacterial two-hybrid screen, since only interactions of two proteins can be examined. Nevertheless, the copurification of AccD has to be evaluated carefully. The protein amount in the crude extract is significantly higher due to the overexpression of $\operatorname{accD}$. But in the elution fraction only a little amount of AccD is detectable. In addition to this, a small amount of AccD-FLAG was also detectable in the absence of YqhY-Strep (data not shown), which means that AccD 
can already be purified via the biotinylated AccB. Apart from this, AccA could not be purified in the absence of YqhY-Strep (data not shown), confirming that YqhY undoubtedly interacts with AccA.

The same approach was carried out to test the in vivo interaction of YqhY and AccB and AccC. This time, the latter proteins were fused to a Strep-tag with the help of pGP1460. On the other hand, YqhY was fused to a FLAG tag using pGP1331. Against the expectations given by the bacterial two-hybrid results, there was neither an interaction of YqhY with AccB nor AccC (data not shown).

\subsubsection{Influence of YqhY on the acetyl-CoA carboxylase activity}

The foregoing experiments showed an interaction of YqhY and the subunits of the acetylCoA carboxylase, demonstrating again a clear connection of YqhY to the fatty acid synthesis. In addition to this, an increased fatty acid synthesis was indicated by the lipophilic accumulation in the absence of YqhY. Giving these preconditions, there is the possibility of YqhY altering the activity the acetyl-CoA carboxylase by direct binding to the complex. To study this hypothesis, an in vitro assay was set up in which the reaction of the acetyl-CoA carboxylase was coupled with the reaction of the malonyl-CoA reductase.

\subsubsection{Purification of proteins used in the activity assay}

The first thing to do was the overexpression and purification of YqhY, the ACCase subunits and the malonyl-CoA reductase (MCR). For this purpose, YqhY was brought into the vector pETM-11, resulting in an $\mathrm{N}$-terminal His-tag fusion. The remaining proteins were fused to a Strep tag. All components were overexpressed in E. coli, except AccA and AccD. The overexpression of AccA turned out to be toxic for E. coli, so accA was cloned into pGP382 for overexpression in B. subtilis. AccD could be co-purified with Strep tagged AccA. In a first try, AccB was also expressed without a tag in B. subtilis, as it can be purified via StrepTactin in its biotinylated form. But the protein amount was too low after the purification. Due to this reason, the plasmid pGP1027 was used for Strep tagged AccB purification. The respective fractions are shown in Fig. 12.

The purification of all desired proteins was successful. In case of $A c c B$, the binding partner AccC was co-eluted as well as the biotin carboxylase from E. coli, which was able to bind 
to the Strep-Tactin column with the help of the biotinylated $A c c B_{E c}$. These contaminations were checked later on to exclude the presence of factors that distort the outcomes of the activity assay. Finally, the elution fractions of the proteins were dialyzed against $50 \mathrm{mM}$ Tris/ $100 \mathrm{mM} \mathrm{KCl}$ buffer containing $10 \%$ glycerol and frozen at $20^{\circ} \mathrm{C}$ until usage.

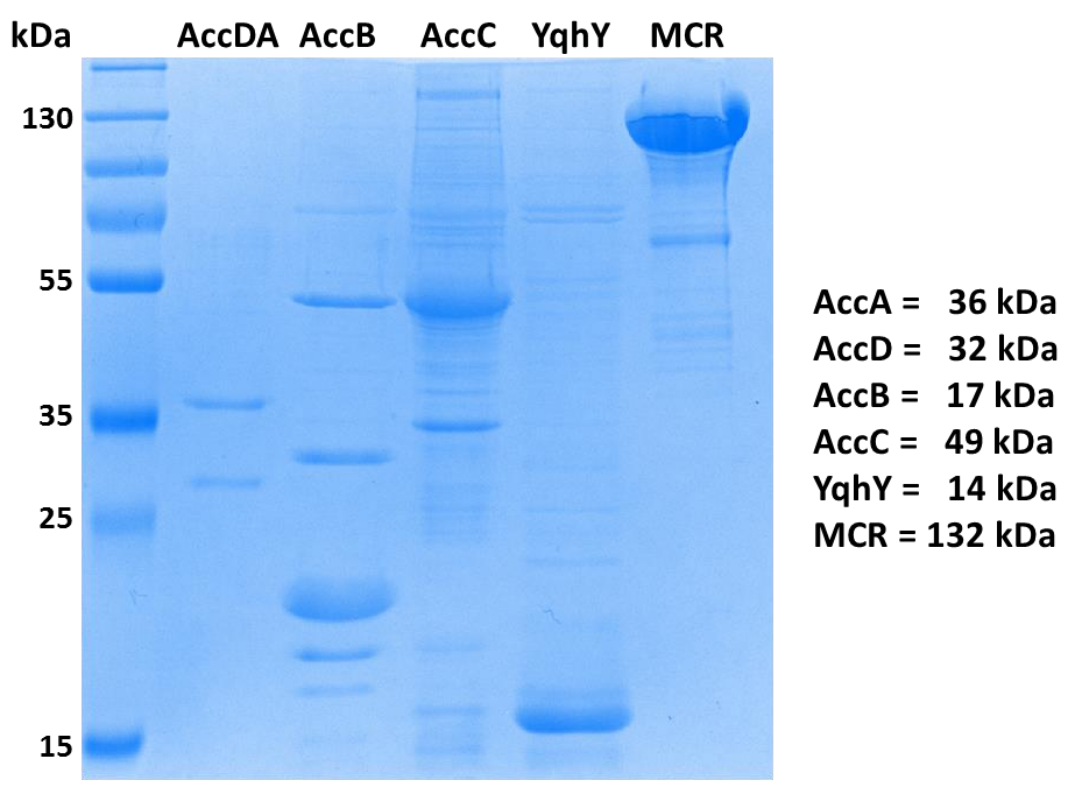

Fig. 12. Purification of the acetyl-CoA subunits, YqhY and malonyl-CoA reductase. The desired proteins were all expressed in E. coli, except AccA and AccD (in B. subtilis). Afterwards, they were purified on a StrepTactin column and $\mathrm{Ni}^{2+}-\mathrm{NTA}$ column (in case of $\mathrm{YqhY}$ ), respectively. In the end, the different fractions were separated by SDS-PAGE and visualized by Coomassie staining.

\subsubsection{Validation of biotinylation of AccB}

A crucial condition for the activity of the acetyl-CoA carboxylase is the biotinylation of AccB. To guarantee that this precondition is given, the previously purified AccB was biotinylated in vitro and tested in a Western blot using the Streptavidin-horseradish peroxidase (HRP). The biotin adding enzyme of AccB is BirA. This ligase was overexpressed in E. coli and subsequently the crude extract of these cells was added to the reaction mix containing AccB, biotin, ATP and protease inhibitor. The following day, this reaction mix was purified with a Heparin column and the obtained elution fractions were separated by SDS-PAGE (Fig. 13a).

The silver staining confirmed the presence of $A c c B$ in the elution fractions E1 to E5, together with the co-purified AccB from E. coli. To test whether AccB was bound to biotin, the same samples where used for Western blot analysis. In this purpose, biotinylated 
proteins were bound to streptavidin coupled with the horseradish peroxidase. This enzyme catalyzes the oxidation of luminol resulting in enhanced light emission. As shown in Fig. 13b, in all fractions other than fraction E5, AccB was detectable, which means that in these samples $A c c B$ was biotinylated. Even the purified $A c c B$ that was not used for in vitro biotinylation was connected to its substrate, demonstrating that an extra biotinylation was unnecessary. Thus, for the following activity assay the pivotal state of AccB was given.

A

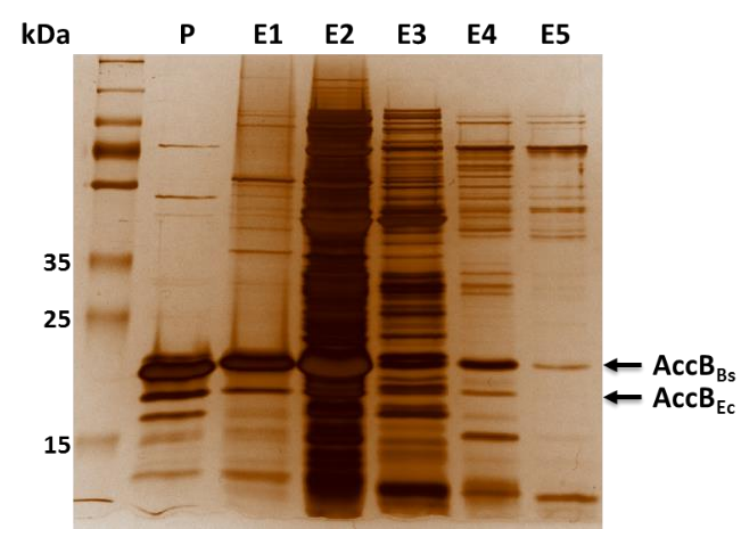

B

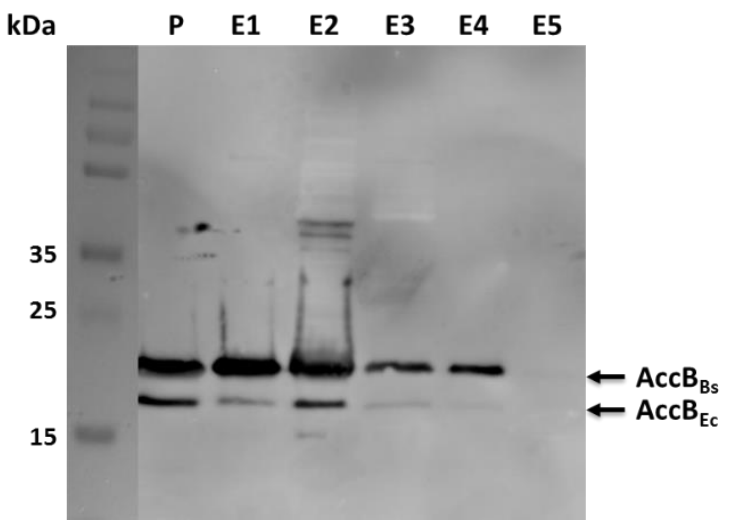

Fig. 13. Confirmation of biotinylation of AccB. The previously purified AccB (P) was used for in vitro biotinylation and afterwards purified again on a heparin column. The presence of $A c C B$ in the elution fractions (E1-E5) was confirmed by silver staining (A). The same fractions were analyzed for AccB biotinylation by Western blot using streptavidin-HRP (B).

\subsubsection{YqhY does not directly influence the acetyl-CoA carboxylase activity}

In order to investigate if the direct interaction of YqhY with the carboxyltransferase implicates a change in ACCase activity, a coupled enzyme assay was set up. In this assay the malonyl-CoA production was followed by NADPH oxidation catalyzed by the malonylCoA reductase (MCR). The activity was thereby measured in the presence and absence of YqhY in different amounts. As can be seen in Fig. 12, the addition of the AccB and AccC could also imply the addition of other enzymes that oxidize NADPH or consume the substrates of the ACCase or MCR. Furthermore, YqhY itself could consume one of the ingredients. To exclude both possibilities, the oxidation of NADPH was also monitored in the absence of AccDA on the one hand and only in the presence of YqhY on the other hand (Fig. 14). 
[U/mg]

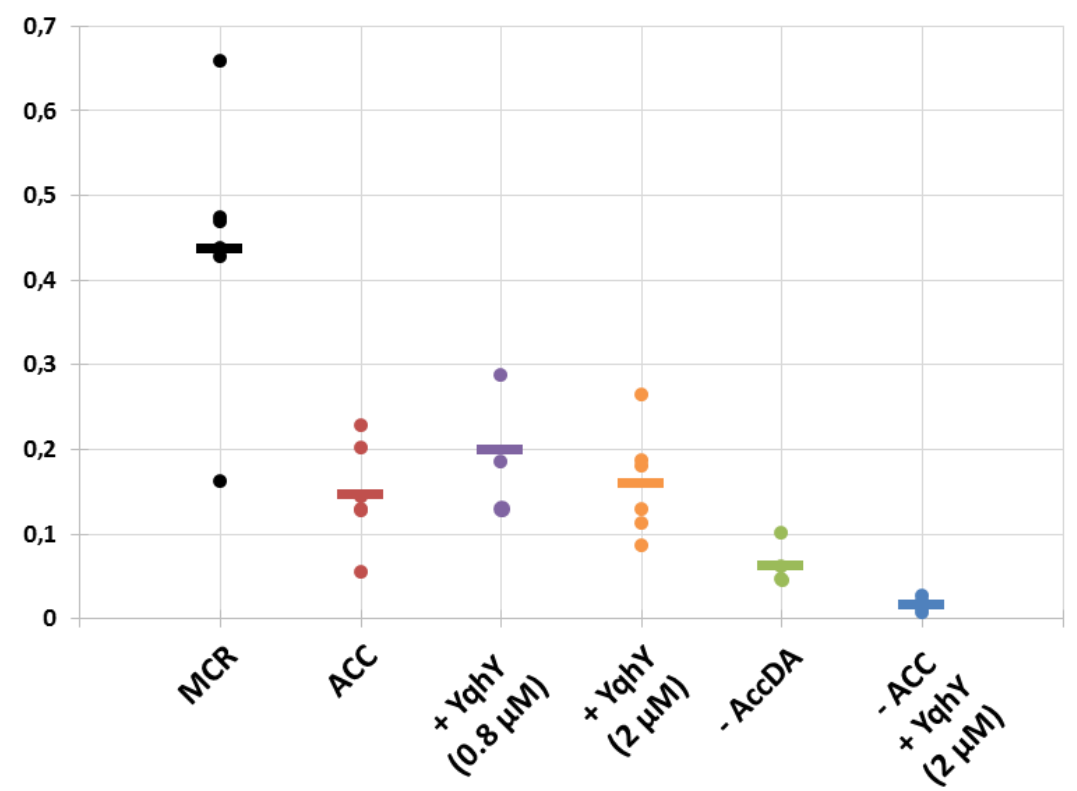

Fig. 14. Impact of YqhY on the ACCase activity. The production of malonyl-CoA by the acetyl-CoA carboxylase (ACC) was coupled to the NADPH dependent reaction of the malonyl-CoA reductase (MCR). The oxidation of NADPH was monitored in a plate reader. Dots represent single measurements and bars indicate the mean value of all measurements. Taking outliners into account, there was no significant change in activity by the addition of YqhY.

In all set ups the activity of the MCR was monitored by the oxidation of NADPH. For the positive control, malonyl-CoA was added and therefore the presence of the ACCase was not needed. Compared to this, the MCR activity was significantly lower in the coupled reaction, making obvious that the malonyl-CoA production by the ACCase in general was low. However, a reaction process of the ACCase was noticeable. In the absence of AccA and $A c c D$ also an activity was measurable, but since this reaction was always slower than the reaction of the whole complex, the participation of adulterating elements could be excluded. Using a composition without the ACCase and only with YqhY showed no activity at all. So, it was evident that YqhY shows no enzyme activity in producing malonyl-CoA or oxidizing NADPH. The original hypothesis, YqhY alters the activity of the ACCase, could not be confirmed. The addition of YqhY in neither lower nor higher amounts had no meaningful impact on the activity of the ACCase. In some cases the activity was increased, in other cases it turned out to be the opposite. On average, the reaction velocity of the acetyl-CoA carboxylase was equal with or without the YqhY. This made clear that YqhY has 
no direct impact on the acetyl-CoA carboxylase activity, although a direct interaction was proven.

\subsubsection{Suppressor mutations in yqhY deletions strains decrease the activity of the acetyl-CoA carboxylase}

Despite the fact that YqhY seems to be no activity changing factor, the previous experiments still implied a change in fatty acid production in suppressor mutants. Hence, there was the question if the mutations resulted in a decreased ACCase activity. To further analyze the aftermath of the mutations, the coupled in vitro activity assay was used. In this approach, $A c c D$ was replaced by mutated versions ( $A_{C C D} D_{138 N}, A_{C C D} D_{2229 S}$ ). At first, the C-terminus of accA was amplified and brought into the vector pGP1389. The resulting plasmid pGP1849 was then used for transformation of GP2321 and GP2322, respectively. AccA were thereby fused to a Strep tag. Again, $A c c A$ and $A c c D_{m u t}$ were co-purified and the assay was performed as described above.

The previous set up verified that YqhY has no direct impact on the activity. Contrary to this, the results shown in Fig. 15 demonstrate that some mutations in AccD lead to a lower activity of the ACCase. In case of the $A_{C C D_{138 N}}$ mutation, the activity of the acetyl-CoA carboxylase was equal to the wild type activity. On the other hand, the $\operatorname{AccD}_{\mathrm{A} 229 \mathrm{~s}}$ mutation caused a significant decrease in malonyl-CoA production. This example shows, that not all mutations but at least some of them are responsible for a change in activity of the ACCase. This lead to the conclusion that YqhY has no direct impact on the activity, but cells missing this protein have to reduce the activity of the acetyl-CoA carboxylase. This might happen by mutating the subunits to either change the localization or decreasing the activity of the complex. 


\section{$[\mathrm{U} / \mathrm{mg}]$}

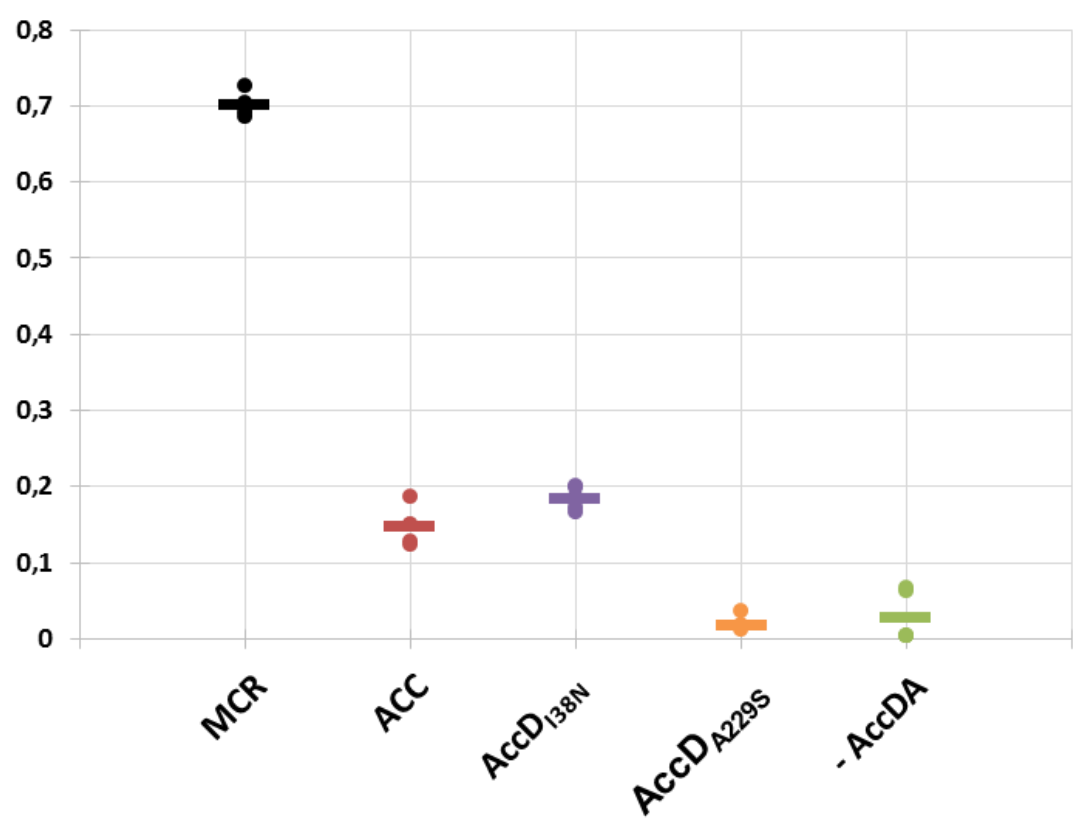

Fig. 15. Effect of suppressor mutations in $y q h Y$ deletions strains on the ACCase activity. The production of malonyl-CoA by the acetyl-CoA carboxylase (ACC) was coupled to the NADPH dependent reaction of the malonyl-CoA reductase (MCR). The oxidation of NADPH was monitored in a plate reader. Dots represent single measurements and bars indicate the mean value of all measurements. Mutations in AccD lead to a reduced activity of the $A C C a s e$, shown by the mutation $A_{C C D} D_{A 229 s}$. On the other hand, not all mutations located in the subunits have direct influence on the activity as it is demonstrated by the mutation AccDi38N.

\subsection{The possible role of YqhY in Clp-mediated protein degradation}

\subsection{1 $\Delta y q h Y$-suppressor mutants hint to involvement in Clp-mediated proteolysis}

Among the suppressor mutants derived after the knockout of yqhY, not all carried a mutation in one of the acetyl-CoA carboxylase subunits. Two of those were analyzed by whole genome sequencing revealing a deletion of $c t s R$ in one strain and an insertion in $y j b H$ in the other strain. Both observations indicated a connection to protein degradation by the $\mathrm{Clp}$ protease. $\mathrm{YjbH}$ is an adaptor protein for $\mathrm{ClpX}$, promoting the degradation of the transcription regulator Spx via ClpXP. CtsR on the other hand is a transcription repressor of the CtsR regulon that contains genes encoding the proteolytic subunit $\mathrm{ClpP}$, the ATPases ClpC, ClpE and ClpX, as well as the adaptor protein McsB. So, in an organism missing CtsR, these components of the Clp mediated protein degradation are upregulated leading to an increased degradation of substrates of ClpXP, ClpEP and ClpCP. 
In order to confirm that the absence of CtsR or YjbH prevents the harming effect appearing after the knockout of $y q h Y$, double deletion strains were constructed. In addition to the knockout of $y q h Y$, a deletion of $y j b H$ or ctsR was performed. As a negative control, a double deletion of $y q h Y$ and $y s z B$ was carried out. In this strain, $y s z B$ was replaced by the same resistance marker as cts $R$ and $y j b H$. The expected outgrowth of suppressor mutants could be observed for the $y q h Y$ single knockout strain and for the

$\Delta y q h Y \Delta y s z B$ control strain. In contrast to this, in a $\Delta c t s R$ and in a $\triangle y j b H$ background the formation of suppressor mutants was almost not existing (Fig. 16). Therefore, the deletion of $c t s R$ or $y j b H$ enables the growth of $B$. subtilis in the absence of YqhY without any other adjustments.

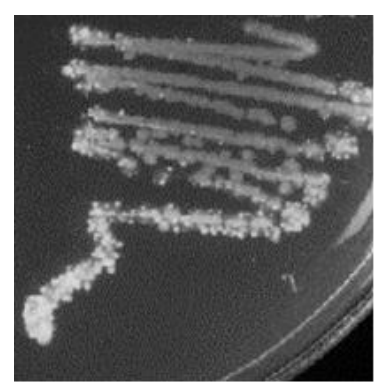

$\Delta y q h Y$
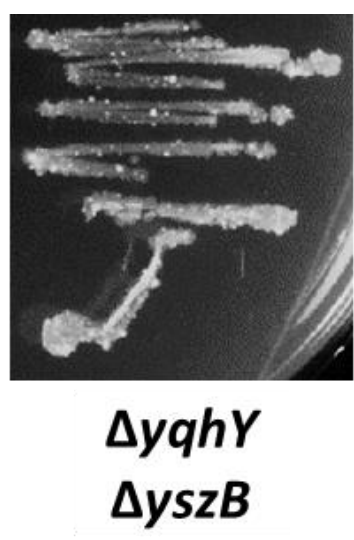

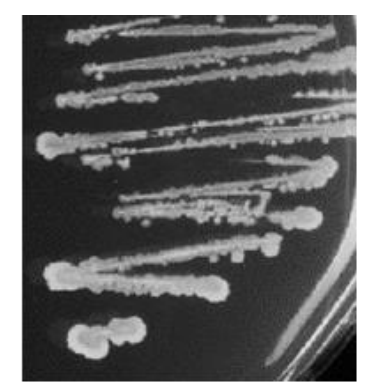

$\Delta y q h Y$

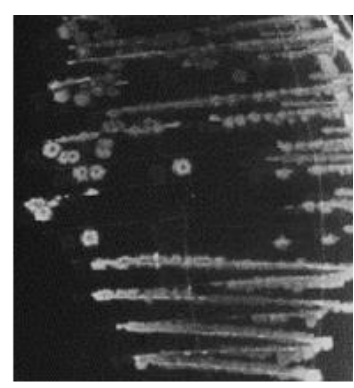

$\Delta y q h Y$ $\Delta c t s R$

Fig. 16. Occurrence of $\Delta y q h Y$-suppressor mutants in a $\Delta c t s R$ and $\Delta y j b H$ background. The deletion of $y q h Y$ lead to suppressor mutant formation. This effect is abolished in double knockout strains missing either $y j b H$ or ctsR in addition to $y q h Y$. The double knockout of $y q h Y$ and $y s z B$ functioned as a negative control showing the same result as the $y q h Y$ single deletion.

\subsubsection{Interaction of YqhY with Clp proteins}

As mentioned above, in the absence of YqhY the degradation of substrates of the Clp machinery is in some cases upregulated, or the fatty acid synthesis is decreased by affecting the acetyl-CoA carboxylase. This lead to the assumption that YqhY might function as an adaptor protein for $A c c A, A c c B, A c c C$ or $A c c D$. In YqhY deletion strains, the production of fatty acids might reach a toxic level, since the amount of the ACCase subunits is too high due to the missing adaptor protein and the concomitant needed degradation. This could be compensated by mutations affecting the functionality of the ACCase or by mutations inducing the degradation of the ACCase complex. 


\subsubsection{YqhY binds Clp ATPases ex vivo}

To examine the hypothesis of YqhY being an adaptor protein, an interaction of YqhY and the Clp proteins had to be proven. In a first approach, the respective protein interactions were tested in a bacterial two-hybrid assay including YqhY, ClpC, ClpE, ClpP and ClpX. clpE was the only gene that has to be brought into the bacterial two-hybrid vectors, for all other genes the necessary constructs were already available. The screen was executed as described above. After two days, the known self-interactions of YqhY, ClpC, ClpE and ClpP were visible (Fig. 17).

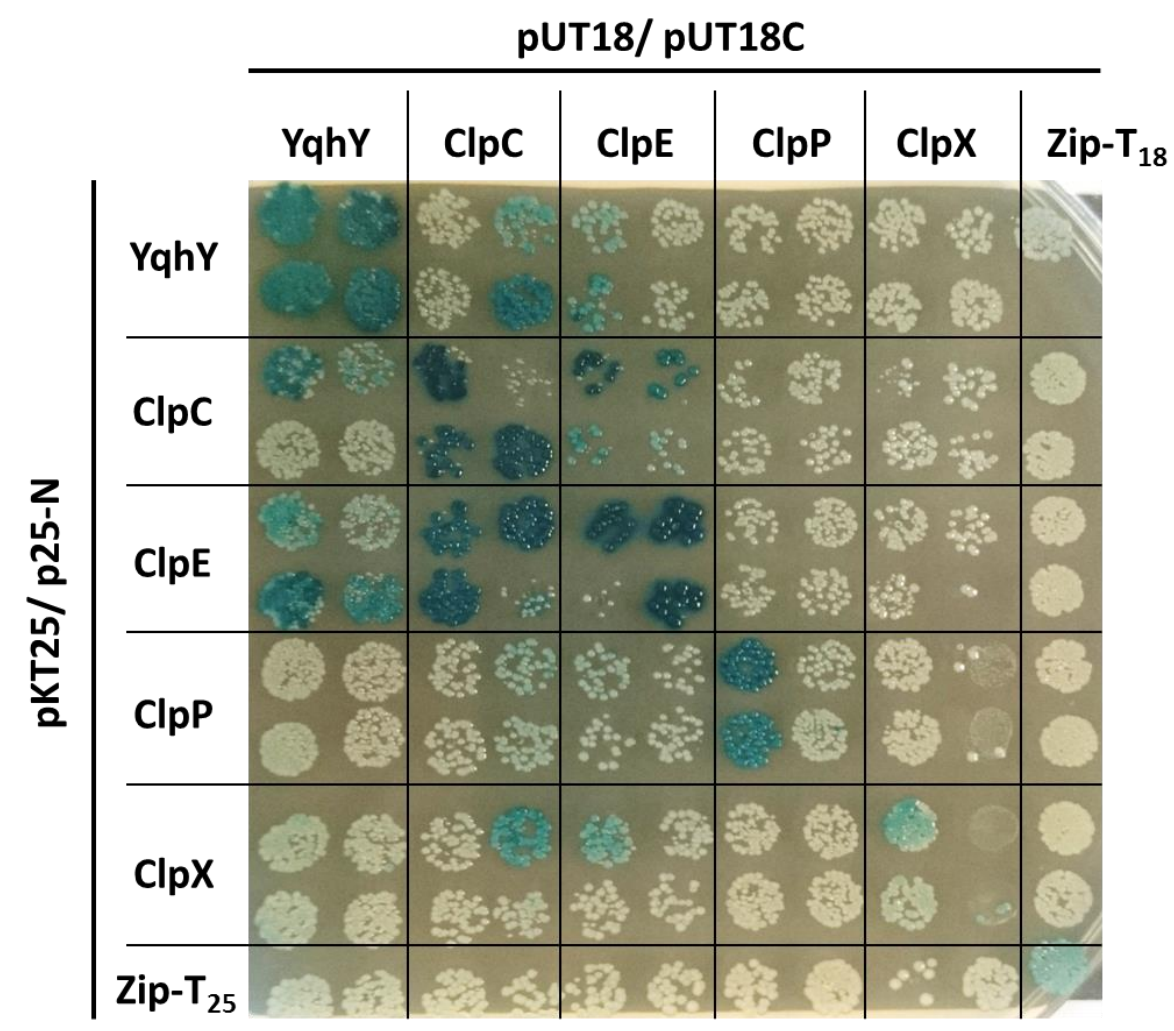

Fig. 17. Bacterial two-hybrid analysis of interactions between YqhY and Clp proteins. The respective genes were fused to the domains of the adenylate cyclase and incubated for two days. Interactions, indicated by blue colonies, were observable among the subunits themselves, between YqhY and ClpE, and YqhY and ClpC.

Regarding ClpX, the missing self-interaction could be observed in repetitions. Moreover, complex formations of $\mathrm{ClpC}$ and $\mathrm{ClpE}$ were detectable and interactions of YqhY with ClpC and ClpE were shown. A striking missing part is the interaction of ClpP with the ATPases $\mathrm{ClpC}, \mathrm{ClpE}$ and $\mathrm{ClpX}$. However, interactions of YqhY and ClpC as well as YqhY and ClpE were 
identified, supporting the possibility of YqhY acting as an adaptor protein for the Clp degradation complex.

\subsubsection{YqhY interacts with the ClpCP protease}

The obtained interactions of YqhY and ClpC and ClpE in the bacterial two-hybrid screen gave a hint on the involvement in Clp-dependent degradation, but were in need of further evaluation. To confirm these interactions in vivo, YqhY, ClpC and ClpP were subject to a SPINE. Again, YqhY was used as bait protein as pointed out in part 3.1.4.2. The strain containing YqhY-Strep was grown in CSE medium containing $0.5 \%$ glucose and was treated with paraformaldehyde during growth to crosslink adjacent proteins. This time, the bait proteins $\mathrm{ClpC}$ and $\mathrm{ClpP}$ were detected by their respective antibodies during Western Blot analysis.

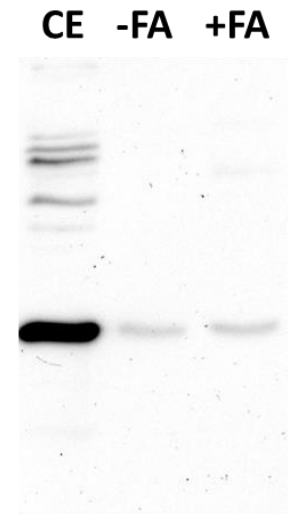

$\alpha-C l p P$

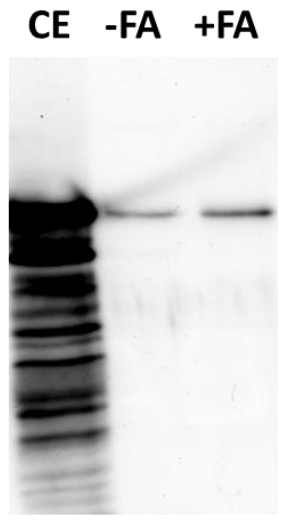

$\alpha-\mathrm{ClpC}$

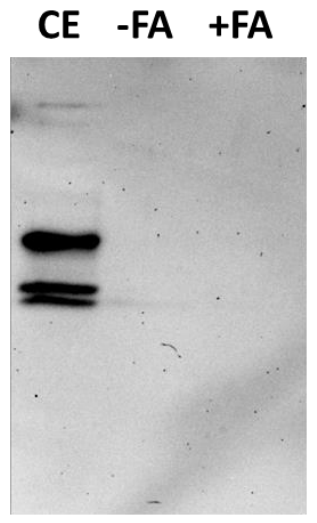

$\alpha-C g g R$

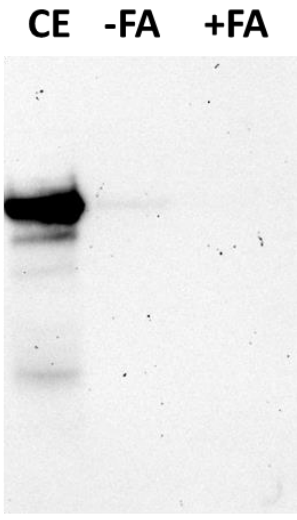

$\alpha-G a p A$

Fig. 18. Proof of interaction between YqhY and the ClpCP complex via SPINE. Strains expressing YqhY-Strep were grown in CSE medium containing $0.5 \%$ glucose, adjacent proteins were crosslinked by the addition of paraformaldehyde (FA). The pray proteins (ClpC, ClpP, CggR and GapA) were detected by its respective antibody in a Western blot analysis. YqhY was purified using a StrepTactin column and was co-eluted with $\mathrm{ClpC}$ and ClpP. CggR and GapA functioned as negative controls.

The detected signals shown in Fig. 18 affirmed the interaction between YqhY and ClpC. Furthermore, an association of YqhY and ClpP was given, indicating a connection to Clpdependent protein degradation, since ClpP is the main proteolytic unit in this process. Regarding the signal strength of $\mathrm{ClpC}$ and $\mathrm{ClpP}$ in the elution fractions, only a week or brief interaction could be assumed. Nevertheless, this interactions are given, because 
unspecific interactions between YqhY and the two ClpP proteins could be excluded. This became clear by considering the negative controls in which no signal of CggR and GapA was detectable.

A similar approach in which the interaction of YqhY and ClpE should be verified was not successful (data not shown). After the purification of YqhY-Strep, ClpE-FLAG could not be detected in a Western Blot via FLAG tag antibody. On the one hand, this could be due to the fact that there is simply no interaction in vivo between these proteins. On the other hand, the expression of $c / p E$ is basically low and almost only upregulated under heat stress conditions. The short life time and quick degradation by ClpCP or ClpXP (Gerth et al., 2004) make it even more difficult to find the right conditions to detect ClpE. Therefore, an interaction of YqhY and ClpE seems unlikely, but cannot be excluded.

\subsubsection{Analyzing the interaction of YqhY with Clp adaptor proteins}

The substrate specificity in protein degradation is promoted by adaptor proteins. Normally, only one adaptor protein is necessary to target a certain substrate for decomposition. Recent studies have shown, that an adaptor hierarchy for ClpXP exists in Caulobacter crescentus, in which selective protein degradation depends on several adaptor proteins and their degree of assembly (Joshi et al., 2015). Assuming that YqhY is an adaptor protein, the ability of YqhY to bind other adaptor proteins and maybe build up a similar adaptor hierarchy in B. subtilis should be investigated. In order to get a first impression, the interactions of YqhY and several adaptor proteins from B. subtilis have been checked in a bacterial two hybrid assay (Fig. 19). All relevant genes were cloned into the BACTH vectors and the following screen was carried out as described above.

All tested proteins showed self-interactions. Apart from that, no significant complex formations among the adaptor proteins was noticeable. Only an interaction between $\mathrm{YjbH}$ and MecA could be observed. Thus, there were no indications pointing to a network of several adaptor priming the protease complex to confer substrate specificity.

Although, YqhY only interacted with $\mathrm{YjbH}$, this result fits with suppressor mutation located in $y j b H$ (s. 3.2.1). If YjbH is sometimes needed to be inactive in the absence of YqhY, a connection of these two proteins is reasonable and an interaction would definitely make sense. 


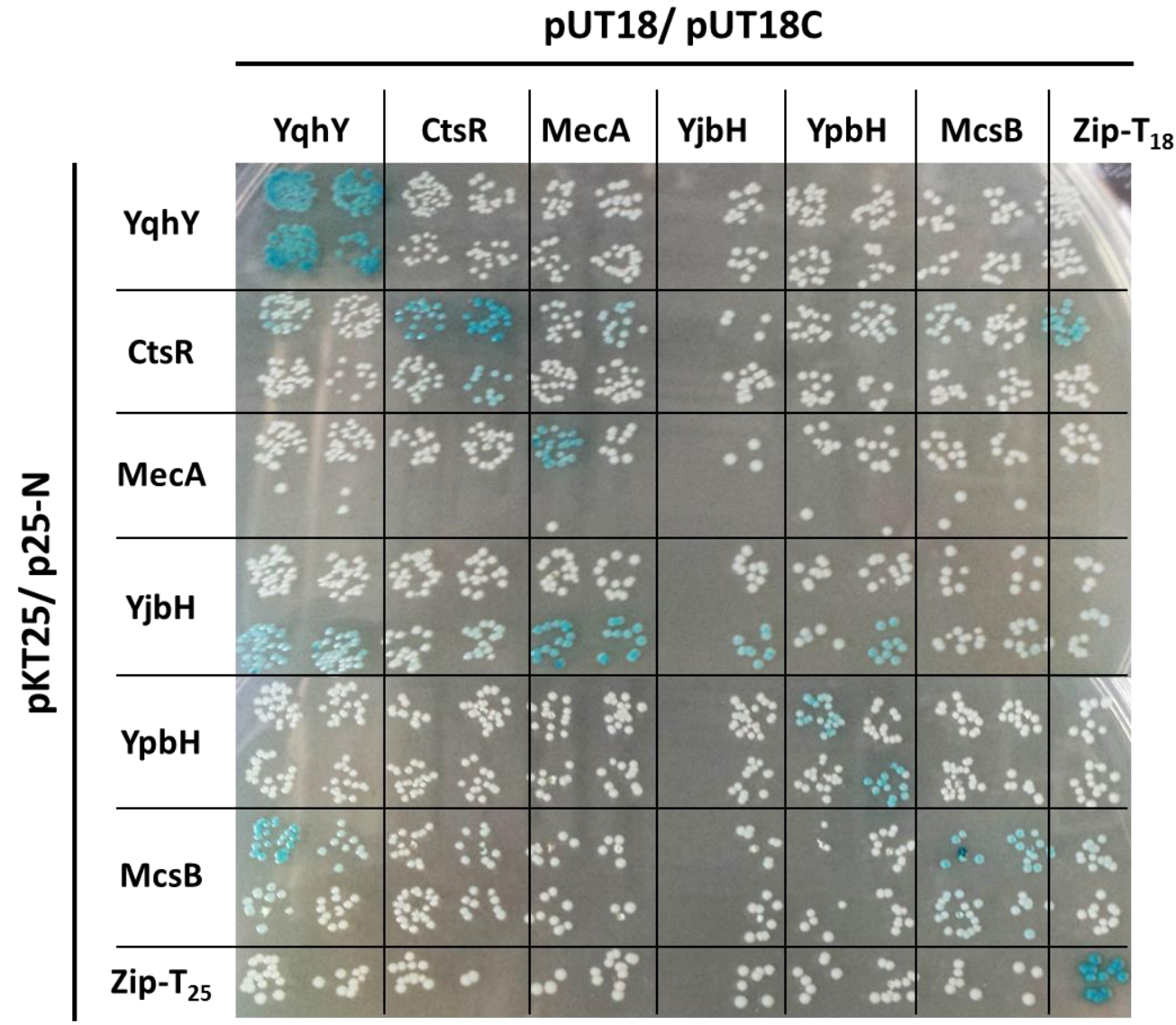

Fig. 19. Bacterial two-hybrid analysis of interactions between YqhY and adaptor proteins. The respective genes were fused to the domains of the adenylate cyclase and incubated for two days. Interactions are indicated by blue colonies. Besides self-interactions of every tested protein, associations between YqhY and $\mathrm{YjbH}$, and YqhY and McsB were observable.

\subsubsection{The ACCase subunits are no substrate of ClpCP protease}

The observations that YqhY showed interactions with the carboxyltransferase on the one hand and with the ClpCP protease on the other hand, raised the question whether YqhY fulfills the function of an adaptor protein to promote the degradation of AccA and/or AccD. If this assumption is true, the protein amounts of the ACCase subunits have to be decreased in the absence of YqhY or the Clp proteins. To test this hypothesis, the protein amount of $A c c A, A c c B, A c c C$ and $A c c D$ was analyzed by Western blot in strains missing YqhY, ClpX or ClpP. The cells were grown in CSE medium containing $0.5 \%$ glucose until they reached an $\mathrm{OD}_{600}$ of about 1.0 and the proteins were detected by their respective antibodies (Fig. 20). 


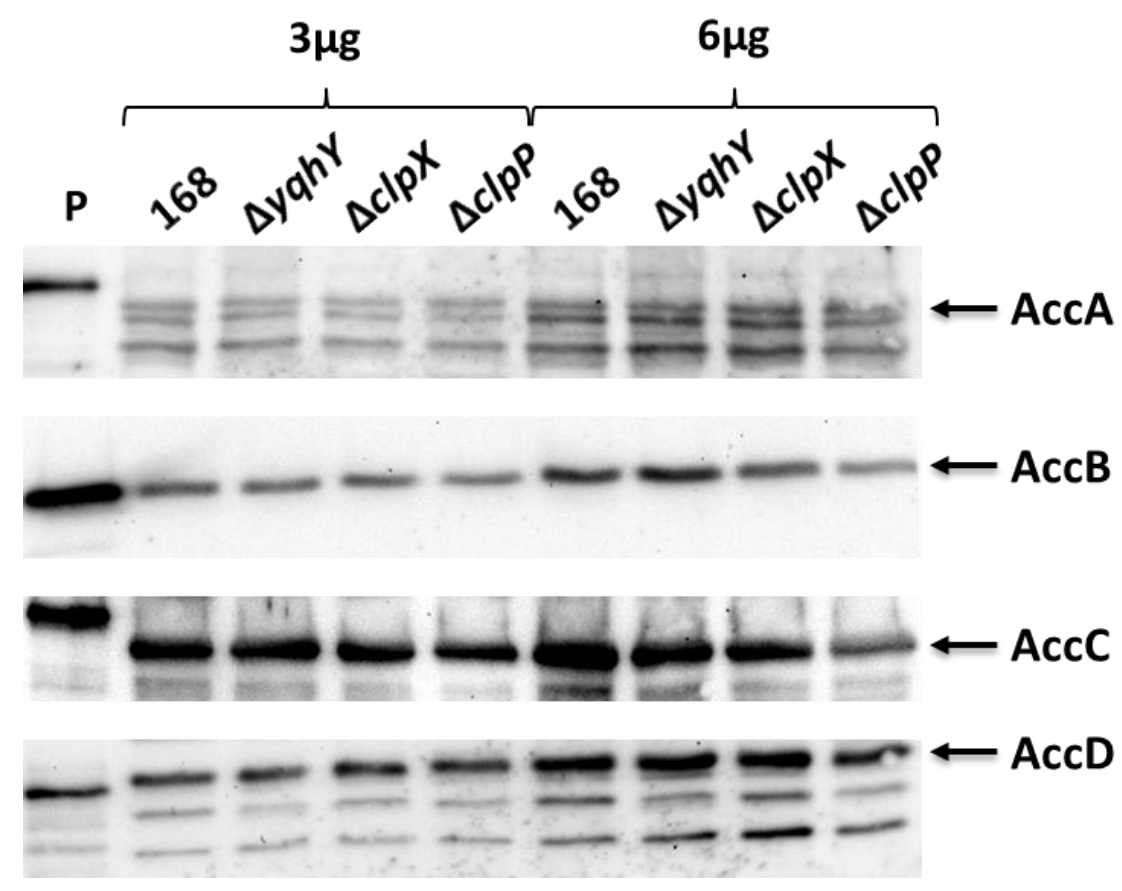

Fig. 20. Protein amount of AccA, AccB, AccC and AccD in $y q h Y, c l p X$ and $c l p P$ deletion strains. The cells were grown in CSE medium containing $0.5 \%$ glucose and afterwards, $3 \mu \mathrm{g}$ and $6 \mu \mathrm{g}$ of the crude extract were used for Western blot analysis. The target proteins were detected by their respective antibodies. The purified proteins (P) functioned as internal marker and the wild type (168) was used as a control.

In comparison to the wild type, there was no significant change in the protein amount of any subunit in the deletion strains. Although, in case of $A c c B$ and $A c c C$ the amount seems to be lowered in the absence of $\mathrm{ClpX}$ and ClpP, these results could not be repeated. Taking all experimental repetitions into account, a change in expression or an increase in degradation of $A c c A, A c c B, A c c C$ and $A c c D$ was not recognizable. Apart from this, a lower amount of the target proteins is improbable since the supposed degrading complex is missing.

Another problem was the unspecific band pattern of the AccA antibody. Therefore, a new approach was carried out to determine the dependency of AccA on ClpX and ClpP. This time, AccA was fused to a FLAG tag keeping the expression under control of the natural promoter. The cells were grown in LB medium and samples were taken at different growth phases. The final detection was again performed via Western Blot using the FLG tag antibody (Fig. 21). 


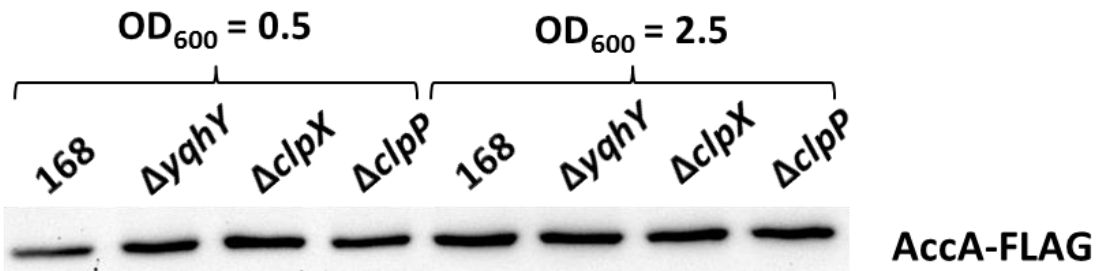

$\mathrm{Hpr}$

$5 \mu \mathrm{g}$

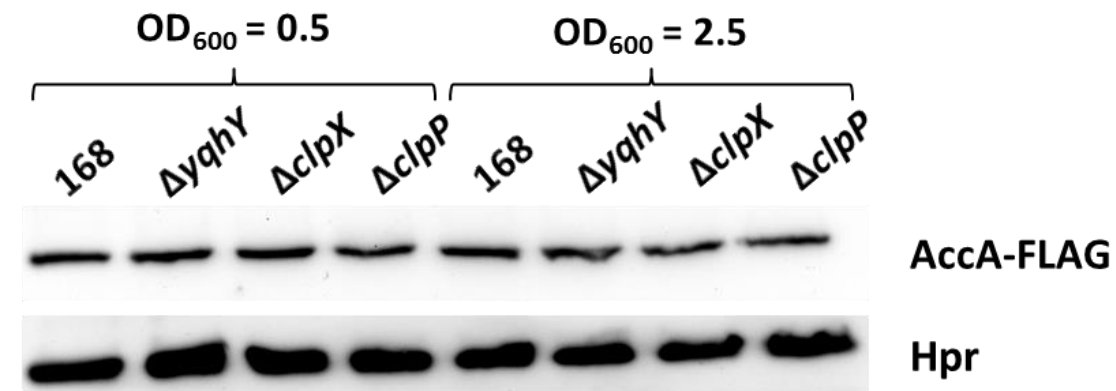

$10 \mu \mathrm{g}$

Fig. 21. Protein amount of AccA-FLAG in $y q h Y, c l p X$ and $c l p P$ deletion strains. The cells were grown in LB medium and afterwards, $5 \mu \mathrm{g}$ and $10 \mu \mathrm{g}$ of the crude extract were used for Western blot analysis. AccA was detected by the FLAG antibody and the wild type (168) was used as a control. Hpr functioned as a loading control and was detected by its antibody.

The detection of Hpr ensured that for each sample the same amount of protein crude extract $(5 \mu \mathrm{g}$ and $10 \mu \mathrm{g}$ ) was used. However, the deletion of neither yqhY nor $c l p X$ or $c l p P$ showed any impact on the protein amount of AccA-FLAG independent of the growth phase. All in all, the theory of YqhY being an adaptor protein for the ACCase complex could not be validated. Moreover, the subunits of the acetyl-CoA carboxylase are not substrates of $\mathrm{Clp}$ dependent degradation, otherwise the deletion of $c l p P$ would have resulted in an increased protein amount. 


\section{Discussion}

\subsection{The role of YqhY in regulation of acetyl-CoA carboxylase activity}

The synthesis of fatty acids is a fundamental process in all organisms. Its first committed step is the production of the precursor malonyl-CoA carried out by the acetyl-CoA carboxylase. This makes this enzyme complex a logical target for regulating the amount of fatty acids. A feedback inhibition by acyl-ACP like in E. coli seems reasonable, as the end product regulates the supply of the precursor (Davis and Cronan, 2001). Another possibility is the change of activity triggered by proteins interacting with the ACCase. The PII-like protein GInB decreases the ACCase activity in E. coli through interacting with the biotinylated region of $\mathrm{AccB}$ and concomitantly perturbing the transport of biotin to AccAD. This inhibition is dependent on 2-oxoglutarate and nitrogen levels. Low nitrogen conditions facilitate the uridylylation of $\mathrm{G} \ln \mathrm{B}$, whereas high 2-oxoglutarate amounts favor the interaction of 2-oxoglutarate and GlnB. Both 2-oxoglutarate binding and uridylylation alter the structure of the PII T-loop resulting in decreased binding abilities of GInB (Gerhardt et al., 2015). It should be noted, that PII-like proteins are only able to inhibit malonyl-CoA production in case of an interaction with both $\mathrm{AccB}$ and $\mathrm{AccC}$. This is exemplified by GlnK that only interacts with $A c c B$ and has no effect on ACCase activity. Since YqhY only interacted with AccC in a BACTH screen, a similar function to GInB is unlikely for YqhY. In green algae and land plants, biotin attachment domain-containing (BADC) proteins also act as a negative effector of AccBC. According to a proposed model, AccC binding sites are occupied by BADCs preventing the interaction between $A c c C$ and AccB. As a result, the ACCase activity is decreased (Salie et al., 2016).

However, the regulation of the ACCase in B. subtilis is poorly understood so far, since neither a feedback inhibition nor the presence of an activity controlling protein is known. The unknown protein YqhY was considered to be such a regulating factor, after in vivo experiments showed a direct interaction between YqhY and AccAD. In addition to this, the deletion of yqhY caused an accumulation of lipophilic clusters mainly at the cell poles, which was a further indication for a changed fatty acid production. In order to determine if these cluster were formed due to a missing regulatory effect by YqhY, the ACCase activity was measured in dependency of YqhY in vitro. The results revealed no significant 
impact of YqhY on the ACCase activity, consequently YqhY cannot be regarded as a negative effector.

On the other hand, the purification of a sufficient amount of AccA turned out to be difficult. The overexpression of this protein was toxic for $E$. coli and only a relatively low protein amount could be obtained through overexpression in B. subtilis. Since the ACCase complex is believed to dissociate at the low subunit concentrations, high amounts of the subunits are needed to reach a certain threshold for catalytic activity in vitro (Davis and Cronan, 2001). For this reason, the low overall activity of the acetyl-CoA carboxylase, measured in the coupled reaction assay, might be explained by an insufficient amount of the subunits added to the reaction mix. Thus, slight changes in activity caused by YqhY could appear to be negligible and are not recognized as regulatory effects. Nonetheless, YqhY has to be somehow involved in regulation of fatty acid production or the synthesis of one of the precursors. In some cases the lack of YqhY is overcome by suppressor mutations resulting in a decreased ACCase activity, which is indicated by the reduced activity of the ACCase caused by the suppressor mutation $A c c D_{A 2295}$. The effect of repressing the occurrence of suppressor mutants was also given in a $\triangle S p o O A$ background. During growth on sporulation medium, the deletion of yqhY has no harmful effect and suppressor mutants were not formed in the absence of SpoOA (data not shown). This is in accordance with the fact that Spo0A activates accDA expression under sporulation conditions. Thus, the aftermath of a yqhY deletion can be overcome by downregulation of the ACCase, either by the lack of SpoOA or mutations in the subunits.

Another possibility to influence ACCase activity is the correct localization of its subunits. In Mycobacterium smegmatis, a homolog of DivIVA, Wag31, interacts with AccA (Xu et al., 2014). Based on this observation and the localization dependency of YqhY on DivIVA, a function as a linker protein between DivIVA and ACCase subunits seemed possible for YqhY. Fluorescence microscopy experiments revealed an equal cytoplasmic distribution of $A c c A, A c c B$ and $A c c C$ in a wild type background, which was in accordance with the results of Meile et al., 2006, but in contrast to the polar localization of YqhY. Due to this contrary localization, YqhY could be considered as an antagonist, preventing the polar accumulation of the acetyl-CoA carboxylase. Indeed, AccA showed a polar localization pattern in the absence of YqhY. Since YqhY is mainly distributed in the whole cell in a $\triangle$ divIVA background, a deletion of divIVA should also display a polar localization of AccA. 
In order to examine this theory, the localization of AccA was monitored in a $\triangle y q h Y \triangle \operatorname{div} I V A$ double mutant strain. Against the expectations, AccA was still equally spread over the cell. Thus, an antagonistic role of YqhY against AccA could not be proven, but YqhY nevertheless influences the correct localization of AccA.

A regulatory function for YqhY could not be shown, but the connection of YqhY with ACCase activity cannot be excluded. It is obvious that cells lacking YqhY have most likely an increased malonyl-CoA production possibly resulting in fatty acid overproduction. How this metabolic defect is triggered and why it has a toxic effect for the cell is in need of further investigation.

\subsection{Fatty acid uptake in Bacillus subtilis}

Fatty acid binding proteins (FABPs) are abundantly expressed proteins in eukaryotic cells. These lipid chaperones bind long-chain fatty acids and are involved in fatty acid import and export, as well as in lipid storage (Furuhashi and Hotamisligil, 2008). Since bacteria lack these proteins, they had to evolve other ways to transport and store fatty acids. Many microorganisms store lipids by producing polyhyroxyalkanoates (PHAs) in abundance of carbon sources while lacking other essential nutrients. The synthases of these biopolymers (PhaA, PhaB and PhaC) are expressed in many Bacillus species, but $B$. subtilis lacks genes related to PHA biosynthesis (Singh et al., 2009). The missing storage function could be fulfilled by YqhY. In this case, the accumulation of lipophilic clusters in cells lacking YqhY would be due to released fatty acids previously bound to YqhY, instead of an increased fatty acid synthesis.

Another possibility is a role of YqhY in fatty acid uptake. For incorporation of exogenous fatty acids, Gram-positive bacteria need to phosphorylate them in a first step. The resulting acyl-phosphate is either be used by PIsY to initiate phospholipid synthesis or it is converted to acyl-ACP by PIsX. This in turn serves as substrate for PIsC or for fatty acid elongation (Yao and Rock, 2015). The activation of exogenous fatty acids is executed by two proteins, FakA and FakB. The latter one is a fatty acid binding protein and belongs to the DegV protein family, named after its homologue in $B$. subtilis. FakA is responsible for phosphorylation of fatty acids bound to FakB and is homologous to YloV from B. subtilis 
(Parsons et al., 2014). Since yloV is located on an operon with yloU, the paralogue of $y q h Y$, this is an additional hint for a connection of YqhY to fatty acid homeostasis.

The determination of a role for YqhY in fatty acid uptake is difficult, because YloV and DegV are most likely responsible for fatty acid activation in B. subtilis. Although there is no evidence for a protein-mediated fatty acid transporter in bacteria (Parsons et al., 2014), the existence of such a transporter is unlikely and unnecessary at the same time, since fatty acids cross the membrane by spontaneous flipping (Garlid et al., 1996). Broussard et al. (2016), identified five conserved residues in FakB2 from S. aureus that probably fulfill the same critical functions in all bacterial fatty acid-binding proteins. As YqhY does not contain these residues, a storage or chaperone function of YqhY can also be excluded. Nevertheless, a regulatory effect by binding of YqhY to YloV or DegV is conceivable.

\subsection{YqhY, a potential adaptor protein mediating Clp degradation?}

It could be shown that YqhY has no direct impact on ACCase activity, but the absence of this protein leads to stress effects, probably caused by excessive amounts of fatty acids. Expression of staphylococcal asp23 is upregulated upon alkaline stress and is dependent on $\sigma^{B}$. The same sigma factor controls the genes responsible for Clp-mediated protein degradation and their transcription repressor ctsR in $B$. subtilis. In this work, sequencing analysis of two $\Delta y q h Y$-suppressor mutants, in which the ACCase subunits were not affected, revealed the absence of CtsR or the adaptor protein $\mathrm{YjbH}$. In addition, YqhY was shown to interact with AccAD and ClpCP. Thus, YqhY was considered to be part of stress response, possibly functioning as adaptor protein to facilitate the degradation of AccA, $A c c B, A c c C$ or $A c c D$ by $C l p$ proteases. This theory was also supported by the polar localization of YqhY, which was in accordance with the polar cluster formations of Clp and its ATPases. But, not only the Clp proteins co-localize at the cell poles, also the adaptor protein McsB and its substrate CtsR were found in these regions, determining them as important subcellular sites for protein degradation in B. subtilis (Kirstein et al., 2008).

Based on the assumption of YqhY being an adaptor protein, the degradation of ACC subunits becomes more unspecific in the absence of YqhY, which leads to a higher amount of the target proteins. In order to compensate this excess and maintain a vital level of ACC 
subunits, expression of $c / p$ genes is upregulated leading to an increased chance of unspecific degradation of ACC. The down-regulation of fatty acid synthesis by degradation of ACCase would restore the wild type situation and seems to be a plausible solution to overcome toxic amounts of fatty acids. To address this theory, the amounts of AccA, AccB, AccC and AccD were checked in the absence of YqhY, ClpX or ClpP through Western blot analysis. In all tested backgrounds the protein level was equal compared to the wild type. Therefore, the ACC subunits are pretty likely no target for Clp degradation, which becomes especially clear by the unchanged protein levels in cells lacking the proteolytic subunit ClpP. Nevertheless, it has to be considered that the experiments took place under normal growth conditions and that heat or oxidative stress induce other factors necessary for substrate targeting. Moreover, there is still the possibility of ClpYQ degrading one of the ACC subunits, since this complex was not part of the investigations and neither an adaptor protein nor any targets for ClpYQ are known.

Taking the bacterial two-hybrid experiments with several Clp adaptor proteins into account, also an adapter hierarchy like in C. crescentus was not indicated. The interaction of YqhY and YjbH was relatively weak and besides, MecA and YjbH were the only adaptor proteins interacting with each other. Thus, a network of adaptor proteins activating each other cannot be expected to be present in B. subtilis. In order to get further evidence for YqhY being involved in protein degradation, proteomic analysis of a yqhY mutant needs to be performed. It is nonetheless possible that the amount of fatty acids is controlled by proteolytic processes. In a comprehensive study, AccA and AccB were proposed as potential targets of Clp-dependent proteolysis. Among the other potential candidates was also YloV (Gerth et al., 2008), previously implicated in fatty acid uptake. In the end, it is difficult to determine new target proteins, because of the immense number of potential substrates and their adaptor proteins.

\subsection{Connecting protein degradation and fatty acid synthesis}

This work indicates a connection of YqhY with both fatty acid synthesis and protein degradation, but how to combine these distinct processes? The function of YqhY is elusive, but there are possible explanations for how cells are affected by the lack of YqhY. The previous assumption was a downregulation of fatty acid production by mutations in the 
ACCase subunits. In accordance to this, another mutant was deficient of CtsR, which results in a higher amount of CIPXP and increased Spx degradation. Since Spx induces birA expression (Gaballa et al., 2013) and BirA is essential for biotinylation of AccB, the absence of CtsR probably also results in reduced ACCase activity. In contrast to this, a further mutation resulting in truncated $\mathrm{YjbH}$ has the opposite effect, as the protein level of Spx is increased. Due to this conflicting effects, a different connection of fatty acid synthesis and protein degradation has to be found.

Fatty acids are also components of other metabolites, for example surfactin. This lipopeptide contains $\beta$-hydroxy fatty acid (Kakinuma et al., 1969) and was shown to be involved in biofilm formation (Zeriouh et al., 2014). Furthermore, it exerts antibacterial activities through destabilization of lipid layers causing the release of aqueous vesicle contents (Carrillo et al., 2003). YqhY could be responsible for surfactin export and its absence leads to a toxic accumulation of surfactin. This can be explained by the key role of Spx that not only activates birA transcription but also represses the srf-operon encoding surfactin synthases (Zuber, 2004). The suppressor mutations identified in strains lacking YqhY imply three different scenarios to decrease surfactin production. In the first one, a decreased ACCase activity lowers the amount of fatty acids and therefore the availability of precursors for surfactin synthesis. The same effect is achieved in the absence of CtsR, due to a lower amount of BirA as mentioned above. In the last one, the lack of YjbH leads to an increased repression of the srf genes by Spx resulting in decreased overall surfactin production. Thus, either an upregulation or downregulation of Spx can have the same effect regarding surfactin production.

Based on the precondition that YqhY is a surfactin exporter, this explains why suppressor mutations hit genes involved in fatty acid synthesis or protein degradation. On the other hand, Asp23 is highly conserved in Firmicutes whereas surfactin is only produced in Bacillus species. Therefore, this hypothesis can only be confirmed, if Asp23 proteins are in addition responsible for export of other surfactant-like molecules, for example phenolsoluble modulin (PSM) in S. aureus (Periasamy et al., 2012). Moreover, the lack of CtsR leads to upregulation of all Clp proteins resulting in a global response, since proteolysis influences many important cellular processes. That means that a controlled downregulation of surfactin synthesis is not possibly without affecting other pathways. 


\subsection{Increased malonyl-CoA amounts may lead to unspecific protein acylation}

The control of the surfactin synthesis appears to be too complex and the high number of suppressor mutations hitting the acetyl-CoA carboxylase indicate a more obvious problem occurring in the absence of YqhY. The supposed higher ACCase activity increases the amount of malonyl-CoA. Since malonyl-CoA is only a substrate to FabD, this results in a bottleneck effect and accumulation of malonyl-CoA. Due to its similarity to acetyl-CoA (Fig. 22a), an acylation of lysine residues by unbound malonyl-CoA is possible. Lysine acetylation is conserved in organisms from bacteria to human (Kim and Yang, 2011) and was shown to regulate many eukaryotic processes like cell cycle, cell morphology, protein synthesis, mRNA splicing and central metabolism (Kuczyńska-Wiśnik et al., 2016). In prokaryotes little is known about protein acetylation, but it has been proposed to be related to energy metabolism, ribosomal functions and transcription (Zhang et al., 2008; Zhang et al., 2014).

A recent study in $E$. coli demonstrated that acetylation promotes the formation of inclusion bodies and a lower activity of these acetylated proteins. It was further suggested that acetylation of misfolded proteins increases resistance to heat and oxidative stress (Kuczyńska-Wiśnik et al., 2016).

Apart from this, there are several other lysine modifications known, for example lysine malonylation (Peng et al., 2011), succinylation (Zhang et al., 2011) and glutarylation (Tan et al., 2014). All three modifications were thought to have a different impacts on protein functions than acetylation, because they change the charge on lysine. This is concomitant with disruption of ionic interactions with other negatively charged molecules and alterations in protein structure and function (Hirschey and Zhao, 2015). So far, lysine malonylation has been mainly investigated in eukaryotic cells with over thousand proteins identified to be subject of this modification. The most lysine-malonylated substrates were found to be part of ribosomes, valine/ leucine/ isoleucine degradation, proteasome and fatty acid metabolism, including acetyl-CoA carboxylase. In addition, fatty acid oxidation activity was inhibited by lysine malonylation (Colak et al., 2015). The deacetylase SIRT5 is able to remove acyl residues from lysine, since it also possesses desuccinylation, demalonylation (Du et al., 2011) and deglutarylation (Tan et al., 2014) activity. For its 
counterpart in B. subtilis, SrtN, only deacetylation activity is known, but it was proposed that this enzyme is capable of removing a broad range of acyl groups (Seidel et al., 2016). Nevertheless, substrate malonylation is poorly understood in prokaryotes. In order to get more insight into this field, a recent study investigated lysine malonylation in E. coli (Qian et al., 2016). The authors identified 1745 malonylation sites in 594 proteins, of which approximately one third is overlapping with acetylation and succinylation sites (Fig. 22b). As shown in previous studies in eukaryotes, lysine malonylation was highly enriched in protein synthesis and energy metabolism. 68 proteins were related to ribosomes (Fig. 22C) and 19 proteins were associated to citric acid cycle, suggesting that malonylation plays a major role in regulation of substantial processes in bacteria. Moreover, malonylation sites were detected in eleven proteins of fatty acid synthesis, among them Fabl, the enzyme catalyzing the last step of fatty acid elongation and malonyl-CoA transacylase FabD which loads the acyl carrier protein with malonyl-CoA prior to fatty acid elongation. Strikingly, the acetyl-CoA carboxylase subunits $A c c A, A c c C$ and $A c c D$ were also subject to malonylation. AccB was not malonylated which can be explained by a protected lysine residue through biotin binding.

These results indicate a regulation of malonyl-CoA production and fatty acid synthesis by malonylation. Assuming that the lack of YqhY leads to higher malonyl-CoA levels, this could result in unspecific protein acylation. Since many important pathways, especially protein synthesis, are affected by malonylation, the cell would have to deal with increasing amounts of misfolded and inactive proteins. Thus, suppressor mutations related to protein degradation and stress response are part of a global response in order to remove protein debris. Suppressor mutations decreasing the ACCase activity would reduce malonyl-CoA concentrations and the overall effect of malonylation. It is also possible that the absence of YqhY leads to delocalization of important proteins, making them targets for unspecific malonylation. These hypotheses give still no answer on the actual function of YqhY, but investigations on protein malonylation could give further hints on its role in $B$. subtilis. 
A

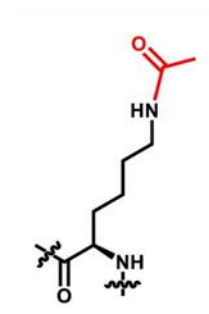

Acetyllysine
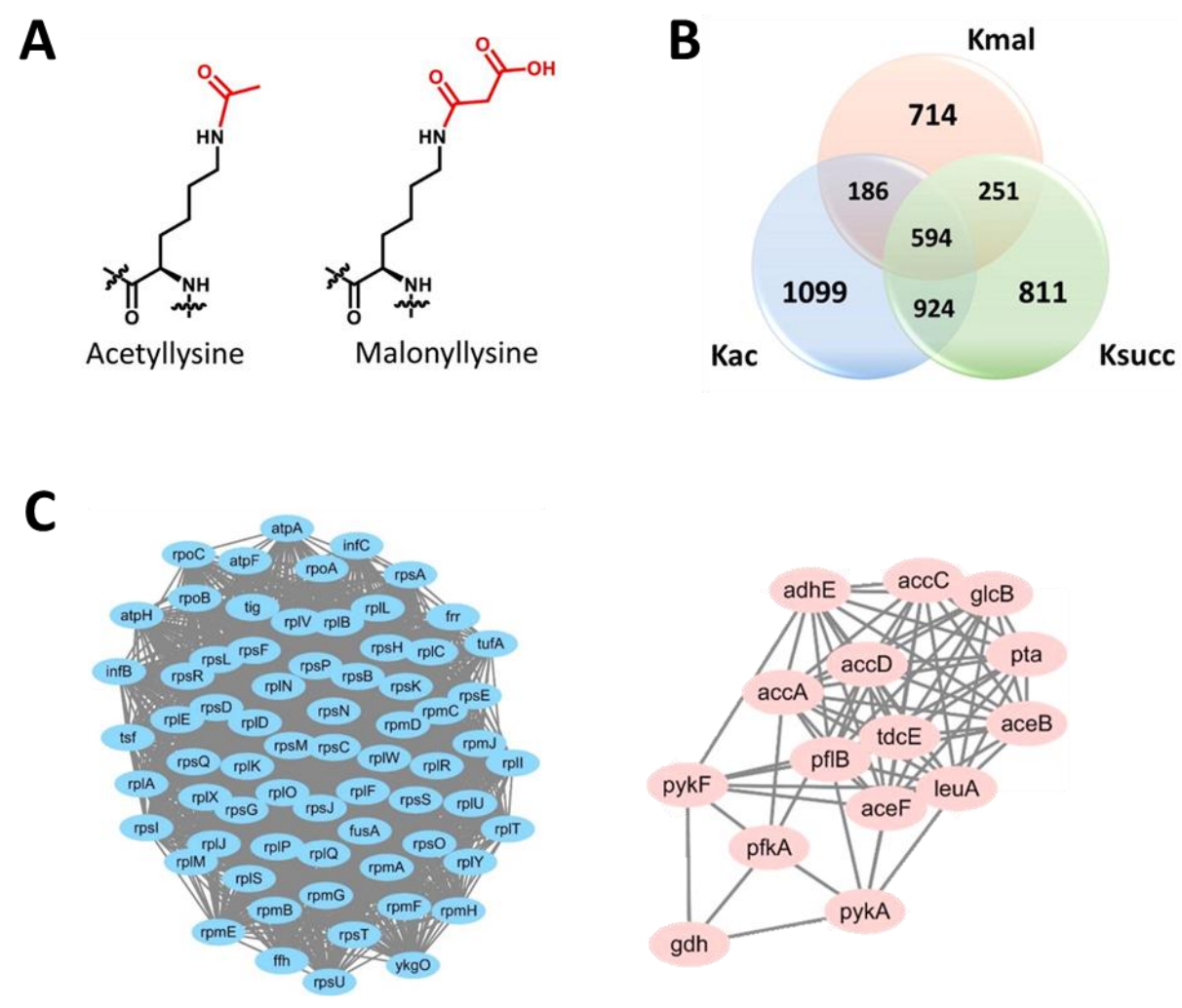

Fig. 22. Lysine malonylation in E. coli. (A) Comparison of lysine acetylation and malonylation. (B) Overlap of lysine acetylation (Kac), succinylation (Ksucc) and malonylation (Kmal) sites. (C) Interaction network of lysine malonylated proteins related to ribosome and acetyl-CoA carboxylase (Qian et al., 2016).

\subsection{Outlook}

A regulation of the acetyl-CoA carboxylase in B. subtilis is very likely and there are plenty of examples found in other organisms. The malonylation of ACC subunits is a plausible mechanism to down regulate the enzymatic activity by feedback inhibition through malonyl-CoA. Since malonylation is poorly investigated in prokaryotes and malonylated proteins have not been identified in $B$. subtilis so far, a definition of the malonylome by proteome analysis would give further insights into this mechanism. A changed malonylome in yqhY mutant strains would show, if YqhY has an impact on the malonylation of proteins.

Proteomics could also give evidence for YqhY being involved in protein degradation. Without potential target proteins, it is difficult to define YqhY as an adaptor protein, thus, a global protein profile possibly highlights increased protein concentrations in the 
absence of YqhY. It should be considered to test interactions with target proteins under heat or oxidative stress, as the proteolytic activity is increased under stress conditions. Regarding a role of YqhY in fatty acid homeostasis, mass spectrometry analysis can provide certainty on the ability to bind fatty acids. Moreover, interaction experiments with YqhY and YloV or DegV could reveal a possible impact on fatty acid uptake and a comparison of surfactin concentrations in wild type cells and yqhY mutant strains would either support or decline the hypothesis that YqhY is involved in surfactin export. 


\section{References}

Abdel-Hamid, A.M., and Cronan, J.E. (2007) Coordinate expression of the acetyl coenzyme $A$ carboxylase genes, accB and $\mathrm{acc} C$, is necessary for normal regulation of biotin synthesis in Escherichia coli. J Bacteriol 189: 369-376.

Aguilar, P.S., Hernandez-Arriaga, A.M., Cybulski, L.E., Erazo, A.C., and Mendoza, D. De (2001) Molecular basis of thermosensing: A two-component signal transduction thermometer in Bacillus subtilis. EMBO J 20: 1681-1691.

Battesti, A., and Gottesman, S. (2013) Current opinion in Microbiology Roles of adaptor proteins in regulation of bacterial proteolysis. Curr Opin Microbiol 16: 140-147.

Benson, B.K., Meades, G., Grove, A., and Waldrop, G.L. (2008) DNA inhibits catalysis by the carboxyltransferase subunit of acetyl-CoA carboxylase: Implications for active site communication. Prot Sci 17: 34-42.

Bilder, P., Lightle, S., Bainbridge, G., Ohren, J., Finzel, B., Sun, F., et al. (2006) The structure of the carboxyltransferase component of acetyl-CoA carboxylase reveals a zincbinding motif unique to the bacterial enzyme. Biochemistry 45: 1712-1722.

Bradford, M.M. (1976) A rapid and sensitive method for the quantitation of microgram quantities of protein using the principle of protein dye binding. Anal Biochem 72: 248254.

Broussard, T.C., Kobe, M.J., Pakhomova, S., Neau, D.B., Amanda, E., Champion, T.S., and Waldrop, G.L. (2013a) The Three-Dimensional Structure of the Biotin Carboxylase- Biotin Carboxyl Carrier Protein Complex of E. coli Acetyl-CoA Carboxylase. Structure 21: 650657. 


\section{References}

Broussard, T.C., Miller, D.J., Jackson, P., Nourse, A., White, S.W., and Rock, C.O. (2016) Biochemical Roles for Conserved Residues in the Bacterial Fatty Acid-binding Protein Family. J Biol Chem 291: 6292-303.

Broussard, T.C., Price, A.E., Laborde, S.M., and Waldrop, G.L. (2013b) Complex Formation and Regulation of Escherichia coli Acetyl-CoA Carboxylase. Biochemistry 52: 3346-3357.

Carrillo, C., Teruel, J.A., Aranda, F.J., and Ortiz, A. (2003) Molecular mechanism of membrane permeabilization by the peptide antibiotic surfactin. Biochim Biophys Acta Biomembr 1611: 91-97.

Cascante-Estepa, N., Gunka, K., and Stülke, J. (2016) Localization of Components of the RNA-Degrading Machine in Bacillus subtilis. Front Microbiol 7: 1-9.

Choi, K.-H.H.K., Heath, R.J., and Rock, C.O. (2000) $\beta$-Ketoacyl-Acyl Carrier Protein Synthase III ( FabH ) Is a Determining Factor in Branched-Chain Fatty Acid Biosynthesis. J Bacteriol 182: 365-370.

Chou, C.-Y., Yu, L.P.C., and Tong, L. (2009) Crystal structure of biotin carboxylase in complex with substrates and implications for its catalytic mechanism. J Biol Chem 284: 11690-7.

Claessen, D., Emmins, R., Hamoen, L.W., Daniel, R.A., Errington, J., and Edwards, D.H. (2008) Control of the cell elongation-division cycle by shuttling of PBP1 protein in Bacillus subtilis. Mol Microbiol 68: 1029-46.

Colak, G., Pougovkina, O., Dai, L., Tan, M., Brinke, H. Te, Huang, H., et al. (2015) Proteomic and Biochemical Studies of Lysine Malonylation Suggest Its Malonic Aciduriaassociated Regulatory Role in Mitochondrial Function and Fatty Acid Oxidation. Mol Cell Proteomics 14: 3056-71. 
Commichau, F.M., Blötz, C., and Stülke, J. (2015) Methods in Molecular Biology of Bacteria.

Cronan, J.E., and Waldrop, G.L. (2002) Multi-subunit acetyl-CoA carboxylases. Prog Lipid Res 41: 407-435.

Davis, M.S., and Cronan, J.E. (2001) Inhibition of Escherichia coli acetyl coenzyme A carboxylase by acyl-acyl carrier protein. J Bacteriol 183: 1499-503.

Derré, I., Rapoport, G., and Msadek, T. (1999) CtsR, a novel regulator of stress and heat shock response, controls clp and molecular chaperone gene expression in Gram-positive bacteria. Mol Microbiol 31: 117-131.

Dirusso, C.C., Heimert, T.L., and Metzger, A.K. (1992) Characterization of FadR , a Global Transcriptional Regulator of Fatty Acid Metabolism in Escherichia coli. J Biol Chem 267: 8685-8691.

Du, J., Zhou, Y., Su, X., Yu, J.J., Khan, S., Jiang, H., et al. (2011) Sirt5 Is an NAD-Dependent Protein Lysine Demalonylase and Desuccinylase. Science (80- ) 334: 806-809.

Duman, R.E., and Löwe, J. (2010) Crystal structures of Bacillus subtilis lon protease. J Mol Biol 401: 653-670.

Elsholz, A.K.W., Hempel, K., Michalik, S., Gronau, K., Becher, D., Hecker, M., and Gerth, U. (2011a) Activity Control of the ClpC Adaptor McsB in Bacillus subtilis. J Bacteriol 193: 3887-3893.

Elsholz, A.K.W., Hempel, K., Pöther, D.-C., Becher, D., Hecker, M., and Gerth, U. (2011b) CtsR inactivation during thiol-specific stress in low GC, Gram+ bacteria. Mol Microbiol 79: 772-785. 


\section{References}

Elsholz, A.K.W., Michalik, S., Zühlke, D., Hecker, M., and Gerth, U. (2010) CtsR, the Grampositive master regulator of protein quality control, feels the heat. EMBO J 29: 3621-3629.

Forchhammer, K. (2008) PII signal transducers: novel functional and structural insights. Trends Microbiol 16: 65-72.

Fuhrmann, J., Schmidt, A., Spiess, S., Lehner, A., Turgay, K., Mechtler, K., et al. (2009) McsB Is a Protein Arginine Kinase That Phosphorylates and Inhibits the Heat-Shock Regulator CtsR. Science (80- ) 324: 1323-1327.

Fujita, Y., Matsuoka, H., and Hirooka, K. (2007) Regulation of fatty acid metabolism in bacteria. Mol Microbiol 66: 829-839.

Furuhashi, M., and Hotamisligil, G.S. (2008) Fatty acid-binding proteins: role in metabolic diseases and potential as drug targets. Nat Rev Drug Discov 7: 489-503.

Gaballa, A., Antelmann, H., Hamilton, C.J., and Helmann, J.D. (2013) Regulation of Bacillus subtilis bacillithiol biosynthesis operons by Spx. Microbiology 159: 2025-35.

Garg, S.K., Kommineni, S., Henslee, L., Zhang, Y., and Zuber, P. (2009) The YjbH protein of Bacillus subtilis enhances ClpXP-catalyzed proteolysis of Spx. J Bacteriol 191: 12681277.

Garlid, K.D., Orosz, D.E., Modrianský, M., Vassanelli, S., and Jezek, P. (1996) On the mechanism of fatty acid-induced proton transport by mitochondrial uncoupling protein. $J$ Biol Chem 271: 2615-20.

Gerhardt, E.C.M., Rodrigues, T.E., Müller-Santos, M., Pedrosa, F.O., Souza, E.M., Forchhammer, K., and Huergo, L.F. (2015) The Bacterial signal transduction protein GInB regulates the committed step in fatty acid biosynthesis by acting as a dissociable regulatory subunit of acetyl-CoA carboxylase. Mol Microbiol 95: 1025-1035. 
Gerth, U., Kirstein, J., Mostertz, J., Miethke, M., Kock, H., Waldminghaus, T., and Hecker, M. (2004) Fine-Tuning in Regulation of Clp Protein Content in Bacillus subtilis. J Bacteriol 186: 179-191.

Gerth, U., Kock, H., Kusters, I., Michalik, S., Switzer, R.L., and Hecker, M. (2008) Clpdependent proteolysis down-regulates central metabolic pathways in glucose-starved Bacillus subtilis. J Bacteriol 190: 321-31.

Gertz, S., Engelmann, S., Schmid, R., Ohlsen, K., Hacker, J., and Hecker, M. (1999) Regulation of sigmaB-dependent transcription of sigB and asp23 in two different Staphylococcus aureus strains. Mol Gen Genet 261: 558-566.

Guchhait, R.B., Polakis, S.E., Dimroth, P., Stoll, E., Moss, J., and Lane, M.D. (1974) Acetyl Coenzyme A Carboxylase System of Escherichia coli. J Biol Chem 249: 6633-6645.

Guérout-Fleury, A.M., Shazand, K., Frandsen, N., and Stragier, P. (1995) Antibioticresistance cassettes for Bacillus subtilis. Gene 167: 335-6.

Heath, R.J., and Rock, C.O. (1995) Enoyl-acyl carrier protein reductase (fabl) plays a determinant role in completing cycles of fatty acid elongation in Escherichia coli. J Biol Chem 270: 26538-26542.

Heath, R.J., and Rock, C.O. (1996a) Roles of the FabA and FabZ $\beta$-hydroxyacyl-acyl carrier protein dehydratases in Escherichia coli fatty acid biosynthesis. J Biol Chem 271: 2779527801.

Heath, R.J., and Rock, C.O. (1996b) Regulation of fatty acid elongation and initiation by acyl-acyl carrier protein in Escherichia coli. J Biol Chem 271: 1833-1836.

Heath, R.J., Su, N., Murphy, C.K., and Rock, C.O. (2000) The enoyl-[acyl-carrier-protein] reductases Fabl and FabL from Bacillus subtilis. J Biol Chem 275: 40128-40133. 


\section{References}

Henry, M.F., and Cronan, J.E. (1991) Escherichia coli transcription factor that both activates fatty acid synthesis and represses fatty acid degradation. J Mol Biol 222: 843-9.

Herzberg, C., Weidinger, L.A.F., Dörrbecker, B., Hübner, S., Stülke, J., and Commichau, F.M. (2007) SPINE: A method for the rapid detection and analysis of protein-protein interactions in vivo. Proteomics 7: 4032-4035.

Higashitani, A., Nishimura, Y., Hara, H., Aiba, H., Mizuno, T., and Horiuchi, K. (1993) Osmoregulation of the fatty acid receptor gene fadL in Escherichia coli. Mol Gen Genet 240: 339-347.

Hirschey, M.D., and Zhao, Y. (2015) Metabolic Regulation by Lysine Malonylation, Succinylation, and Glutarylation. Mol Cell Proteomics 14: 2308-15.

Hügler, M., Menendez, C., Schägger, H., and Fuchs, G. (2002) Malonyl-coenzyme A reductase from Chloroflexus aurantiacus, a key enzyme of the 3-hydroxypropionate cycle for autotrophic $\mathrm{CO}(2)$ fixation. J Bacteriol 184: 2404-10.

Joshi, K.K., Bergé, M., Radhakrishnan, S.K., Viollier, P.H., and Chien, P. (2015) An Adaptor Hierarchy Regulates Proteolysis during a Bacterial Cell Cycle. Cell 163: 419-431.

Kakinuma, A., Ouchida, A., Shima, T., Sugino, H., Isono, M., Tamura, G., and Arima, K. (1969) Confirmation of the Structure of Surfactin by Mass Spectrometry. Agric Biol Chem 33: 1669-1671.

Karimova, G., Dautin, N., and Ladant, D. (2005) Interaction Network among Escherichia coli Membrane Proteins Involved in Cell Division as Revealed by Bacterial Two-Hybrid Analysis Interaction Network among Escherichia coli Membrane Proteins Involved in Cell Division as Revealed by Bacteri. J Bacteriol 187: 2233-2243. 
Karimova, G., Pidoux, J., Ullmann, a, and Ladant, D. (1998) A bacterial two-hybrid system based on a reconstituted signal transduction pathway. Proc Natl Acad Sci U S A 95: 57525756.

Karow, M., Fayet, O., and Georgopoulos, C. (1992) The lethal phenotype caused by null mutations in the Escherichia coli htrB gene is suppressed by mutations in the $\operatorname{accBC}$ operon, encoding two subunits of acetyl coenzyme A carboxylase. J Bacteriol 174: 74077418.

Kim, G.-W., and Yang, X.-J. (2011) Comprehensive lysine acetylomes emerging from bacteria to humans. Trends Biochem Sci 36: 211-20.

Kirstein, J., Dougan, D. a, Gerth, U., Hecker, M., and Turgay, K. (2007) The tyrosine kinase McsB is a regulated adaptor protein for ClpCP. EMBO J 26: 2061-2070.

Kirstein, J., Hoffmann, A., Lilie, H., Schmidt, R., Rübsamen-Waigmann, H., BrötzOesterhelt, H., et al. (2009a) The antibiotic ADEP reprogrammes ClpP, switching it from a regulated to an uncontrolled protease. EMBO Mol Med 1: 37-49.

Kirstein, J., Molière, N., Dougan, D. a, and Turgay, K. (2009b) Adapting the machine: adaptor proteins for Hsp100/Clp and AAA+ proteases. Nat Rev Microbiol 7: 589-599.

Kirstein, J., Schlothauer, T., Dougan, D.A., Lilie, H., Tischendorf, G., Mogk, A., et al. (2006) Adaptor protein controlled oligomerization activates the AAA+ protein ClpC. EMBO J 25: 1481-91.

Kirstein, J., Strahl, H., Molière, N., Hamoen, L.W., and Turgay, K. (2008) Localization of general and regulatory proteolysis in Bacillus subtilis cells. Mol Microbiol 70: 682-94.

Kirstein, J., Zühlke, D., Gerth, U., Turgay, K., and Hecker, M. (2005) A tyrosine kinase and its activator control the activity of the CtsR heat shock repressor in B. subtilis. EMBO J 24: 3435-3445. 
Klewing, A. (2015) Investigation of the impact of YqhY on the acetyl-CoA carboxylase activity in Bacillus subtilis.

Kobayashi, K., Ehrlich, S.D., Albertini, A., Amati, G., Andersen, K.K., Arnaud, M., et al. (2003) Essential Bacillus subtilis genes. Proc Natl Acad Sci U S A 100: 4678-83 Accessed October 18, 2016.

Kommineni, S., Garg, S.K., Chan, C.M., and Zuber, P. (2011) YjbH-enhanced proteolysis of Spx by ClpXP in Bacillus subtilis is inhibited by the small protein YirB (YuzO). J Bacteriol 193: $2133-2140$.

Kroeger, J.K., Zarzycki, J., and Fuchs, G. (2011) A spectrophotometric assay for measuring acetyl-coenzyme A carboxylase. Anal Biochem 411: 100-105.

Kuczyńska-Wiśnik, D., Moruno-Algara, M., Stojowska-Swędrzyńska, K., and Laskowska, E. (2016) The effect of protein acetylation on the formation and processing of inclusion bodies and endogenous protein aggregates in Escherichia coli cells. Microb Cell Fact 15: 189.

Laemmli, U.K. (1970) Cleavage of structural proteins during the assembly of the head of bacteriophage T4. Nature 227: 680-685.

Lee, M.E., Baker, T.A., and Sauer, R.T. (2010) Control of substrate gating and translocation into ClpP by channel residues and ClpX binding. J Mol Biol 399: 707-718.

Lehnik-Habrink, M., Newman, J., Rothe, F.M., Solovyova, A.S., Rodrigues, C., Herzberg, C., et al. (2011) RNase $Y$ in Bacillus subtilis: a Natively disordered protein that is the functional equivalent of RNase E from Escherichia coli. J Bacteriol 193: 5431-41.

Lehnik-Habrink, M., Pförtner, H., Rempeters, L., Pietack, N., Herzberg, C., and Stülke, J. (2010) The RNA degradosome in Bacillus subtilis: identification of CshA as the major RNA helicase in the multiprotein complex. Mol Microbiol 77: 958-71. 
Li, S., and Cronan, J.E. (1993) Growth rate regulation of Escherichia coli acetyl coenzyme A carboxylase, which catalyzes the first committed step of lipid biosynthesis. 175: 332340.

Lu, Y.J., Zhang, Y.M., Grimes, K.D., Qi, J., Lee, R.E., and Rock, C.O. (2006) Acyl-Phosphates Initiate Membrane Phospholipid Synthesis in Gram-Positive Pathogens. Mol Cell 23: 765772.

Maass, S., Sievers, S., Zühlke, D., Kuzinski, J., Sappa, P.K., Muntel, J., et al. (2011) Efficient, global-scale quantification of absolute protein amounts by integration of targeted mass spectrometry and two-dimensional gel-based proteomics. Anal Chem 83: 2677-2684.

Marini, P.E., Perez, C.A., and Mendoza, D. de (2001) Growth-rate regulation of the Bacillus subtilis $\operatorname{accBC}$ operon encoding subunits of acetyl-CoA carboxylase, the first enzyme of fatty acid synthesis. Arch Microbiol 175: 234-7.

Martin-Verstraete, I., Débarbouillé, M., Klier, A., and Rapoport, G. (1994) Interactions of wild-type and truncated LevR of Bacillus subtilis with the upstream activating sequence of the levanase operon. J Mol Biol 241: 178-92.

Mehne, F.M.P., Gunka, K., Eilers, H., Herzberg, C., Kaever, V., and Stülke, J. (2013) Cyclic di-AMP homeostasis in Bacillus subtilis: both lack and high level accumulation of the nucleotide are detrimental for cell growth. J Biol Chem 288: 2004-17.

Meile, J.C., Wu, L.J., Ehrlich, S.D., Errington, J., and Noirot, P. (2006) Systematic localisation of proteins fused to the green fluorescent protein in Bacillus subtilis: Identification of new proteins at the DNA replication factory. Proteomics 6: 2135-2146.

Merzbacher, M., Detsch, C., Hillen, W., and Stülke, J. (2004) Mycoplasma pneumoniae $\mathrm{HPr}$ kinase/phosphorylase: Assigning functional roles to the P-loop and the HPr kinase/phosphorylase signature sequence motif. Eur J Biochem 271: 367-374. 
Miethke, M., Hecker, M., and Gerth, U. (2006) Involvement of Bacillus subtilis ClpE in CtsR degradation and protein quality control. J Bacteriol 188: 4610-9.

Mogk, A., Deuerling, E., Vorderwülbecke, S., Vierling, E., and Bukau, B. (2003) Small heat shock proteins, ClpB and the DnaK system form a functional triade in reversing protein aggregation. Mol Microbiol 50: 585-595.

Molière, N., and Turgay, K. (2013) Regulated Proteolysis in Microorganisms. Subcell Biochem 66: 73-103.

Molle, V., Fujita, M., Jensen, S.T., Eichenberger, P., González-Pastor, J.E., Liu, J.S., and Losick, R. (2003) The SpoOA regulon of Bacillus subtilis. Mol Microbiol 50: 1683-701.

Moore, S.D., and Sauer, R.T. (2007) The tmRNA System for Translational Surveillance and Ribosome Rescue. Annu Rev Biochem 76: 101-124.

Müller, M., Reiß, S., Schlüter, R., Mäder, U., Beyer, A., Reiß, W., et al. (2014) Deletion of membrane-associated Asp23 leads to upregulation of cell wall stress genes in Staphylococcus aureus. Mol Microbiol 93: 1259-68.

Muto, A., Fujihara, A., Ito, K.I., Matsuno, J., Ushida, C., and Himeno, H. (2000) Requirement of transfer-messenger RNA for the growth of Bacillus subtilis under stresses. Genes to Cells 5: 627-635.

Nakano, S., Nakano, M.M., Zhang, Y., Leelakriangsak, M., and Zuber, P. (2003) A regulatory protein that interferes with activator-stimulated transcription in bacteria. Proc Natl Acad Sci U S A 100: 4233-8.

Nesterenko, M. V., Tilley, M., and Upton, S.J. (1994) A simple modification of Blum's silver stain method allows for 30 minute detection of proteins in polyacrylamide gels. J Biochem Biophys Methods 28: 239-242. 
Nicolas, P., Mäder, U., Dervyn, E., Rochat, T., Leduc, A., Pigeonneau, N., et al. (2012) Condition-dependent transcriptome reveals high-level regulatory architecture in Bacillus subtilis. Science 335: 1103-6.

Oliva, M. a, Halbedel, S., Freund, S.M., Dutow, P., Leonard, T. a, Veprintsev, D.B., et al. (2010) Features critical for membrane binding revealed by DivIVA crystal structure. EMBO J 29: 1988-2001.

Parsons, J.B., Broussard, T.C., Bose, J.L., Rosch, J.W., Jackson, P., Subramanian, C., and Rock, C.O. (2014) Identification of a two-component fatty acid kinase responsible for host fatty acid incorporation by Staphylococcus aureus. Proc Natl Acad Sci U S A 111: 10532-7.

Parsons, J.B., and Rock, C.O. (2013) Bacterial Lipids: Metabolism and Membrane Homeostasis. Prog Lipid Res 52: 249-276.

Pech-Canul, A., Nogales, J., Miranda-Molina, A., Álvarez, L., Geiger, O., Soto, M.J., and López-Lara, I.M. (2011) FadD is required for utilization of endogenous fatty acids released from membrane lipids. J Bacteriol 193: 6295-6304.

Pedrido, M.E., Oña, P. de, Ramirez, W., Leñini, C., Goñi, A., and Grau, R. (2013) Spo0A links de novo fatty acid synthesis to sporulation and biofilm development in Bacillus subtilis. Mol Microbiol 87: 348-67.

Peng, C., Lu, Z., Xie, Z., Cheng, Z., Chen, Y., Tan, M., et al. (2011) The first identification of lysine malonylation substrates and its regulatory enzyme. Mol Cell Proteomics 10: M111.012658.

Periasamy, S., Joo, H.-S., Duong, A.C., Bach, T.-H.L., Tan, V.Y., Chatterjee, S.S., et al. (2012) How Staphylococcus aureus biofilms develop their characteristic structure. Proc Natl Acad Sci U S A 109: 1281-6. 


\section{References}

Polyak, S.W., Abell, A.D., Wilce, M.C.J., Zhang, L., and Booker, G.W. (2012) Structure, function and selective inhibition of bacterial acetyl-CoA carboxylase. Appl Microbiol Biotechnol 93: 983-992.

Qian, L., Nie, L., Chen, M., Liu, P., Zhu, J., Zhai, L., et al. (2016) Global Profiling of Protein Lysine Malonylation in Escherichia coli Reveals Its Role in Energy Metabolism. J Proteome Res 15: 2060-71.

Qiu, X., Choudhry, A.E., Janson, C. a, Grooms, M., Daines, R. a, Lonsdale, J.T., and Khandekar, S.S. (2005) Crystal structure and substrate specificity of the beta-ketoacyl-acyl carrier protein synthase III (FabH) from Staphylococcus aureus. Protein Sci 14: 2087-94.

Reuß, D.R., Commichau, F.M., Gundlach, J., Zhu, B., and Stülke, J. (2016) The Blueprint of a Minimal Cell: MiniBacillus. Microbiol Mol Biol Rev 80: 955-987.

Rothe, F.M., Wrede, C., Lehnik-Habrink, M., Görke, B., and Stülke, J. (2013) Dynamic localization of a transcription factor in Bacillus subtilis: the LicT antiterminator relocalizes in response to inducer availability. J Bacteriol 195: 2146-54.

Salie, M.J., Zhang, N., Lancikova, V., Xu, D., and Thelen, J.J. (2016) A Family of Negative Regulators Targets the Committed Step of De novo Fatty Acid Biosynthesis. Plant Cell .

Sambrook, J., Fritsch, E.F., and Maniatis, T. (1989) Molecular Cloning: A Laboratory Manual. In Cold Spring Harbor Laboratory Press. pp. 931-957.

Sanger, F., Nicklen, S., and Coulson, a R. (1977) DNA sequencing with chain-terminating inhibitors. Proc Natl Acad Sci U S A 74: 5463-7.

Sauer, R.T., and Baker, T.A. (2011) AAA+ proteases: ATP-fueled machines of protein destruction. Annu Rev Biochem 80: 587-612. 
Schilling, O., Herzberg, C., Hertrich, T., Vörsmann, H., Jessen, D., Hübner, S., et al. (2006) Keeping signals straight in transcription regulation: specificity determinants for the interaction of a family of conserved bacterial RNA-protein couples. Nucleic Acids Res 34: 6102-15.

Schirmer, F., Ehrt, S., and Hillen, W. (1997) Expression, inducer spectrum, domain structure, and function of MopR, the regulator of phenol degradation in Acinetobacter calcoaceticus NCIB8250. J Bacteriol 179: 1329-1336.

Schlothauer, T., Mogk, A., Dougan, D.A., Bukau, B., and Turgay, K. (2003) MecA, an adaptor protein necessary for ClpC chaperone activity. Proc Natl Acad Sci U S A 100: 230611.

Schujman, G.E., Altabe, S., and Mendoza, D. De (2008) A malonyl-CoA-dependent switch in the bacterial response to a dysfunction of lipid metabolism. Mol Microbio/ 68: 987-996.

Schujman, G.E., Paoletti, L., Grossman, A.D., and Mendoza, D. de (2003) FapR, a bacterial transcription factor involved in global regulation of membrane lipid biosynthesis. Dev Cell 4: 663-672.

Seidel, J., Klockenbusch, C., and Schwarzer, D. (2016) Investigating Deformylase and Deacylase Activity of Mammalian and Bacterial Sirtuins. Chembiochem 17: 398-402.

Singh, M., Patel, S.K., and Kalia, V.C. (2009) Bacillus subtilis as potential producer for polyhydroxyalkanoates. Microb Cell Fact 8: 38.

Singh, V.K., Hattangady, D.S., Giotis, E.S., Singh, A.K., Chamberlain, N.R., Stuart, M.K., and Wilkinson, B.J. (2008) Insertional inactivation of branched-chain alpha-keto acid dehydrogenase in Staphylococcus aureus leads to decreased branched-chain membrane fatty acid content and increased susceptibility to certain stresses. Appl Environ Microbiol 74: 5882-90. 


\section{References}

Stannek, L. (2015) Control of glutamate homeostasis in the Gram-positive model organism Bacillus subtilis.

Tan, M., Peng, C., Anderson, K.A., Chhoy, P., Xie, Z., Park, J.S., et al. (2014) Lysine Glutarylation Is a Protein Post-Translational Modification Regulated by SIRT5. Cell Metab 19: 605-617.

Tao, L., and Biswas, I. (2015) Degradation of SsrA-tagged proteins in streptococci. Microbiology 161: 884-94.

Thomaides, H.B., Davison, E.J., Burston, L., Johnson, H., Brown, D.R., Hunt, A.C., et al. (2007) Essential bacterial functions encoded by gene pairs. J Bacteriol 189: 591-602.

Tödter, D. (2013) Characterization of the unknown genes yloU and yqhY from Bacillus subtilis.

Trentini, D.B., Suskiewicz, M.J., Deszcz, L., and Mechtler, K. (2015) Arginine phosphorylation marks proteins for degradation by the ClpCP protease. Nat Publ Gr 539: $1-41$.

Turgay, K., Hahn, J., Burghoorn, J., and Dubnau, D. (1998) Competence in Bacillus subtilis is controlled by regulated proteolysis of a transcription factor. EMBO J 17: 6730-8.

Waldrop, G.L., Holden, H.M., and Maurice, M.S. (2012) The enzymes of biotin dependent CO2 metabolism: What structures reveal about their reaction mechanisms. Protein Sci 21: $1597-1619$.

Wang, J., Hartling, J.A., and Flanagan, J.M. (1997) The Structure of ClpP at $2.3 \AA$ Resolution Suggests a Model for ATP-Dependent Proteolysis. Cell 91: 447-456. 
Weber, M.H., Klein, W., Müller, L., Niess, U.M., and Marahiel, M.A. (2001) Role of the Bacillus subtilis fatty acid desaturase in membrane adaptation during cold shock. Mol Microbiol 39: 1321-9.

White, S.W., Zheng, J., Zhang, Y.-M., and Rock, C.O. (2005) THE STRUCTURAL BIOLOGY OF TYPE II FATTY ACID BIOSYNTHESIS. Annu Rev Biochem 74: 791-831.

Wiegert, T., and Schumann, W. (2001) SsrA-mediated tagging in Bacillus subtilis. J Bacteriol 183: 3885-9.

Xu, W., Zhang, L., Mai, J., Peng, R., Yang, E., Peng, C., and Wang, H. (2014) The Wag31 protein interacts with AccA3 and coordinates cell wall lipid permeability and lipophilic drug resistance in Mycobacterium smegmatis. Biochem Biophys Res Commun 448: 255260.

Yao, J., and Rock, C.O. (2015) How bacterial pathogens eat host lipids: implications for the development of fatty acid synthesis therapeutics. J Biol Chem 290: 5940-6.

Zeriouh, H., Vicente, A. de, Pérez-García, A., and Romero, D. (2014) Surfactin triggers biofilm formation of Bacillus subtilis in melon phylloplane and contributes to the biocontrol activity. Environ Microbiol 16: 2196-2211.

Zhang, J., Sprung, R., Pei, J., Tan, X., Kim, S., Zhu, H., et al. (2008) Lysine Acetylation Is a Highly Abundant and Evolutionarily Conserved Modification in Escherichia Coli. Mol Cell Proteomics 8: 215-225.

Zhang, Y.-M., Marrakchi, H., and Rock, C.O. (2002) The FabR (YijC) transcription factor regulates unsaturated fatty acid biosynthesis in Escherichia coli. J Biol Chem 277: 1555865.

Zhang, Y.-M., and Rock, C.O. (2008) Membrane lipid homeostasis in bacteria. Nat Rev Microbiol 6: 222-233. 
Zhang, Y., Wu, Z., Wan, X., Liu, P., Zhang, J., Ye, Y., et al. (2014) Comprehensive profiling of lysine acetylome in Staphylococcus aureus. Sci China Chem 57: 732-738.

Zhang, Y., and Zuber, P. (2007) Requirement of the zinc-binding domain of ClpX for Spx proteolysis in Bacillus subtilis and effects of disulfide stress on ClpXP activity. J Bacteriol 189: 7669-7680.

Zhang, Z., Tan, M., Xie, Z., Dai, L., Chen, Y., and Zhao, Y. (2011) Identification of lysine succinylation as a new post-translational modification. Nat Chem Biol 7: 58-63.

Zuber, P. (2004) Spx-RNA polymerase interaction and global transcriptional control during oxidative stress. J Bacteriol 186: 1911-8.

Zuber, P. (2009) Management of oxidative stress in Bacillus. Annu Rev Microbiol 63: 57597. 


\section{Appendix}

\subsection{Materials}

\subsubsection{Chemicals}

\begin{tabular}{|c|c|}
\hline Acrylamide & Roth, Karlsruhe \\
\hline Agar & Roth, Karlsruhe \\
\hline Agarose & Peqlab, Erlangen \\
\hline Ammonium iron (III) citrate & Sigma, Munich \\
\hline Ammonium Peroxydisulfate & Roth, Karlsruhe \\
\hline Antibiotics & Sigma, Munich \\
\hline Bromphenol blue & Serva, Heidelberg \\
\hline Casein & Sigma, Munich \\
\hline CDP* & Roche Diagnostics, Mannheim \\
\hline Coomassie Brilliant Blue, G250 & Roth, Karlsruhe \\
\hline Desthiobiotin & IBA, Göttingen \\
\hline dNTPs & Roche Diagnostics, Mannheim \\
\hline Ethidium bromide & Roth, Karlsruhe \\
\hline D-Fructose-1,6-bisphosphate & Sigma, Munich \\
\hline D-Glucose & Merck, Darmstadt \\
\hline Glycerine & Merck, Darmstadt \\
\hline Immidazole & Sigma, Munich \\
\hline Isopropyl ß-D-1- thiogalactopyranoside & Peqlap, Erlangen \\
\hline DL-Malate & Applichem, Darmstadt \\
\hline
\end{tabular}


ß-Mercaptoethanol

$\mathrm{Ni}^{2+}$-nitrilotriacetic acid superflow

Nutrient Broth

Pefabloc

Skim milk powder

Sodium succinate

Sodium Dodecyl Sulfate

Strep-Tactin Sepharose

Tetramethylethylenediamine (TEMED)

Tris(hydroxymethyl)aminomethane

Trypton

Tween 20

X-Gal

Yeast extract
Roth, Karlsruhe

Qiagen, Hilden

Merck, Darmstadt

Roth, Karlsruhe

Oxoid, Heidelberg

Fluka, Buchs, Switzerland

Roth, Karlsruhe

IBA, Göttingen

Roth, Karlsruhe

Roth, Karlsruhe

Oxoid, Heidelberg

Sigma, München

Peqlab, Erlangen

Oxoid, Hampshire, U.K.

Other chemicals were purchased from Merck, Serva, Sigma or Roth.

\subsubsection{Auxiliary materials}

96-Well-plates

Centrifuge cups

Cuvettes (microlitre, plastic)

Dialysis tube

Eppendorf tubes
Sarstedt, Nürmbrecht

Beckmann, Munich

Greiner, Nürtingen

Serva, Heidelberg

Greiner, Nürtingen 
Falcon tubes

Gene amp reaction tubes (PCR)

Glas pipette

Microlitre pipettes

$(1 \mu \mathrm{l}, 2 \mu \mathrm{l}, 20 \mu \mathrm{l}, 200 \mu \mathrm{l}, 1000 \mu \mathrm{l}, 5 \mathrm{ml})$

Petri dishes

Pipette tips

Poly-Prep Chromatography columns

Polyvinylidene difluoride (PVDF) membrane
Sarstedt, Nürmbrecht

Perkin Elmer, Weiterstadt

Brand, Wertheim

Eppendorf, Hamburg

Greiner, Nürtingen

Greiner, Nürtingen

Bio-Rad, Munich

Bio-Rad, Munich

\subsubsection{Intruments}

ÄKTAprime

Autoclave

Biofuge fresco

Chemiluminescence system ChemiSmart

Contamination meter

Fluorescence microscope Axioskop 40FL +

Kamera (AxioCam MRm)

French pressure cell press

French pressure cell press

Gel electrophoresis apparatus

Ice maschine
GE Healthcare, Freiburg

Zirbus technology, Bad Grund

Heraeus Christ, Osterode

Peqlab, Erlangen

Berthold, Bad Wildbad

Zeiss, Göttingen

SLM Aminco, Lorch

Spectonic Unicam, England

PeqLab, Erlangen

Ziegra, Isernhagen 
Image eraser

Heating block Dri Block DB3

Horizontal shaker 3006

Hydro tech vacuum pump

LabCycler

Microplate reader Epoch2

Microplate reader SynergyMx

Mini-Protean III System

Nanodrop ND-1000

Open air shaker Innova 2300

Phosphor imagerStorm 860

$\mathrm{pH}$ meter Calimatic

Refrigerated centrifuge

Scale

Semi Dry Transfer Unit TE70 SemiPhor

Special accuracy weighing machine

Spectral photometer

Standard power pack

Thermocycler

Ultra centrifuge, Sorvall Ultra Pro 80
Molecular Dynamics, USA

Waasetec, Göttingen

GFL, Burgwedel

Bio-Rad, Munich

SensorQuest, Göttingen

BioTek, Bad Friedrichshall

BioTek, Bad Friedrichshall

Bio-Rad, Munich

Thermoscientific, Bonn

New Brunswick, Neu-Isenburg

Molecular Dynamics, USA

Knick, Berlin

Kendro, Hanau

Sartorius, Göttingen

Amersham, Freiburg

Sartorius, Göttingen

Amersham, Freiburg

Bio-Rad, Munich

Biometra, Göttingen

Thermoscientific, Bonn 
Ultrasonic device

UV Transilluminator 2000

Vortex

Water-bath incubation system

Water desalination plant
Dr. Hielscher, Teltow

Bio-Rad, Munich

Bender \& Hobein, Bruchsal

GFL, Burgwedel

Millepore, Schwalbach

\subsubsection{Commercial systems}
peqGOLD Bacterial DNA Kit
PEQLAB, Erlangen
peqGOLD PCR Purification Kit
PEQLAB, Erlangen
NucleoSpin Plasmid-Kit
Macherey-Nagel, Düren
PageRuler ${ }^{\mathrm{TM}}$ Plus Prestained Protein Ladder
ThermoFisher, Waltham, USA
QIAquick PCR Purification Kit
Qiagen, Hilden
Midori Green
Biozym, Hessisch Oldendorf

\subsubsection{Antibodies and enzymes}

\begin{tabular}{|c|c|}
\hline Anti-FLAG ${ }^{\circledR}$ & Sigma-Aldrich, Munich \\
\hline Anti-Rabbit IgG-AP secondary antibody & Promega, Mannheim \\
\hline FastAPTM & ThermoFisher, Waltham, USA \\
\hline Lysozym & Merck, Darmstadt \\
\hline Phusion ${ }^{T M}$ DNA polymerase & Biozym, Hessisch Oldendorf \\
\hline Restriction nucleases & ThermoFisher, Waltham, USA \\
\hline
\end{tabular}


T4-DNA ligase

Taq-DNA polymerase
ThermoFisher, Waltham, USA

Roche Diagnostics, Mannheim

\subsection{Oligonucleotides}

Oligonucleotides were purchased from Sigma Aldrich (Munich, Germany). Underlined are restriction sites.

\begin{tabular}{|c|c|c|}
\hline Name & Sequenz (5'-3') & Description \\
\hline \multirow[t]{2}{*}{ cat-fwd (kan) } & 5'CGGCAATAGTTACCCTTATTATCAA & Amplification of cat-cassette \\
\hline & G & from pGem-cat for LFH-PCR \\
\hline \multirow[t]{2}{*}{ cat-rev (kan) } & 5'CCAGCGTGGACCGGCGAGGCTAG & Amplification of cat-cassette \\
\hline & TTACCC & from pGem-cat for LFH-PCR \\
\hline FC146 & 5'CGATGCGTTCGCGATCCAGGC & Sequencing of pUT18 \\
\hline FC147 & 5'CCAGCCTGATGCGATTGCTGCAT & Sequencing of $\mathrm{p} 25-\mathrm{N}$ \\
\hline FC148 & 5'GTCACCCGGATTGCGGCGG & Sequencing of pUT18C, \\
\hline \multirow[t]{2}{*}{ FC149 } & 5'GCTGGCTTAACTATGCGGCATCAG & Sequencing of pUT18C \\
\hline & $A$ & \\
\hline FC150 & 5'GATTCGGTGACCGATTACCTGGC & Sequencing of pKT25 \\
\hline FC151 & 5'CGCCAGGGTTTTTCCCAGTCACG & Sequencing of pKT25 \\
\hline FM70 & 5'CCGGCTCGTATGTTGTGTGGAAT & Sequencing of $\mathrm{p} 25-\mathrm{N}$ \\
\hline \multirow[t]{2}{*}{ kan-fwd } & 5'CAGCGAACCATTTGAGGTGATAGG & Amplification of apha3 from \\
\hline & & pDG780 for LFH-PCR \\
\hline \multirow[t]{2}{*}{ kan-rev } & 5'CGATACAAATTCCTCGTAGGCGCT & Amplification of apha3 from \\
\hline & CGG & pDG780 for LFH-PCR \\
\hline \multirow[t]{2}{*}{ KG64 } & 5'TATCAGGGCCTCGACTACA & Sequencing of pGP882 \\
\hline & & derivatives, fwd \\
\hline \multirow[t]{2}{*}{ KG65 } & 5'CGCTGATTAAATACAGCATCGG & Sequencing of pGP882 \\
\hline & & derivatives, rev \\
\hline M13 pUC for & 5`GTAAAACGACGGCCAGTG & Sequencing of pBS-plasmides \\
\hline
\end{tabular}




\begin{tabular}{|c|c|c|}
\hline M13 pUC rev & $5^{`}$ GGAAACAGCTATGACCATG & $\begin{array}{l}\text { Sequencing of pBS-plasmides } \\
\text { and pUC derivatives, rev }\end{array}$ \\
\hline ML84 & 5'CTAATGGGTGCTTTAGTTGAAGA & $\begin{array}{l}\text { Cat check up-fragment } \\
\text { (sequencing of up-fragement) }\end{array}$ \\
\hline ML85 & 5'CTCTATTCAGGAATTGTCAGATAG & $\begin{array}{l}\text { Cat check down-fragment } \\
\text { (sequencing of down-fragment) }\end{array}$ \\
\hline ML107 & $\begin{array}{l}\text { 5'GCTTCATAGAGTAATTCTGTAAAG } \\
\text { G }\end{array}$ & $\begin{array}{l}\text { kan check up-fragment } \\
\text { (sequencing of up-fragement) }\end{array}$ \\
\hline ML108 & $\begin{array}{l}\text { 5'GACATCTAATCTTTTCTGAAGTACA } \\
\text { TCC }\end{array}$ & $\begin{array}{l}\text { kan check down-fragment } \\
\text { (sequencing of down- } \\
\text { fragement) }\end{array}$ \\
\hline ML109 & $\begin{array}{l}\text { 5'GTCTAGTGTGTTAGACTTTATGAA } \\
\text { ATC }\end{array}$ & $\begin{array}{l}\text { mls check up-fragment } \\
\text { (sequencing of up-fragement) }\end{array}$ \\
\hline ML110 & $\begin{array}{l}\text { 5'CTTTAATAATTCATCAACATCTACA } \\
\text { CC }\end{array}$ & $\begin{array}{l}\text { mls check down-fragment } \\
\text { (sequencing of down- } \\
\text { fragement) }\end{array}$ \\
\hline mls fwd (kan) & $\begin{array}{l}\text { 5'CAGCGAACCATTTGAGGTGATAGG } \\
\text { GATCCTTTAACTCTGGCAACCCTC }\end{array}$ & $\begin{array}{l}\text { LFH-PCR, amplification of ermC } \\
\text { from pDG647, fwd }\end{array}$ \\
\hline mls rev (kan) & $\begin{array}{l}\text { 5'CGATACAAATTCCTCGTAGGCGCT } \\
\text { CGGGCCGACTGCGCAAAAGACATAA } \\
\text { TCG }\end{array}$ & $\begin{array}{l}\text { LFH-PCR, amplification of ermC } \\
\text { from pDG647, rev }\end{array}$ \\
\hline mls-check fwd & 5'CCTTAAAACATGCAGGAATTGACG & $\begin{array}{l}\text { LFH-PCR, sequencing of the } \\
\text { down-fragment }\end{array}$ \\
\hline mls-check rev & 5'GTTTTGGTCGTAGAGCACACGG & $\begin{array}{l}\text { LFH-PCR, sequencing of the up- } \\
\text { fragment }\end{array}$ \\
\hline pWH844 fwd & 5'TATGAGAGGATCGCATCACCAT & $\begin{array}{l}\text { Sequencing of } \mathrm{pWH} 844 \\
\text { constructs }\end{array}$ \\
\hline T7-Prom. & 5'TAATACGACTCACTATAGGG & $\begin{array}{l}\text { Sequencing primer, starts at } 5{ }^{\prime} \\
\text { end of } \mathrm{T7} \text { promotor }\end{array}$ \\
\hline DT64 & $\begin{array}{l}\text { AAAGGATCCCCTAGTCCGCAATTTTG } \\
\text { GGATGCC }\end{array}$ & $\begin{array}{l}\text { Cloning of accA into pGP1331, } \\
\text { pBP43, fwd (BamHI) }\end{array}$ \\
\hline
\end{tabular}




\begin{tabular}{|c|c|c|}
\hline DT66 & $\begin{array}{l}\text { TTTGTCGACGTTTACCCCGATATATT } \\
\text { GATCTTCAACCG }\end{array}$ & $\begin{array}{l}\text { Cloning of accA into pGP1331, } \\
\text { pGP382, pBP43, rev (Sall) }\end{array}$ \\
\hline DT73 & $\begin{array}{l}\text { AAAGGATCCCTCACTTATTTAAAGGA } \\
\text { GGAAACAATCATGTTAAATATCAAA } \\
\text { GAAATCCACGAGCTGATTAAAG }\end{array}$ & $\begin{array}{l}\text { Cloning of } a c c B \text { into pGP1460, } \\
\text { fwd (BamHI) }\end{array}$ \\
\hline DT74 & $\begin{array}{l}\text { TTTGTCGACCTCCGCTTTTACAAGAA } \\
\text { ATAGAGGTTG }\end{array}$ & $\begin{array}{l}\text { Cloning of } a c c B \text { into pGP1460, } \\
\operatorname{rev}(\text { Sall) }\end{array}$ \\
\hline DT75 & $\begin{array}{l}\text { AAAGGATCCCTCACTTATTTAAAGGA } \\
\text { GGAAACAATCATGATTAAAAAGCTA } \\
\text { TTGATCGCCAACAGAG }\end{array}$ & $\begin{array}{l}\text { Cloning of accC into pGP1460, } \\
\text { fwd (BamHI) }\end{array}$ \\
\hline DT76 & $\begin{array}{l}\text { TTTGTCGACTGAGCCCATTACATCAT } \\
\text { ATGTTTCTAAAAATTTCG }\end{array}$ & $\begin{array}{l}\text { Cloning of accC into pBP43, } \\
\text { pGP1460, pGP1331, rev (Sall) }\end{array}$ \\
\hline DT77 & $\begin{array}{l}\text { AAATCTAGAAATAATTTTGTTTAACT } \\
\text { TTAAGAAGGAGATATAATGAAAGAC } \\
\text { AACAGCTTGCTTAAAATGGATCAC }\end{array}$ & $\begin{array}{l}\text { Cloning of } y q h Y \text { into } p E T-28 a \text {, } \\
\text { fwd (Xbal) }\end{array}$ \\
\hline DT78 & $\begin{array}{l}\text { TTTGCGGCCGCCATTTCTTCGTCGAT } \\
\text { TTGGACTTCTTGG }\end{array}$ & $\begin{array}{l}\text { Cloning of yqhY into pET-28a, } \\
\text { rev (Notl) }\end{array}$ \\
\hline DT79 & $\begin{array}{l}\text { AAAGGTACCGGAGAACTTGTACTTC } \\
\text { CAAGGAACATTGAATAAATCAATTTT } \\
\text { AGTTGCTCAAGAAGCG }\end{array}$ & $\begin{array}{l}\text { Cloning of divIVA C-term. into } \\
\text { pGP172, fwd (Kpnl) }\end{array}$ \\
\hline DT80 & $\begin{array}{l}\text { TTTGGATCCTTATTCCTTTTCCTCAAA } \\
\text { TACAGCGTCGAC }\end{array}$ & $\begin{array}{l}\text { Cloning of divIVA C-term. into } \\
\text { pGP172, rev (BamHI) }\end{array}$ \\
\hline DT81 & $\begin{array}{l}\text { AAAGGATCCGAGAACTTGTACTTCC } \\
\text { AAGGAATGAAAGACAACAGCTTGCT } \\
\text { TAAAATGGATCAC }\end{array}$ & $\begin{array}{l}\text { Cloning of yqhY into pwh844, } \\
\text { fwd (BamHI) }\end{array}$ \\
\hline DT82 & $\begin{array}{l}\text { TTTCTGCAGTTACATTTCTTCGTCGAT } \\
\text { TTGGACTTCTTGG }\end{array}$ & $\begin{array}{l}\text { Cloning of yqhY into pwh844, } \\
\text { rev (Pstl) }\end{array}$ \\
\hline DT83 & $\begin{array}{l}\text { AAAGGATCCCTCACTTATTTAAAGGA } \\
\text { GGAAACAATCGTGGCTCCAAGATTA } \\
\text { GAATTTGAAAAACCG }\end{array}$ & $\begin{array}{l}\text { Cloning of accA into pGP382, } \\
\text { fwd (BamHI) }\end{array}$ \\
\hline
\end{tabular}


DT84

DT85

DT86

DT87

DT88

DT89

DT90

DT91

DT92

DT93

DT94

DT95

DT96

DT97

DT102
AAAGGATCCCTCACTTATTTAAAGGA Cloning of $\operatorname{accD}$ into pGP382,

GGAAACAATCTTGTTAAAGGATATA pGP1370, pBQ200, fwd (BamHI)

TTCACGAAAAAGAAAAAGTATGC

TTTGTCGACATCTTGGAGCCACTCAA Cloning of accD into pGP382,

TGTCACC pGP1370, rev (Sall)

CCTTGTCGTTTCAACACCTTATCTGAT Sequencing of accAD, fwd TTC

GCTGTTGTGACAGGCAAGGGC Sequencing of accAD, fwd

CTCCATCCTCCCTATGAAACCTTAC Sequencing of accAD, rev

AAATCTAGAGGTGGCTCCAAGATTA Cloning of accA into BACTH, fwd

GAATTTGAAAAACCG

(Xbal)

TTTGGTACCCGGTTTACCCCGATATA Cloning of accA into BACTH, rev

TTGATCTTCAACCG

(Kpnl)

AAATCTAGAGATGTTAAATATCAAA Cloning of $a c c B$ into BACTH, fwd

GAAATCCACGAGCTGATTAAAG

(Xbal)

TTTGGTACCCGCTCCGCTTTTACAAG Cloning of $\operatorname{accB}$ into BACTH, rev

AAATAGAGGTTGTC

(Kpnl)

AAATCTAGAGATGATTAAAAAGCTA Cloning of accC into BACTH, fwd TTGATCGCCAACAGAGG

(Xbal)

TTTGGTACCCGTGAGCCCATTACATC Cloning of accC into BACTH, rev ATATGTTTCTAAAAATTTCG

(Kpnl)

AAATCTAGAGTTGTTAAAGGATATAT Cloning of $a c c D$ into BACTH, fwd TCACGAAAAAGAAAAAGTATGC (Xbal)

TTTGGTACCCGATCTTGGAGCCACTC Cloning of $a c c D$ into BACTH, rev AATGTCACC (Kpnl)

TTTGTCGACATCTTGGAGCCACTCAA Cloning of $\operatorname{accD}$ into pGP382, TGTCAACTCC mutation in SD seq. of $\operatorname{acc} A$, rev (Sall)

AAAGGATCCCTCACTTATTTAAAGGA Cloning of divIVA into pGP1460, GGAAACAATCATGCCATTAACGCCA fwd (BamHI)

AATGATATTCACAACAAG 


\begin{tabular}{|c|c|c|}
\hline DT103 & $\begin{array}{l}\text { TTTCTGCAGTTCCTTTTCCTCAAATAC } \\
\text { AGCGTCGAC }\end{array}$ & $\begin{array}{l}\text { Cloning of divIVA into pGP1460, } \\
\text { pGP1331, rev (PstI) }\end{array}$ \\
\hline DT104 & $\begin{array}{l}\text { AAAGGTACCCGGTTCAAGTCATGCA } \\
\text { GCAGGC }\end{array}$ & $\begin{array}{l}\text { Cloning of } a c c B \text { into pGP1080, } \\
\text { pGP1087, fwd (Kpnl) }\end{array}$ \\
\hline DT105 & $\begin{array}{l}\text { TTTGGTACCCTCCGCTTTTAACAAGAA } \\
\text { ATAGAGGTTGTC }\end{array}$ & $\begin{array}{l}\text { Cloning of } a c c B \text { into pGP1080, } \\
\text { pGP1087, rev (Kpnl) }\end{array}$ \\
\hline DT106 & $\begin{array}{l}\text { AAAGGATCCGGAGCAAATGGGAGA } \\
\text { TGCAGCG }\end{array}$ & $\begin{array}{l}\text { Cloning of accC into pGP1331, } \\
\text { pBP43, fwd (BamHI) }\end{array}$ \\
\hline DT107 & $\begin{array}{l}\text { GGAACTGACCTGATCAAGGAACAAA } \\
\text { TC }\end{array}$ & $\begin{array}{l}\text { LFH-PCR yqhY, yfp, cat, (fwd up- } \\
\text { fragment, sequencing) }\end{array}$ \\
\hline DT108 & GATGTTGAATTTGAAGGCTGGGCC & $\begin{array}{l}\text { LFH-PCR yqhY, yfp, cat, (fwd up- } \\
\text { fragment) }\end{array}$ \\
\hline DT109 & $\begin{array}{l}\text { CATTTCTTCGTCGATTTGGACTTCTTG } \\
\text { G }\end{array}$ & $\begin{array}{l}\text { LFH-PCR yqhY, yfp, cat, (rev up- } \\
\text { fragment) }\end{array}$ \\
\hline DT110 & $\begin{array}{l}\text { CGAGCGCCTACGAGGAATTTGTATC } \\
\text { GATGGCTTAACACGAAACCAAGGGG }\end{array}$ & $\begin{array}{l}\text { LFH-PCR yqhY, yfp, cat, (fwd } \\
\text { down-fragment) }\end{array}$ \\
\hline DT111 & $\begin{array}{l}\text { GATCATCTCCAATCAAAATAACCGCC } \\
\text { AG }\end{array}$ & $\begin{array}{l}\text { LFH-PCR yqhY, yfp, cat, (rev } \\
\text { down-fragment) }\end{array}$ \\
\hline DT112 & $\begin{array}{l}\text { CTTGAAATTCATTCCCATTGTTTCTGC } \\
\text { CG }\end{array}$ & $\begin{array}{l}\text { LFH-PCR yqhY, yfp, cat, (fwd } \\
\text { down-fragment, sequencing) }\end{array}$ \\
\hline DT113 & CCTGGCGGATGACGGAATTACG & $\begin{array}{l}\text { LFH-PCR yqhY, yfp, cat, (fwd } \\
\text { sequencing from } y q h Y)\end{array}$ \\
\hline DT114 & $\begin{array}{l}\text { GTCCAAATCGACGAAGAAATGATGG } \\
\text { TGAGCAAGGGCGAGGAG }\end{array}$ & Amplification of $y f p, f w d$ \\
\hline DT115 & $\begin{array}{l}\text { СCTATCACCTCAAATGGTTCGCTGTT } \\
\text { ACTTGTACAGCTCGTCCATGCCG }\end{array}$ & Amplification of $y f p$, rev \\
\hline DT116 & $\begin{array}{l}\text { GTCCAAATCGACGAAGAAATGATGG } \\
\text { TCAGCAAGGGAGAGGAAGATAATAT }\end{array}$ & Amplification of mCherry, fwd \\
\hline
\end{tabular}


DT117

DT118

DT119

DT120

DT121

DT122

DT123

DT124

DT125

DT126

DT127

DT128

DT129

DT130

DT131
CCTATCACCTCAAATGGTTCGCTGCT Amplification of mCherry, rev

ATTTGTATAATTCGTCCATTCCACCTG

TAGAG

AAACCATGGCGATGAAAGACAACAG Cloning of $y q h Y$ into pETM-11,

CTTGCTTAAAATGGATCAC

AAAGGATCCATGCCATTAACGCCAA

ATGATATTCACAACAAG

GCTGTCATATTAGAGTTGAATTCAAA Sequencing of $\operatorname{accBC}$, fwd AGTCC

AAAGGATCCCCTTACTCTGTCGTGCT

TCTTGATGAG

TTTCTGCAGATTCGTTTTAGCAGTCG

TTTTTACGACAAATTCG

AAATCTAGAGATGTGGAAAGGACTT

ATCCATCAATATAAAGAATTTTTAC

TTTGGTACCTCATACACGGGCCGCTC

CTTTTAC

AAAGGATCCATGAAAGAGGAGACAT

TTTATCTTGTCCGTG

TTTGTCGACTTATGCACCTGAACCTA

ATATTTCAACCTTTTC

AAATCTAGAGGTGGGACATAATATT

TCTGACATCATTGAAC

TTTGGTACCCGTTTTAATTTTAAAGA

AGTCAGCATTGCCTTCATC

AAAGGATCCGATGGAAATTGAAAGA

ATTAACGAGCATACAGTAAAATT

TTTGGTACCCGTGATGCAAAGTGTTT

TTTTATCGTTTCTAGAGC

AAATCTAGAGTTGACAAACTATCAG

CATGAGCTATACTTCG fwd (Ncol)

Cloning of divIVA into pGP1331, fwd (BamHI)

Cloning of $c / p C$ into pGP1331,

fwd (BamHI)

Cloning of $c / p C$ into pGP1331, rev (Pstl)

Cloning of thrC into pGP888,

fwd (Xbal)

Cloning of thrC into pGP888, rev

(Kpnl)

Cloning of thrR into pGP380,

fwd (BamHI)

Cloning of thrR into pGP380, rev (Sall)

Cloning of ctsR into BACTH, fwd (Xbal)

Cloning of ctsR into BACTH, rev (Kpnl)

Cloning of mecA into BACTH, fwd (BamHI)

Cloning of mecA into BACTH, rev (Kpnl)

Cloning of $y j b H$ into BACTH, fwd (Xbal) 


\begin{tabular}{|c|c|c|}
\hline DT132 & $\begin{array}{l}\text { TTTGGTACCCGTTTTTCACATGATTG } \\
\text { ATATTCATCAGAATAAGTGCTG }\end{array}$ & $\begin{array}{l}\text { Cloning of yjbH into BACTH, rev } \\
(K p n l)\end{array}$ \\
\hline DT133 & $\begin{array}{l}\text { AAATCTAGAGATGCGGCTTGAGCGT } \\
\text { CTGAATTATAATAAG }\end{array}$ & $\begin{array}{l}\text { Cloning of ypbH into BACTH, } \\
\text { fwd (Xbal) }\end{array}$ \\
\hline DT134 & $\begin{array}{l}\text { TTTGGTACCCGTGAAAAATGAGTTTG } \\
\text { TATCGTTTCTACGGCATTAC }\end{array}$ & $\begin{array}{l}\text { Cloning of ypbH into BACTH, rev } \\
\text { (Kpnl) }\end{array}$ \\
\hline DT135 & $\begin{array}{l}\text { AAATCTAGAGATGCGTTGTCAACATT } \\
\text { GTCATCAAAACGAG }\end{array}$ & $\begin{array}{l}\text { Cloning of cplE into BACTH, fwd } \\
\text { (Xbal) }\end{array}$ \\
\hline DT136 & $\begin{array}{l}\text { TTTGGTACCCGTTTTGCTCGCACTTT } \\
\text { GATTTTATCATCTTCTAAAATC }\end{array}$ & $\begin{array}{l}\text { Cloning of } c p I E \text { into BACTH, rev } \\
(K p n l)\end{array}$ \\
\hline DT137 & GCGCGACAACACTGAAAGAATATCG & Sequencing of $c p / E$ \\
\hline DT138 & $\begin{array}{l}\text { TTTGTCGACTTAGTTTACCCCGATAT } \\
\text { ATTGATCTTCAACCG }\end{array}$ & $\begin{array}{l}\text { Cloning of } a c c D A \text { into } \mathrm{pBQ} 200 \text {, } \\
\text { rev (Sall) }\end{array}$ \\
\hline DT139 & $\begin{array}{l}\text { AAAGAGCTCGAGGAAGCTGGACAAT } \\
\text { TAACTGAGAAGGT }\end{array}$ & $\begin{array}{l}\text { Cloning of clpE into pGP1331, } \\
\text { fwd (Sacl) }\end{array}$ \\
\hline DT140 & $\begin{array}{l}\text { TTTGGATCCTTTTGCTCGCACTTTGAT } \\
\text { TTTATCATCTTCTAAAATCAC }\end{array}$ & $\begin{array}{l}\text { Cloning of clpE into pGP1331, } \\
\operatorname{rev}(B a m H I)\end{array}$ \\
\hline
\end{tabular}

\subsection{Plasmids}

\begin{tabular}{llll}
\hline Name & Relevant characteristics & $\begin{array}{l}\text { Primer/ } \\
\text { Restriction } \\
\text { sites }\end{array}$ & Reference \\
\hline pBP43 & fusion of the monomeric variant of GFP A206K to the & Cascante-Estepa \\
& C-terminus of a protein & et al., 2016 \\
pBP190 & pUT18-mcs $B$ & Stannek, 2015 \\
pBP191 & pUT18C-mcs & Stannek, 2015 \\
pBP192 & pKT25- $m c s B$ & & Stannek, 2015
\end{tabular}




\begin{tabular}{|c|c|c|}
\hline pBP193 & $\mathrm{p} 25-\mathrm{N}-m c s B$ & Stannek, 2015 \\
\hline pBP198 & pUT18-clpP & Stannek, 2015 \\
\hline pBP199 & pUT18C-clpP & Stannek, 2015 \\
\hline pBP200 & pKT25-clpP & Stannek, 2015 \\
\hline pBP201 & $\mathrm{p} 25-\mathrm{N}-c / p P$ & Stannek, 2015 \\
\hline pBP202 & pUT18-clpC & Stannek, 2015 \\
\hline pBP203 & pUT18C-clpC & Stannek, 2015 \\
\hline pBP204 & pKT25-clpC & Stannek, 2015 \\
\hline pBP205 & p25-N-clpC & Stannek, 2015 \\
\hline pBP206 & pUT18-clpX & Stannek, 2015 \\
\hline pBP207 & pUT18C-clpX & Stannek, 2015 \\
\hline pBP208 & pKT25-clpX & Stannek, 2015 \\
\hline pBP209 & $\mathrm{p} 25-\mathrm{N}-\mathrm{clp} X$ & Stannek, 2015 \\
\hline pBQ200 & allows overexpression of proteins in $B$. subtilis & $\begin{array}{l}\text { Martin- } \\
\text { Verstraete et al., } \\
1994\end{array}$ \\
\hline pDG646 & $\begin{array}{l}\text { amplification of ermC resistance cassette for LFH PCR } \\
\mathrm{Erm}^{\mathrm{R}}\end{array}$ & $\begin{array}{l}\text { Guérout-Fleury et } \\
\text { al., } 1995\end{array}$ \\
\hline pDG780 & $\begin{array}{l}\text { amplification of apha3 resistance cassette for LFH PCR } \\
\mathrm{Km}^{R}\end{array}$ & $\begin{array}{l}\text { Guérout-Fleury et } \\
\text { al., } 1995\end{array}$ \\
\hline pDG1726 & $\begin{array}{l}\text { amplification of aad9 resistance cassette for LFH PCR } \\
\text { Spec }^{R}\end{array}$ & $\begin{array}{l}\text { Guérout-Fleury et } \\
\text { al., } 1995\end{array}$ \\
\hline pGEM-cat & amplification of cat resistance cassette for LFH Cat ${ }^{R}$ & $\begin{array}{l}\text { Guérout-Fleury et } \\
\text { al., } 1995\end{array}$ \\
\hline
\end{tabular}




\section{Appendix}

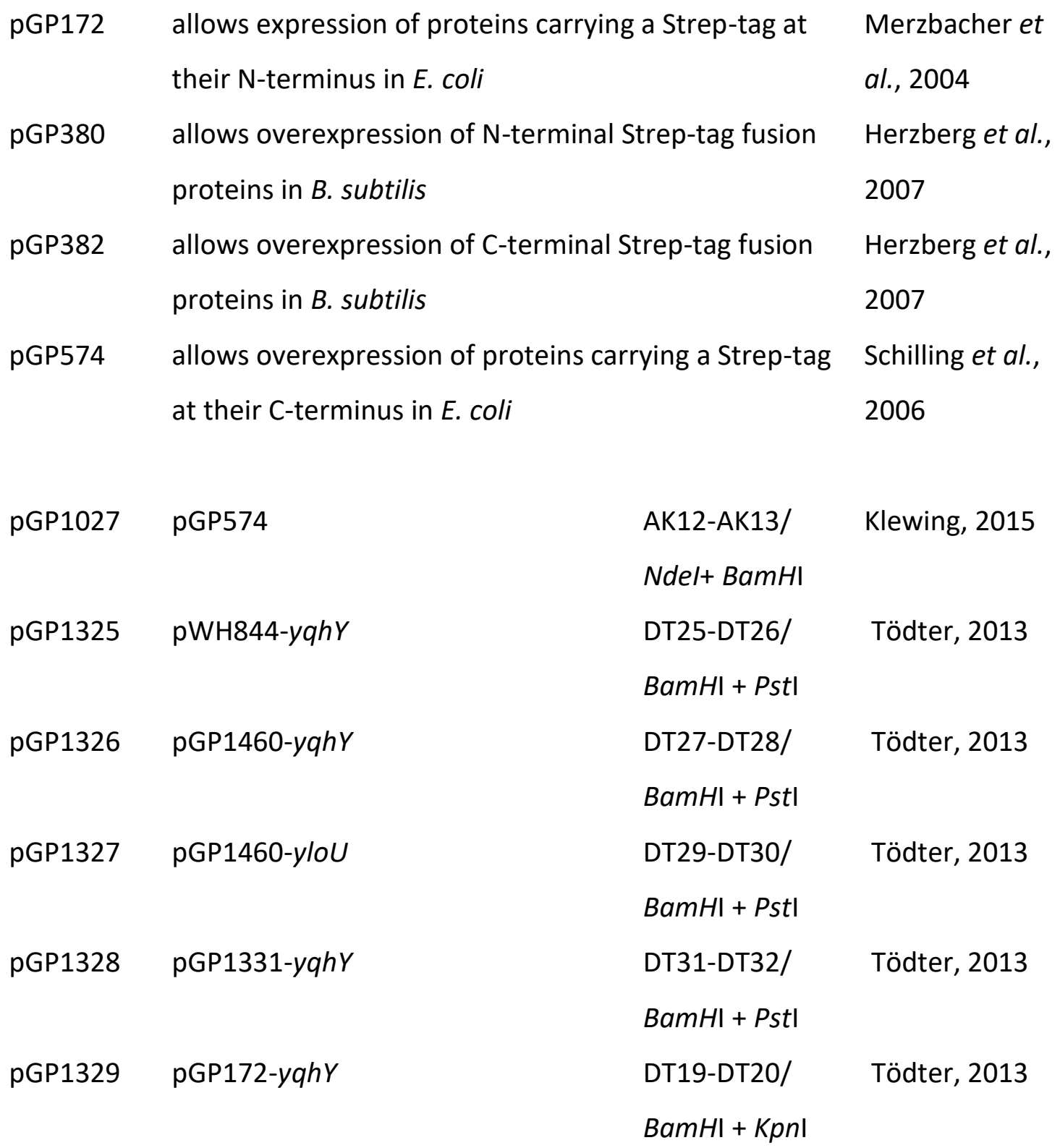

pGP1331 allows fusion of 3x FLAG tag at the C-terminus of a Lehnik-Habrink et protein, keeping the expression under control of the al., 2010 natural promotor

pGP1333 3' end of cshA with 3x FLAG tag at C-terminus

Lehnik-Habrink et al., 2010

pGP1370 allows fusion of 3x FLAG tag at the C-terminus of a Lehnik-Habrink et protein al., 2011

pGP1389 allows expression of C-terminal Strep-tag fusion Lehnik-Habrink et proteins in B. subtilis, keeping the expression under al., 2011 control of the natural promotor 


\begin{tabular}{|c|c|c|c|}
\hline pGP1460 & $\begin{array}{l}\text { constitutive expression of C-termina } \\
\text { proteins in } B \text {. subtilis; integrates in } I\end{array}$ & Strep-tagged & $\begin{array}{l}\text { Mehne et al., } \\
2013\end{array}$ \\
\hline pGP1470 & pUT18-yqhY & $\begin{array}{l}\text { DT45-DT46/ } \\
\text { Xbal + Kpnl }\end{array}$ & Tödter, 2013 \\
\hline pGP1471 & pUT18C-yqhY & $\begin{array}{l}\text { DT45-DT46/ } \\
X b a l+K p n l\end{array}$ & Tödter, 2013 \\
\hline pGP1472 & $\mathrm{p} 25-\mathrm{N}-y q h Y$ & $\begin{array}{l}\text { DT45-DT46/ } \\
\text { Xbal + Kpnl }\end{array}$ & Tödter, 2013 \\
\hline pGP1473 & pKT25-yqhY & $\begin{array}{l}\text { DT45-DT46/ } \\
X b a l+K p n l\end{array}$ & Tödter, 2013 \\
\hline pGP1482 & pBP43-yqhy & $\begin{array}{l}\text { DT31-DT32/ } \\
\text { BamHI + PstI }\end{array}$ & Tödter, 2013 \\
\hline pGP1484 & pGP1460-accB & $\begin{array}{l}\text { DT73-DT74/ } \\
\text { BamHI + Sall }\end{array}$ & This study \\
\hline pGP1485 & pGP1460-accC & $\begin{array}{l}\text { DT75-DT76/ } \\
\text { BamHI + Sall }\end{array}$ & This study \\
\hline pGP1496 & pET28a+-yqhY & $\begin{array}{l}\text { DT77-DT78/ } \\
\text { Xbal + NotI }\end{array}$ & This study \\
\hline pGP1497 & $\begin{array}{l}\text { pGP172-C-terminus of divIVA+TEV- } \\
\text { site }\end{array}$ & $\begin{array}{l}\text { DT79-DT80/ } \\
\text { Kpnl + BamHI }\end{array}$ & This study \\
\hline pGP1498 & pWH844-yqhY+TEV-site & $\begin{array}{l}\text { DT81-DT82/ } \\
\text { BamHI + PstI }\end{array}$ & This study \\
\hline pGP1499 & pGP1331-accA & $\begin{array}{l}\text { DT64-DT66/ } \\
\text { BamHI + Sall }\end{array}$ & This study \\
\hline pGP1723 & pGP382-accA & $\begin{array}{l}\text { DT83-DT66/ } \\
\text { BamHI + Sall }\end{array}$ & This study \\
\hline pGP1724 & pGP382-accD & $\begin{array}{l}\text { DT84-DT85/ } \\
\text { BamHI + Sall }\end{array}$ & This study \\
\hline pGP1725 & pGP382-accD-G283V & $\begin{array}{l}\text { DT84-DT97/ } \\
\text { BamHI + Sall }\end{array}$ & This study \\
\hline
\end{tabular}




\begin{tabular}{|c|c|c|c|}
\hline pGP1726 & pGP1460-divIVA & $\begin{array}{l}\text { DT102-DT103/ } \\
\text { BamHI + Pstl }\end{array}$ & This study \\
\hline pGP1727 & pGP1331-accC & $\begin{array}{l}\text { DT106-DT76/ } \\
\text { BamHI + Sall }\end{array}$ & This study \\
\hline pGP1728 & pGP1087-accB & $\begin{array}{l}\text { DT104-DT105/ } \\
\text { Kpnl }\end{array}$ & This study \\
\hline pGP1729 & pGP1871-yqhY & $\begin{array}{l}\text { DT25-DT28/ } \\
\text { BamHI + Pstl }\end{array}$ & This study \\
\hline pGP1730 & pBP43-accA & $\begin{array}{l}\text { DT64-DT66/ } \\
\text { BamHI + Sall }\end{array}$ & This study \\
\hline pGP1731 & pBP43-accC & $\begin{array}{l}\text { DT106-DT76/ } \\
\text { BamHI + Sall }\end{array}$ & This study \\
\hline pGP1732 & pGP1080- $a c c B$ & $\begin{array}{l}\text { DT104-DT105/ } \\
\text { Kpnl }\end{array}$ & This study \\
\hline pGP1733 & pUT18-accA & $\begin{array}{l}\text { DT89-DT90/ } \\
\text { Xbal + Kpnl }\end{array}$ & This study \\
\hline pGP1734 & pUT18C-accA & $\begin{array}{l}\text { DT89-DT90/ } \\
\text { Xbal + Kpnl }\end{array}$ & This study \\
\hline pGP1735 & $\mathrm{p} 25-\mathrm{N}-a c c A$ & $\begin{array}{l}\text { DT89-DT90/ } \\
\text { Xbal + Kpnl }\end{array}$ & This study \\
\hline pGP1736 & pUT18- $a c c B$ & $\begin{array}{l}\text { DT91-DT92/ } \\
\text { Xbal + Kpnl }\end{array}$ & This study \\
\hline pGP1737 & pUT18C-accB & $\begin{array}{l}\text { DT91-DT92/ } \\
\text { Xbal + Kpnl }\end{array}$ & This study \\
\hline pGP1738 & $\mathrm{p} 25-\mathrm{N}-a c c B$ & $\begin{array}{l}\text { DT91-DT92/ } \\
\text { Xbal + Kpnl }\end{array}$ & This study \\
\hline pGP1739 & pKT25- $a c c B$ & $\begin{array}{l}\text { DT91-DT92/ } \\
\text { Xbal + KpnI }\end{array}$ & This study \\
\hline pGP1740 & pUT18-accC & $\begin{array}{l}\text { DT93-DT94/ } \\
\text { Xbal + Kpnl }\end{array}$ & This study \\
\hline
\end{tabular}




\begin{tabular}{|c|c|c|c|}
\hline pGP1741 & pUT18C-accC & DT93-DT94/ & This study \\
\hline & & $X b a l+K p n l$ & \\
\hline pGP1742 & p25-N-accC & DT93-DT94/ & This study \\
\hline & & $X b a l+K p n l$ & \\
\hline pGP1743 & рKT25-accC & DT93-DT94/ & This study \\
\hline & & $X b a l+K p n l$ & \\
\hline pGP1744 & pUT18-accD & DT95-DT96/ & This study \\
\hline & & $X b a l+K p n l$ & \\
\hline pGP1745 & pUT18C-accD & DT95-DT96/ & This study \\
\hline & & $X b a l+K p n l$ & \\
\hline pGP1746 & $\mathrm{p} 25-\mathrm{N}-a c c D$ & DT95-DT96/ & This study \\
\hline & & $X b a l+K p n l$ & \\
\hline pGP1747 & pGP1370-accD & DT84-DT85/ & This study \\
\hline & & BamHI + Sall & \\
\hline pGP1748 & pETM-11-yqhY & DT118-DT20/ & This study \\
\hline & & $\mathrm{Ncol}+\mathrm{BamHI}$ & \\
\hline pGP1749 & pGP1331-divIVA & DT119-DT103/ & This study \\
\hline & & $B a m H I+P s t I$ & \\
\hline pGP1750 & pGP1331-clpC & DT121-DT122/ & This study \\
\hline & & BamHI + Pstl & \\
\hline pGP1828 & pGP888-thrC & DT123-DT124/ & This study \\
\hline & & $X b a l+K p n l$ & \\
\hline pGP1829 & pUT18-ctsR & DT127-DT128/ & This study \\
\hline & & $X b a l+K p n l$ & \\
\hline pGP1830 & pUT18C-ctsR & DT127-DT128/ & This study \\
\hline & & $X b a l+K p n l$ & \\
\hline pGP1831 & $\mathrm{p} 25-\mathrm{N}-\mathrm{cts} R$ & DT127-DT128/ & This study \\
\hline & & $X b a l+K p n l$ & \\
\hline pGP1832 & pKT25-ctsR & DT127-DT128/ & This study \\
\hline & & $X b a l+K p n l$ & \\
\hline
\end{tabular}




\begin{tabular}{|c|c|c|c|}
\hline pGP1833 & pUT18-mecA & $\begin{array}{l}\text { DT129-DT130/ } \\
\text { BamHI + Kpnl }\end{array}$ & This study \\
\hline pGP1834 & pUT18C-mecA & $\begin{array}{l}\text { DT129-DT130/ } \\
\text { BamHI + Kpnl }\end{array}$ & This study \\
\hline pGP1835 & p25-N-mecA & $\begin{array}{l}\text { DT129-DT130/ } \\
\text { BamHI + Kpnl }\end{array}$ & This study \\
\hline pGP1836 & pKT25-mecA & $\begin{array}{l}\text { DT129-DT130/ } \\
\text { BamHI + Kpnl }\end{array}$ & This study \\
\hline pGP1837 & pUT18-yjbH & $\begin{array}{l}\text { DT131-DT132/ } \\
\text { Xbal + Kpnl }\end{array}$ & This study \\
\hline pGP1838 & pUT18C-yjbH & $\begin{array}{l}\text { DT131-DT132/ } \\
\text { Xbal + Kpnl }\end{array}$ & This study \\
\hline pGP1839 & $\mathrm{p} 25-\mathrm{N}-y j b H$ & $\begin{array}{l}\text { DT131-DT132/ } \\
\text { Xbal + Kpnl }\end{array}$ & This study \\
\hline pGP1840 & pKT25-yjbH & $\begin{array}{l}\text { DT131-DT132/ } \\
\text { Xbal + Kpnl }\end{array}$ & This study \\
\hline pGP1841 & pUT18-урьн & $\begin{array}{l}\text { DT133-DT134/ } \\
\text { Xbal + Kpnl }\end{array}$ & This study \\
\hline pGP1842 & pUT18C-ypbH & $\begin{array}{l}\text { DT133-DT134/ } \\
\text { Xbal + Kpnl }\end{array}$ & This study \\
\hline pGP1843 & $\mathrm{p} 25-\mathrm{N}-y p b H$ & $\begin{array}{l}\text { DT133-DT134/ } \\
\text { Xbal + Kpnl }\end{array}$ & This study \\
\hline pGP1844 & рKT25-урbH & $\begin{array}{l}\text { DT133-DT134/ } \\
\text { Xbal + Kpnl }\end{array}$ & This study \\
\hline pGP1845 & pGP172-accA-H105P & $\begin{array}{l}\text { АК01-AK02/ } \\
\text { Kpnl + BamHI }\end{array}$ & This study \\
\hline pGP1846 & pGP172-accD-L176F & $\begin{array}{l}\text { AK07-AK08/ } \\
\text { KpnI + BamHI }\end{array}$ & This study \\
\hline pGP1847 & pGP172-accD-A229S & $\begin{array}{l}\text { AK07-AK08/ } \\
\text { KpnI + BamHI }\end{array}$ & This study \\
\hline
\end{tabular}




\begin{tabular}{|c|c|c|c|}
\hline pGP1848 & pGP172-accD-I38N & $\begin{array}{l}\text { AK07-AK08/ } \\
\text { Kpnl + BamHI }\end{array}$ & This study \\
\hline pGP1849 & pGP1389-accA & $\begin{array}{l}\text { DT64-DT66/ } \\
\text { BamHI + Sall }\end{array}$ & This study \\
\hline pGP1850 & $\mathrm{pBQ} 200-a c c D A$ & $\begin{array}{l}\text { DT84-DT138/ } \\
\text { BamHI + Sall }\end{array}$ & This study \\
\hline pGP1870 & pUS19-gfp & & Rothe et al., 2013 \\
\hline pGP1871 & pUS19-yfp & & Rothe et al., 2013 \\
\hline pGP2157 & pUT18-clpE & $\begin{array}{l}\text { DT135-DT136/ } \\
\text { Xbal + Kpnl }\end{array}$ & This study \\
\hline pGP2158 & pUT18C-clpE & $\begin{array}{l}\text { DT135-DT136/ } \\
\text { Xbal + Kpnl }\end{array}$ & This study \\
\hline pGP2159 & $\mathrm{p} 25-\mathrm{N}-c / p E$ & $\begin{array}{l}\text { DT135-DT136/ } \\
\text { Xbal + Kpnl }\end{array}$ & This study \\
\hline pGP2160 & pKT25-clpE & $\begin{array}{l}\text { DT135-DT136/ } \\
\text { Xbal + Kpnl }\end{array}$ & This study \\
\hline pGP2161 & pGP1331-clpE & $\begin{array}{l}\text { DT139-DT140/ } \\
\text { Sacl + BamHI }\end{array}$ & This study \\
\hline pGP2162 & pBQ200-yqhY & $\begin{array}{l}\text { DT27-DT26/ } \\
\text { BamHI + PstI }\end{array}$ & This study \\
\hline pGP2690 & pWH844-birA & $\begin{array}{l}\text { JN335-JN336/ } \\
\text { BamHI + Sall }\end{array}$ & $\begin{array}{l}\text { J. Gundlach, } \\
\text { unpublished }\end{array}$ \\
\hline p25-N & Plac-mcs-cyaA kan & & $\begin{array}{l}\text { Claessen et al., } \\
2008\end{array}$ \\
\hline pKT25 & $\mathrm{P}_{\text {lac }}$ - cyaA-mcs kan & & $\begin{array}{l}\text { Karimova et al., } \\
1998\end{array}$ \\
\hline pKT25::zip & $\mathrm{P}_{l a c^{-}}$cyaA-zip kan & & $\begin{array}{l}\text { Karimova et al., } \\
1998\end{array}$ \\
\hline pUT18 & Plac-mcs-cyaA bla & & $\begin{array}{l}\text { Karimova et al., } \\
1998\end{array}$ \\
\hline
\end{tabular}




\begin{tabular}{lll} 
pUT18C & Plac - cyaA-mcs bla & Karimova et al., \\
\multirow{2}{*}{ pUT18::zip } & Plac - cyaA-zip bla & 1998 \\
& & Karimova et al., \\
pWH844 & allows expression of proteins & 1998 \\
& carrying a His tag at their $\mathrm{N}-$ & Schirmer et al., \\
& terminus in $E$. coli & 1997
\end{tabular}

\subsection{Strains}

Bacillus subtilis strains used in this study

\begin{tabular}{|c|c|c|}
\hline Strain & Genotype & Reference/ Construction \\
\hline 168 & $\operatorname{trpC2}$ & Laboratory collection \\
\hline 4041 & $\operatorname{trpC2} \triangle \operatorname{divIVA::tet}$ & Oliva et al., 2010 \\
\hline BKE00830 & $\operatorname{trpC2} \Delta c t s R:: e r m$ & BGSC \\
\hline BKE11550 & $\operatorname{trpC2} \Delta y j b H:: e r m$ & BGSC \\
\hline BKE27910 & $\operatorname{trpC2} \Delta y s z B:: e r m$ & BGSC \\
\hline BKG09 & $\operatorname{trpC2} \triangle$ spoOA::aphA3 & K. Gunka, UMG \\
\hline GP1468 & $\operatorname{trpC2} \Delta y q h Y:: e r m$ & Tödter, 2013 \\
\hline GP1469 & $\operatorname{trpC2} \Delta y q h Y:: e r m(A c c D$ G283V) & Tödter, 2013 \\
\hline GP1470 & $\operatorname{trpC2} \Delta y q h Y:: e r m$ syloU::cat (AccA H105P) & Tödter, 2013 \\
\hline GP1473 & $\operatorname{trpC2}$ yqhY-gfp spc, $\Delta$ divIVA::tet & Tödter, 2013 \\
\hline GP1474 & $\operatorname{trpC2}$ lacA::(yqhY-Strep aphA3) & Tödter, 2013 \\
\hline GP1477 & $\operatorname{trp} C 2$ lacA::(accB-Strep aphA3) & pGP1484 $\rightarrow 168$ \\
\hline GP1478 & $\operatorname{trpC2}$ lacA::(accC-Strep aphA3) & pGP1485 $\rightarrow 168$ \\
\hline GP1479 & $\begin{array}{l}\operatorname{trpC2} \text { lacA::(accB-Strep aphA3) yqhY-3xFLAG } \\
s p c\end{array}$ & pGP1328 $\rightarrow$ GP1477 \\
\hline GP1480 & $\begin{array}{l}\operatorname{trpC2} \text { lacA::(accC-Strep aphA3) yqhY-3xFLAG } \\
s p c\end{array}$ & pGP1328 $\rightarrow$ GP1478 \\
\hline GP1481 & $\operatorname{trpC2} y q h Y-3 \times \mathrm{FLAG} s p c$ & pGP1328 $\rightarrow 168$ \\
\hline
\end{tabular}




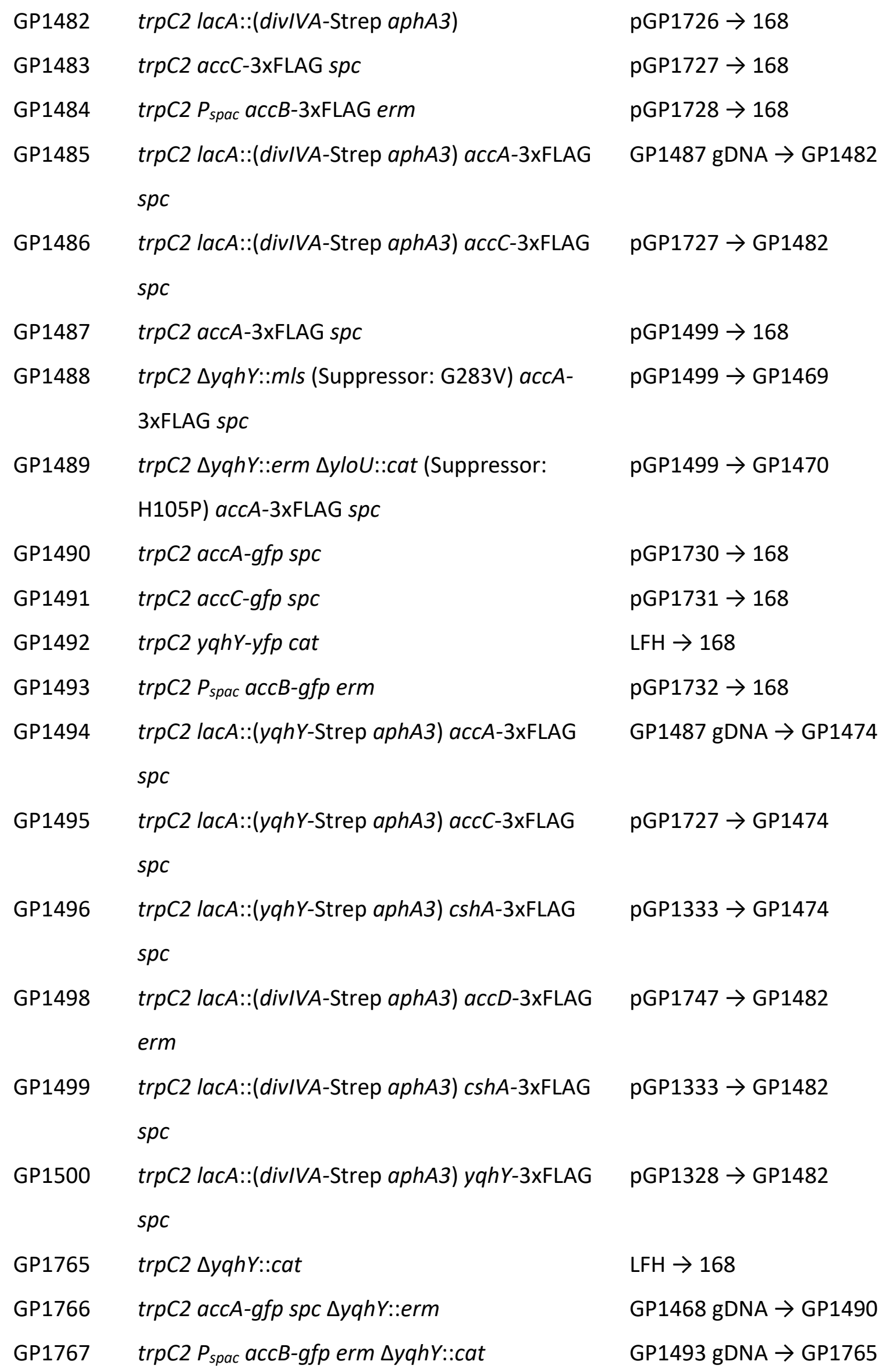




\begin{tabular}{|c|c|c|}
\hline GP1768 & $\operatorname{trpC2} a c c C-g f p$ spc $\Delta y q h Y:: c a t$ & GP1491 gDNA $\rightarrow$ GP1765 \\
\hline GP1769 & $\operatorname{trpC2}$ accA-gfp spc $\triangle$ divIVA::tet & 4041 gDNA $\rightarrow$ GP1490 \\
\hline GP1770 & $\operatorname{trpC2} P_{\text {spac }} a c c B$-gfp erm $\triangle$ divIVA::tet & 4041 gDNA $\rightarrow$ GP1493 \\
\hline GP1771 & $\operatorname{trpC2}$ accC-gfp spc $\triangle$ divIVA::tet & 4041 gDNA $\rightarrow$ GP1491 \\
\hline GP1772 & $\begin{array}{l}\operatorname{trpC2} a c c A-g f p \text { spc } \Delta y q h Y:: e r m \text { (Suppressor: } \\
\text { G283V) }\end{array}$ & GP1490 gDNA $\rightarrow$ GP1469 \\
\hline GP1773 & $\begin{array}{l}\operatorname{trpC2} \text { accA-gfp spc } \Delta y q h Y:: e r m \Delta y l o U:: c a t \\
\text { (AccA H105P) }\end{array}$ & GP1490 gDNA $\rightarrow$ GP1470 \\
\hline GP1774 & $\operatorname{trpC2}$ accA-gfp spc $\Delta y q h Y::$ cat $\Delta$ divIVA::tet & GP1765 gDNA $\rightarrow$ GP1769 \\
\hline GP1775 & $\operatorname{trpC2}$ accA-gfp spc $\Delta y q h Y:: e r m \Delta$ divIVA::tet & GP1766 gDNA $\rightarrow 4041$ \\
\hline GP1776 & $\operatorname{trp} C 2 \operatorname{divIVA-3xFLAG~spc}$ & pGP1749 $\rightarrow 168$ \\
\hline GP1777 & $\begin{array}{l}\operatorname{trpC2} \text { lacA::(yqhY-Strep aphA3)} \operatorname{divIVA-3xFLAG} \\
s p c\end{array}$ & pGP1749 $\rightarrow$ GP1474 \\
\hline GP1778 & $\begin{array}{l}\operatorname{trp} C 2 \text { lacA::(yqhY-Strep aphA3) clpC-3xFLAG } \\
s p c\end{array}$ & pGP1750 $\rightarrow$ GP1474 \\
\hline GP1779 & $\operatorname{trpC2} \Delta c t s R:: e r m \Delta y q h Y:: c a t$ & $\begin{array}{l}\text { BKE00830 gDNA } \rightarrow \\
\text { GP1765 }\end{array}$ \\
\hline GP1780 & $\operatorname{trpC2} \Delta y j b H:: e r m \Delta y q h Y:: c a t$ & $\begin{array}{l}\text { gDNA BKE11550 } \rightarrow \\
\text { GP1765 }\end{array}$ \\
\hline GP1781 & $\operatorname{trpC2} \Delta y s z B:: e r m \Delta y q h Y:: c a t$ & $\begin{array}{l}\text { gDNA BKE27910 } \rightarrow \\
\text { GP1765 }\end{array}$ \\
\hline GP1782 & $\operatorname{trp} C 2 \Delta c t s R:: e r m$ accA-3xFLAG $s p c$ & $\begin{array}{l}\text { GP1487 gDNA } \rightarrow \\
\text { BKE00830 }\end{array}$ \\
\hline GP1786 & $\operatorname{trpC2} \Delta c l p P:: e r m$ & GPUG1 gDNA $\rightarrow 168$ \\
\hline GP1787 & $\operatorname{trpC2} \Delta c / p X:: a p h A 3$ & GPUG2 gDNA $\rightarrow 168$ \\
\hline GP1788 & $\operatorname{trpC2} \Delta s p x:: s p c_{200}$ & GPUG3 gDNA $\rightarrow 168$ \\
\hline GP1789 & $\operatorname{trpC2} \Delta s p x:: s p c_{200} \Delta c / p X:: a p h A 3$ & GP1787 gDNA $\rightarrow$ GP1788 \\
\hline GP1790 & $\operatorname{trp} C 2 \Delta s p x:: s p c_{200} \Delta c l p P:: e r m$ & GP1786 gDNA $\rightarrow$ GP1788 \\
\hline GP1791 & $\operatorname{trpC2}$ accA-3xFLAG spc $\Delta y q h Y:: c a t$ & GP1765 gDNA $\rightarrow$ GP1487 \\
\hline GP1792 & $\operatorname{trpC2}$ accA-3xFLAG spc $\Delta c l p X:: a p h A 3$ & GP1787 gDNA $\rightarrow$ GP1487 \\
\hline GP1793 & $\operatorname{trpC2}$ accA-3xFLAG spc $\triangle c l p P:: e r m$ & GP1786 gDNA $\rightarrow$ GP1487 \\
\hline
\end{tabular}




\begin{tabular}{lll} 
GP1794 & $\operatorname{trpC2}$ accA-gfp spc $\Delta c l p X:: a p h A 3$ & GP1787 gDNA $\rightarrow$ GP1490 \\
GP1795 & $\operatorname{trpC2~accA-gfp~spc~} \Delta c l p P:: e r m$ & GP1786 gDNA $\rightarrow$ GP1490 \\
GP1796 & $\operatorname{trpC2~accA-Strep~spc~} \Delta y q h Y:: e r m$ (Suppressor: & pGP1849 $\rightarrow$ GP2322 \\
& AccD A229S) & \\
GP1797 & $\operatorname{trpC2~accA-Strep~spc~} \Delta y q h Y:: e r m$ (Suppressor: & pGP1849 $\rightarrow$ GP2323 \\
& AccD I38N) & \\
GP1798 & $\operatorname{trpC2~} \Delta y q h Y:: c a t \Delta s p o 0 A:: a p h A 3$ & BKG09 gDNA $\rightarrow$ GP1765 \\
GP1799 & $\operatorname{trpC2~clpE-3xFLAG~spc~}$ & pGP2161 $\rightarrow 168$ \\
GP1800 & $\operatorname{trpC2~lacA::(yqhY-Strep~aphA3)~clpE-3xFLAG~spc~}$ & pGP2161 $\rightarrow$ GP1474 \\
GP2321 & $\operatorname{trpC2~} \Delta y q h Y:: e r m$ (Suppressor: AccD L176F) & GP1468 gDNA $\rightarrow 168$ \\
GP2322 & $\operatorname{trpC2~} \Delta y q h Y:: e r m$ (Suppressor: AccD A229S) & GP1468 gDNA $\rightarrow 168$ \\
GP2323 & $\operatorname{trpC2~} \Delta y q h Y:: e r m$ (Suppressor: AccD I38N) & GP1468 gDNA $\rightarrow 168$ \\
GPUG1 & $\operatorname{trpC2~} \Delta c l p P:: e r m$ & U. Gerth \\
GPUG2 & $\operatorname{trpC2~} \Delta c l p X:: a p h A 3$ & U. Gerth \\
GPUG3 & $\operatorname{trpC2~} \Delta s p x:: s p c$ & U. Gerth \\
QB4913 & $\operatorname{trpC2~} \Delta c l p P:: s p c$ & U. Gerth \\
\hline
\end{tabular}

Escherichia coli strains used in this study

\begin{tabular}{|c|c|c|}
\hline Strain & Genotype & Reference/ Construction \\
\hline BL21 (DE3) & $\begin{array}{l}\text { F- lon ompT rBmB hsdS gal (clts857ind1 Sam7 } \\
\text { nin5 lacUV5- T7 gene1) }\end{array}$ & Sambrook et al., 1989 \\
\hline BTH101 & $\begin{array}{l}\text { F- cya-99 araD139 galE15 galK16 rpsL1 (StrR) } \\
\text { hsdR2 mcrA1 mcrB1 }\end{array}$ & Karimova et al., 2005 \\
\hline $\mathrm{DH} 5 \alpha$ & 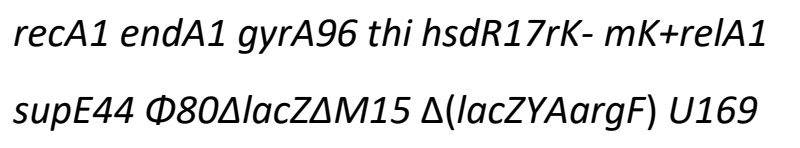 & Sambrook et al., 1989 \\
\hline XL1-Blue & $\begin{array}{l}\text { endA1 gyrA96 (nalR) thi-1 recA1 relA1 lac } \\
\text { glnV44 } F^{\prime}[:: T n 10 \text { proAB+ lacla } \Delta(\text { lacZ)M15] } \\
\text { hsdR17 (rK- } m K+)\end{array}$ & Karimova et al., 2005 \\
\hline
\end{tabular}




\section{Curriculum vitae}

\section{Personal information}

Name

Dominik Tödter

Date of birth

$21^{\text {st }}$ August, 1987

Place of birth

Uelzen

Nationality

German

\section{Education}

2000-2007

2007-2011

2011

Lessing-Gymnasium, Uelzen

Study of Biology, Georg-August-University Göttingen, Bachelor thesis in the group of Prof. Dr. Jörg Stülke, Department of General Microbiology at the Georg-August-University Göttingen Internship at DSM Nutritional Products in Kaiseraugst, Switzerland Study of Microbiology and Biochemistry, Georg-August-University Göttingen, Master thesis in the group of Prof. Dr. Jörg Stülke, Department of General Microbiology at the Georg-AugustUniversity Göttingen PhD thesis in the group of Prof. Dr. Jörg Stülke, Department of General Microbiology at the Georg-August-University Göttingen 